\title{
Energetics in wild female Assamese macaques (Macaca assamensis): a behavioral and physiological approach
}

\author{
Dissertation \\ for the award of the degree \\ "Doctor of Philosophy" (Ph.D.) \\ division of Mathematics and Natural Sciences \\ of the Georg-August-Universität Göttingen \\ within the doctoral program Behavior and Cognition (BeCog) \\ of the Georg-August University School of Science (GAUSS)
}

Submitted by

Sonia Touitou

from Lyon, France

Göttingen, 2021 


\section{Thesis committee}

Prof. Dr. Julia Ostner

Behavioral Ecology, University of Göttingen

PD Dr. Oliver Schülke

Behavioral Ecology, University of Göttingen

Prof. PD Dr. Peter Kappeler

Behavioral Ecology \& Sociobiology, German Primate Center (DPZ)

\section{Members of the Examination Board}

First Reviewer:

Prof. Dr. Julia Ostner

Second Reviewer:

Prof. PD Dr. Peter Kappeler

\section{Further members of the Examination Board}

PD Dr. Oliver Schülke

Prof. Dr. Eckhard W. Heymann

Behavioral Ecology \& Sociobiology, German Primate Center \& University of Göttingen

Dr. Verena Behringer

Endocrinology Laboratory, German Primate Center \& University of Göttingen

Dr. Tanya Behne

Developmental Psychology, University of Göttingen 

To my family, and particularly to Ismaël and Victor. 



\section{Table of contents}

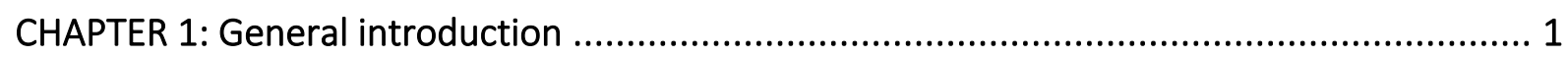

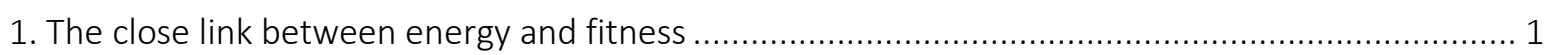

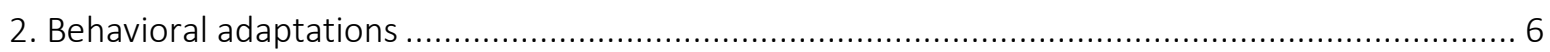

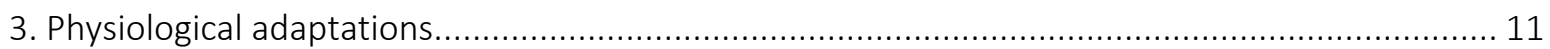

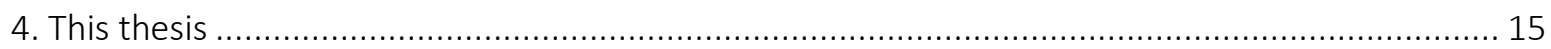

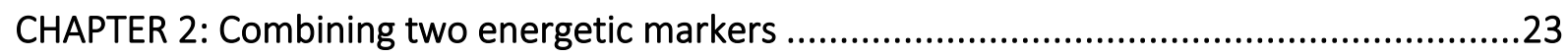

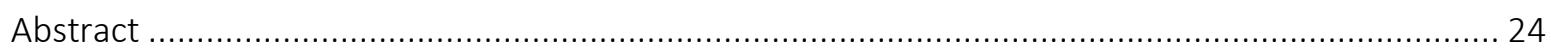

CHAPTER 3: Combining an energetic marker with behavior ..........................................25

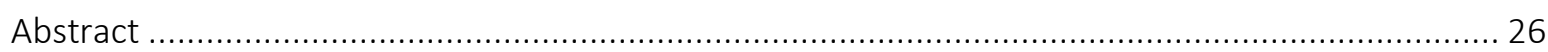

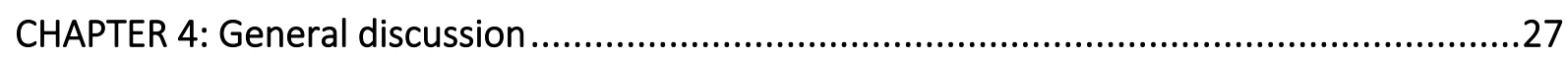

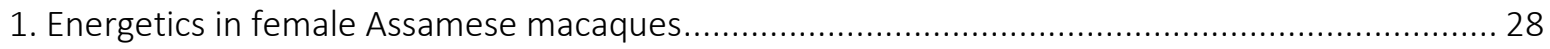

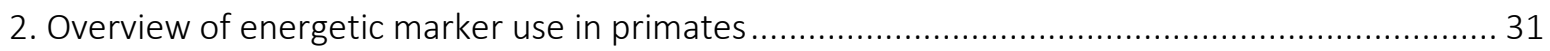

3. Future research directions and recommendations for studies on energetics ............................. 44

4. Research implication on climate change effects and wildlife conservation .................................. 51

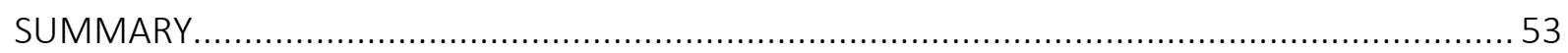

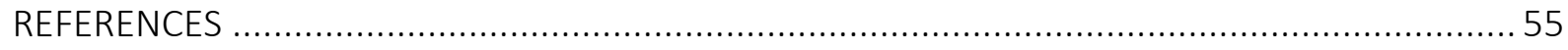

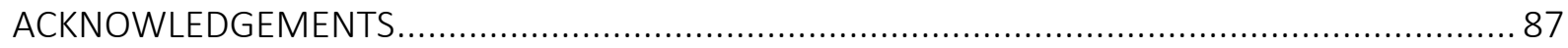

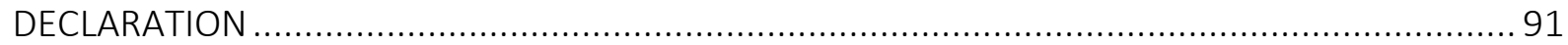





\section{CHAPTER 1}

\section{General introduction}

\section{The close link between energy and fitness}

\subsection{Energy: a cornerstone in life history}

In the same way money fuels trading and economic strategies, energy is the key currency of life and metabolic functions. Energy originally comes from plants that transform solar energy into chemical energy through photosynthesis. This chemical energy is transferred between all living organisms (e.g. from plants to plant-eater animals, and from plant-eater animals to carnivorous animals). Energy is a major requirement for life since living cells need it to perform their biological functions. For that reason, energy lies at the heart of major evolutionary theories such as life history.

Life history theory provides an evolutionary analytical framework connecting a set of individual adaptive traits such as age at first reproduction, interbirth intervals, body size at birth or lifespan (Stearns, 1976). Energy is the underlying connection between life history traits and supports major biological processes that can be ordered in four categories: growth, body maintenance, reproduction and storage (Gadgil and Bossert, 1970; Perrin and Sibly, 1993). Energy is involved in major life components determining fitness (Perrin and Sibly, 1993). On the one hand, energy is a determinant of survival. Oxidation of fat stores in adipose tissue is, for example, an important source of energy on which individuals rely in order to maintain body functions and sustain life (Young, 1976). In addition, female reproductive success is largely dependent upon energy (Wade and Schneider, 1992; Della Torre et al., 2014; Ellison, 2003; Bentley, 1999). For instance, female fertility is promoted by energy and is adjusted according to various metabolic cues of energetic condition (Schneider, 2004; Hill et al., 2008; Ellison, 1990). Finally, a case in point regarding the link between energy and fitness relies in the comparison of life history traits between wild and captive species: the enhanced energetic condition (i.e. readily energy available and energy stored) in the latter typically induces fitness benefits relative to their wild counterparts (Tidière et al., 2016). 
By applying the first law of thermodynamics, energy can be gained, lost or stored but cannot be destroyed or created (Haynie, 2001). Consequently, at a given moment organisms have at their disposal a finite amount of energy to support the numerous bodily functions involved in survival and reproduction. From this energy constraint stems the principal component of life history theory: trade-offs in energy allocation (energy partitioning). A fitness cost will be associated with allocating energy to the support of one adaptive function insofar as it will be at the expense of another (Stearns, 1989; Roff and Fairbairn, 2007). In order to maximize fitness, energy has to be strategically allocated according to an age-dependent set of priorities, ensuring first immediate body maintenance and survival and only then processes promoting growth, reproduction or storage (Perrin and Sibly, 1993). For example, a major trade-off exists between female survival and reproduction, since energy investment in reproductive effort lowers energy allocation to other adaptive traits involved in female survival (Gadgil and Bossert, 1970; Hamel et al., 2010).

Energy is therefore a limiting resource playing a paramount role in fitness as it acts both as fuel for life history traits and as determinant of allocation strategies. Importantly, energy is not static as both energy supply and demands vary, which can lead to challenging situations and bear fitness consequences.

\subsection{Energetic challenges}

Over its lifetime, an individual has different energy requirements according to a myriad of internal factors that impact its metabolic state (such as growth, health, reproductive state; Hou et al., 2008; Devevey et al., 2008; Gittleman and Thompson, 1988). In addition, environment is not stable in most habitats. External factors (such as rainfall, ambient temperature, food availability) fluctuate through distinct seasons inducing changes in energy availability in the environment and in energy demands to survive under different climatic conditions. Internal and external factors can influence energy intake (i.e. energy ingestion in the form of calories extracted from food resources in the environment) and energy expenditure (i.e. energy use to support metabolic needs, which typically increase with body size; Key and Ross, 1999). Energy balance is the net difference between energy intake and energy expenditure (Hall et al., 2012), with a positive energy balance when energy surplus is stored (in the form of glycogen or fat) and a negative energy balance when energy stores are mobilized. An energetic challenge represents any factor that would lead to a negative energy balance and 
therefore trigger shifts in energy allocation with fitness consequences. Specifically, an energetic challenge can occur through situations associated with a decrease in energy intake, an increase in energy expenditure or both. I will present such challenging situations below.

\subsubsection{Decrease in energy intake}

One clear factor inducing a decrease in energy intake is a decline in the amount of food in the environment (Knott, 1998). Food availability and quality affect fitness in mammals as both survival and reproduction are dependent upon them (Bronson, 1985; Knott, 1998; Knott et al., 2009; Watts and Holekamp, 2009; Mduma et al., 1999; Bronson and Marsteller, 1985; Dobson, 1995; Koenig et al., 1997 ; Altmann and Alberts, 2003). For example, food shortage and the ensuing decrease in energy intake can drive a decline in body weight (Goldizen et al., 1988), an increase in infection risk (Gardner et al., 2011) or reproductive impairment in females and males (Emery Thompson and Wrangham, 2008; Gesquiere et al., 2011).

In addition to availability, food access is also a factor constraining energy intake. It is common that competition occurs between groups for access to a limiting food resource (i.e. low food abundance; Isbell, 1991; Kurihara and Hanya, 2015; Harris, 2006). Intra-group feeding competition can also occur and is particularly driven by food distribution (Isbell, 1991). When a food resource is clumped, hierarchical structure among foragers drives food access with highranking individuals getting priority of access and fitness benefits ('contest' competition; Barrette and Vandal, 1986; Appleby, 1980; Janson, 1985; Majolo et al., 2012; Holand et al., 2004; Hofer and East, 2003). When food is dispersed, group size is the diver of intra-group feeding competition, with large group size inducing rapid food resource depletion, low energy intake per individual and fitness costs ('scramble' competition; Borries et al., 2008; Snaith and Chapman, 2005; Chapman et al., 2007).

\subsubsection{Increase in energy expenditure}

Metabolism encompasses all life-sustaining chemical reactions occurring in an organism and involves large molecule breakdown (catabolism) and biosynthesis (anabolism; Cox, 2005). Metabolic rate determines the amount of energy necessary for the metabolism's function. A fast metabolic rate is associated with high energy expenditure in mammals (Ricklefs et al., 1996). Basal metabolic rate represents the rate of energy metabolism (i.e. energy 
flow in the body, comprising intake, expenditure and storage) necessary to maintain critical biological processes such as major organ function, heart pumping and breathing; in an individual who is at rest, in a post-absorptive condition (fasting state where food has been fully digested, absorbed and stored) and undergoing neither heat or cold environmental constraints (Ricklefs et al., 1996; Hulbert and Else, 2004). The ubiquitous need for energy to fuel body maintenance in such a resting state illustrates its fundamental role in life and the energetic cost of living (Hulbert and Else, 2000). Some factor can result in a need to speed metabolism up as basal metabolic rate becomes inadequate in releasing enough energy to support energetic demands. These factors could potentially lead to challenging and fitness-threatening situations since they induce an increase in energy expenditure. Some of the most important factors, i.e. immune function, thermoregulation, physical activity and reproduction, will be presented below.

Factors generating an immune response, e.g. infections, trigger a rise in energy expenditure due to the hypermetabolic state necessary to up-regulate the host's immune system (Garza, 2005; Lochmiller and Deerenberg, 2000). The energetic costs associated with immune defense could consequently have fitness repercussions by shifting energy away from reproduction or growth (Burns et al., 2005; Careau et al., 2010). As illustrated by symptoms such as fever during extreme episodes of infection (Baracos et al., 1987), energy expends as heat. Metabolic rate and the associated energy expenditure has therefore a fundamental role to play in thermoregulation.

Thermoregulation is a process involved in maintaining core body temperature within a narrow viable window in homeotherm species, regardless of environmental conditions (Ivanov, 2006). Within a range of ambient temperatures called the thermoneutral zone, heat dispersion (energy expenditure) from basal metabolic rate is enough to maintain body temperature. When facing ambient temperature above or below thermoneutrality, thermoregulatory mechanisms involving modulation in metabolic rate and heat dissipation will be needed. For example, cold exposure increases energy expenditure and thus, heat production (Ocobock, 2016). This thermoregulatory expense could ultimately induce fitness costs (Xu et al., 2018).

Another important parameter increasing energy expenditure is physical activity as it is associated with a rise in metabolic rate (Sjödin et al., 1996; Taylor et al., 1982). Locomotion is a fundamental physical expense in the wild since animals need to move in their home range in order to reach food resources. Therefore, it is common for locomotion patterns to be closely 
linked to seasonal changes in environmental conditions (Wallace, 2006). In some species, low food availability can induce high foraging effort (Goodson et al., 1991), long travel distances (Harris et al., 2009; Hill and Agetsuma, 1995) and high energy expenditure. Additionally, feeding competition may also affect foraging-induced energy expenditure. Large groups and lower-ranking individuals often travel more as a result of scramble and contest feeding competition, respectively (Saj and Sicotte, 2007; van Schaik and Noordwijk, 1988). Finally, the energetic costs induced by physical activities can impair energy allocation to reproduction and consequently can bear fitness costs (Jasienska, 2003).

Lastly, a major factor involving an increase in metabolic demands and in energy expenditure in mammals is reproduction. Although some important energetic costs have been highlighted in males (Emery Thompson and Georgiev, 2014), female mammals bear the bulk of the energetic burden of reproduction. Females have to support the substantial demands of gestation and lactation, which cause an increase in energy requirements by $20-30 \%$ and 35 $149 \%$, respectively (Gittleman and Thompson, 1988). Lactation is the most expensive stage of the reproductive cycle since a tremendous energetic investment is necessary when producing milk and providing maternal care (Gittleman and Thompson, 1988; Prentice and Prentice, 1988; Pond, 1977). In some species, some of the costs of lactation can be alleviated by allomaternal care (Heldstab et al., 2017). The energetic costs of gestation are also substantial since energy has to be allocated to the support of the fetus and critical tissues (e.g. uterus, placenta, mammary gland; Gittleman and Thompson, 1988). Thus, reproducing females typically exhibit high metabolic rates and energy expenditure (Stephenson and Racey, 1993; Powell and Leonard, 1983; Rashid and Ulijaszek, 1999). The energetic costs of female reproduction can result in fat stores withdrawal (with extreme cases reported in grey seal (Halicoerus grypus): Fedak and Anderson, 1982; Oftedal, 2000; Wade et al., 1986), weight loss (Bercovitch, 1987), oxidative damage (Bergeron et al., 2011), immune deficiency (Festa-Bianchet, 1989; East et al., 2015; Archie et al., 2014) and faster aging (Jasienska, 2020). Ultimately, investing energy in reproduction may lead to severe fitness consequences in females, affecting future reproductive performance and survival (Festa-Bianchet et al., 2019; Koivula et al., 2003; Hamel et al., 2012).

Different energetic challenges, from both internal and external factors, are therefore likely to induce a decrease in energy intake and/or an increase in energy expenditure, leading to a negative energy balance and severe consequences on fitness. Several adaptations have evolved to overcome energetic challenges and their impact on energy balance. 


\section{Behavioral adaptations}

Behavioral plasticity is a key mechanism involved in maintaining a viable energy balance in the face of energetic challenges. Behavioral adaptations have emerged since they enhance fitness by overcoming current or future fluctuations in energy supply and demands. Behaviorally counteracting the costs of energetic challenges particularly relies on adjustments with regards to activity budget and feeding behavior.

\subsection{Modulation in activity budget}

Environmental conditions such as climate or food availability are major factors inducing modulation in activity patterns. When conditions become harsh (e.g. in winter, typically characterized by food shortage and low ambient temperatures), and when species do not migrate to escape them, it becomes vital for individuals to reduce costly activities in order to keep energy expenditure to a minimal level (Riek et al., 2017; Arnold et al., 2006). For example, some species lower physical activity and increase resting time when facing cold ambient temperatures (Hanya, 2004). In addition, behavioral thermoregulation is common when overcoming ambient temperatures outside thermoneutrality. For example, when it is too cold, huddling behaviors limit heat dispersion and increase survival (Terrien et al., 201l; Sealander, 1952).

When coping with cold and energy shortages some species also suspend the maintenance of body temperature by entering a state of hypometabolism, i.e. lowering their metabolic rate, and thus their endogenous heat production, and by becoming more tolerant to low body temperatures (Arnold et al., 2006). In extreme cases, considerable reductions in basal metabolic rate have been reported, with a $65 \%$ reduction during daily torpor (a torpid state characterized by a cold lethargy) and up to a $98 \%$ reduction during hibernation (torpor bouts lasting several days; Ruf and Geiser, 2015; Jastroch et al., 2016). Substantial energy saving can therefore be achieved by entering a torpid state (Armitage et al., 2003; Kelm and Helversen, 2007). Torpor is also typically included in a set of behavioral adaptations. For example, food hoarding or activities promoting fat accumulation prior to environmental harshness can be essential for some species to provide an energy supply during periodic arousals in the course of hibernation (Lyman, 1954; Speakman and Rowland, 1999). 
Besides environmental constraints, energetic challenges relative to internal factors have also induced behavioral adaptations. Gestating or lactating females can reduce their physical activity and increase their resting time as an energy-saving mechanism to cope with the energetic requirements of reproduction (Goldberg et al., 1991; Melzer et al., 2009; Dias et al., 2011; Rose, 1994; Barrett et al., 2006; Miller et al., 2006; Gamo et al., 2013). Such behavioral coping mechanisms enhance female reproductive performance (Roberts et al., 1982).

Behavioral adaptations in response to energetic challenges involve some activities being expressed more or less extensively (e.g. resting) and some emerging only during challenging time (e.g. in torpid state). Another fundamental activity likely to change in the face of energetic challenges is feeding as it determines energy intake and therefore represents in itself a major component of energy balance.

\subsection{Feeding behavior}

\subsubsection{Nutrient extraction from the environment}

Food is the one and only external source of energy for animals and food ingestion is therefore an indispensable activity to extract energy from the environment and fuel an individual's metabolic machinery (Wilmore and Costill, 2001). The energy yield of food is expressed in calories (cal) or joules ( $\mathrm{J}$, with $\mathrm{l} \mathrm{cal}=4.184 \mathrm{~J}$ ) and is determined by three macronutrients providing energy: carbohydrates, proteins and lipids (Robbins, 1993a; Lambert, 2011; National Research Council, 2003a, 2003b, 2003c).

Carbohydrates are present in food in different forms. First, the most rapidly absorbed and metabolized carbohydrates are soluble sugars, which represent a readily accessible source of energy. Soluble sugars include (i) monosaccharides (single carbohydrate unit) such as glucose, which is the primary carbohydrate providing energy to metabolism, and (ii) disaccharides (two monosaccharides bound together) such as sucrose or lactose, i.e. fruit and milk sugars, respectively. Second, complex sugars, or polysaccharides, are large carbohydrates that include starch and fiber. In contrast to starch which is digestible by mammals, fiber requires fermentation in the gut to release energy, particularly insoluble fiber such as hemicellulose and cellulose, i.e. plant cell wall components. Proteins are the second major macronutrient. Unlike carbohydrates, proteins are not only a source of energy but also a source of amino acids. Proteins represent a critical part of animals' diet since some amino acids cannot 
be metabolically synthesized and have to be provided through food. Proteins have a fundamental role to play in growth and tissue maintenance. Lastly, lipids (i.e. fat) are a macronutrient providing twice as much energy as carbohydrates and protein. Lipids are stored in adipose tissue which forms a major bodily energy reserve. They act as a back-up resource from which energy can be drawn upon in case of emergency. In addition to their substantial energy contribution, lipids are also critically involved in other aspects of bodily functions such as in steroid hormone production (Gorbach et al., 1989).

Although they do not yield energy, micronutrients have to be ingested aside from macronutrients in order to provide a healthy diet (Robbins, 1993b, 1993c; National Research Council, 2003d, 2003e; Lambert, 2011). These micronutrients include minerals and vitamins which have key roles in biological processes and body maintenance.

Animals have to extract several important nutrients from their environment in order to gain energy, maintain their energy balance and sustain their metabolism. It is therefore vital that feeding behavior respond to specific needs by providing the adequate nutritional and energetic supply. These requirements have ultimately shaped the way animals feed.

\subsubsection{Feeding adaptations}

Introduced and developed within the last fifty years, the optimal foraging theory aims at predicting animals' foraging behaviors, i.e. how they 'make decisions' on how to obtain food (Emlen, 1966; MacArthur and Pianka, 1966; Schoener, 1971; Pyke et al., 1977). This approach tackles several aspects of foraging behaviors in a patchy environment, such as food patch selection, food patch exploitation (e.g. when leaving a food patch), movements between food patches (e.g. direction, speed, target destination) and diet selection (Pyke et al., 1977). The optimal foraging theory is fundamentally based on the assumption that a behavior maximizing net energy intake, with regards to the time and energy spent foraging, has been selected. Foraging 'decision-making' has therefore been, more or less, optimized in relation to different set of variables (Pyke, 2019). This theory has provided an important and useful framework in understanding animal feeding behavior (Pyke, 2019).

Adaptations in feeding behavior are crucial to maintaining energy balance. Importantly, these feeding adaptations or 'strategies' are not static but rather tuned to both environmental and metabolic conditions. They aim at redirecting energy intake and expenditure toward a fluctuating optimum that largely depends upon external and internal factors. Cues from the 
environment (e.g. food availability and distribution) and cues from the individual's internal state (e.g. internal "detectors" of negative energy balance or of specific nutrient requirements, as suggested by Rozin (1976)) influence mechanisms associated with the control of food intake (Stubbs and Tolkamp, 2006). This allows individuals to feed according to their environmental constraints and metabolic needs, contributing to maintaining energy balance (Stubbs and Tolkamp, 2006; Rozin, 1976). Feeding strategies can be different between species, between populations and also between individuals according to their age, sex or social rank among other factors (Harrison, 1983; Soumah and Yokota, 1991). Below, I focus on two important drivers of feeding behavior, namely resources in the habitat (in terms of quantity and quality) and female reproductive state. I present how these factors can impact the way individuals feed, more specifically for how long they feed and what they feed on.

Maintaining energy balance as food availability and/or quality decreases is challenging and as stated above, feeding strategies can be very different from one species to another. Therefore, different responses in terms of feeding behavior have been reported in wild species coping with fluctuating resources in their habitat. An important coping mechanism is the modulation of feeding time. For example, a nutritional deficit can be compensated by consuming more food through longer feeding bouts. Access to only low-quality food resources can then typically induce an increase in feeding time (Muruthi et al., 1991; Agetsuma and Nakagawa, 1998). In contrast, feeding time can also decrease as food availability declines since poor habitats lower feeding opportunities (Albani et al., 2020). In such food shortage situations, another possible coping mechanism is to adopt a low selectiveness in food consumption (Goodson et al., 1991). It is, for example, common that seasonality in food availability triggers cyclic modification in diet composition, with certain food being consumed only during one period of the year (Hill, 1997). Additionally, a decline in preferred food (i.e. overselected high-quality food) can induce a nutritional compensation with the consumption of 'fallback' food (i.e. relatively low-quality food which becomes a major dietary component when preferred foods are scarce), such as tubers in hunter gatherers or figs in gibbons (Hylobates albibarbis; Marshall and Wrangham, 2007; Lambert and Rothman, 2015; Marlowe and Berbesque, 2009; Marshall et al., 2009). Modulations of feeding time and diet composition are therefore two important feeding adaptations to cope with a reduction of food quantity and quality in the habitat.

Regardless of the environment, reproducing females typically cope with the energetic costs of reproduction by modifying their feeding behavior. Two opposite strategies have been 
described. With the first strategy, gestating or lactating females feed less and ingest less energy than non-reproducing females in order to rest more. By doing so, they minimize energy expenditure induced by activity and foraging, and therefore conserve energy (Harrison, 1983; Miller et al., 2006). The other strategy consists in increasing energy intake during gestation and lactation (Korine et al., 2004). There are two non-exclusive ways through which females can increase their energy intake. First, females can allocate more time to feeding (Muruthi et al., 1991; Rödel et al., 2016). Second, females can become more efficient when feeding, i.e. enhance energy intake per feeding bout (Muruthi et al., 1991). To do so, reproducing females can feed faster (increase in ingestion rate; McCabe and Fedigan, 2007) or they can feed more selectively, modifying their diet composition toward the most nutritional food (Clutton-Brock et al., 2009; Mellado et al., 2005). The latter is particularly important since reproducing females typically require specific nutrients such as proteins to support gestation and lactation (Kusina et al., 1999). It is for example common for a female to adapt her diet in order to fulfill the protein requirements of reproduction (Herrera and Heymann, 2004; Miller et al., 2006; Silk, 1987). Moreover, in order for reproducing females to maximize net intake, their increase in energy intake can also be combined with additional compensatory mechanisms that lower energy expenditure, such as a decrease in physical activity (as presented in part 2.1; Goldberg et al., 1991; Gamo et al., 2013) or in metabolic rate (Korine et al., 2004). To conclude, an increase in energy intake during female reproduction can result from increasing feeding time, increasing ingestion rate or changing diet composition. These feeding adaptations have a major impact on female fitness since deficits in energy or nutrient intake can have drastic consequences in reproductive performance (Roberts et al., 1985; Kohrs et al., 1980).

Although feeding adjustments are fundamental to enhance reproductive success they can be complicated, if not impossible, to implement since feeding behavior is also shaped by environmental conditions. Therefore many mammals living in a seasonal environment have adapted to synchronize reproductive events with food resource fluctuations (Jönsson, 1997; first identified in birds: Drent and Daan, 1980). Such species have consequently become seasonal in their reproduction and different strategies have been described depending on how species synchronize breeding with peaks in food availability. While some species breed after a peak of resource availability and therefore depend on endogenous cues and fat stores to reproduce (capital breeders; e.g. bighorn ewes (Ovis Canadensis): Festa-Bianchet et al., 1998); others living in a predictable environment mate prior to a peak of food availability to synchronize lactation with food abundance (income breeders; e.g. Antarctic fur seals 
(Arctocephalus gazelle): Oftedal et al., 1987). Some species can also meet halfway on the seasonal breeding spectrum and use mixed strategies in their mating pattern (relaxed-income breeders; Weddell seals (Leptonychotes weddellii): Wheatley et al., 2008). Integrating current and/or future external energy supply with reproduction timing has thus become a crucial behavioral adaptation to reproduce successfully in a seasonal habitat.

Species have behaviorally adapted in the face of external and internal energetic challenges by adjusting the way they interact with their environment and how they extract energy and nutrients from it. In addition to behavioral adaptations, species have also adapted physiologically, i.e. with regards to the biology of their body. For example, the composition and activity of the gut microbiota can vary in times of cold or food shortage which appears to be an effective mechanism buffering against a decline in energy balance (Chevalier et al., 2015; Amato et al., 2015; Sommer et al., 2016; Baniel et al., 2021). Hormones are also involved in many stages of the metabolic process ranging from energy intake and storage to energy mobilization and expenditure. For that reason, physiological adaptations regarding hormonal level play an important role when coping with energetic challenges.

\section{Physiological adaptations}

Through evolutionary time, the physiological adaptability of an organism has contributed to the support of metabolic demands and/or the maintenance of homeostasis (i.e. a steady biological state of dynamic equilibrium which is optimal for survival; McEwen and Wingfield, 2003) in response to internal or external sources of disturbances such as female reproduction (Speakman, 2008) or a changing environment (Young et al., 1989). These physiological processes regulating homeostasis rely predominantly on the endocrine system and on the associated hormonal release. Hormones are indispensable organic chemical messengers involved in life history traits (Finch and Rose, 1995) and some of them function as essential modulators of energy metabolism. Below, I present three hormone classes involved in energy assimilation, energy expenditure and energy store mobilization: insulin, thyroid hormones and glucocorticoids. 


\subsection{Insulin and urinary C-peptide}

Insulin is released from the pancreas in response to an increase in blood glucose levels (resulting, for example, from food ingestion; Henquin et al., 2006; Wolever and Bolognesi, 1996; Hedeskov, 1980). This hormone is crucial for energy uptake as it promotes glucose absorption into cells and glucose storage by tissues such as liver, adipose tissue or skeletal muscles (Dimitriadis et al., 2011). In addition to its immediate release following food intake, insulin is on a longer time scale a regulator of energy stores and a signal of energy balance to the brain (Strack et al., 1995). Specifically, insulin acts in the central nervous system by regulating the expression of neurons involved in energy homeostasis (Loh et al., 2017). For example, insulin action on a neurotransmitter called neuropeptide $Y$ induces a reduction in appetite and an increase in energy expenditure (Loh et al., 2017).

The biosynthesis of insulin consists in the breaking down of proinsulin (Kitabchi, 1977), which releases insulin and C-peptide (a small polypeptide) in equimolar amount (i.e. 1:1; Melani et al., 1970; Rubenstein et al., 1969). C-peptide has no biological function and is further excreted into urine at a constant clearance rate (Kruszynska et al., 1987). The concentration of urinary C-peptide ( $\mathrm{uCP}$ ) is positively correlated with circulating insulin (Wolden-Hanson et al., 1993; Hoogwerf and Goetz, 1983; Melani et al., 1970) and therefore, uCP assessment provides an indirect measure of insulin production.

To date studies validating and using uCP levels as a marker of energy balance have been largely performed on primates (Emery Thompson, 2016a). Many studies have provided evidence that uCP (and therefore insulin) concentrations are positively linked to changes in body mass (Deschner et al., 2008; Ellison and Valeggia, 2003; Girard-Buttoz et al., 201l; Hoogwerf and Goetz, 1983; Kruszynska et al., 1987; Wolden-Hanson et al., 1993) and thus, to changes in energy balance (Bergstrom et al., 2020). Consequently, factors affecting energy balance, such as environmental conditions, influence uCP levels. For example, uCP levels are positively associated with food availability (Dias et al., 2018; Emery Thompson et al., 2009; Emery Thompson and Knott, 2008; Grueter et al., 2014; Harris et al., 2009; Lucchesi et al., 2020; Sherry and Ellison, 2007; Wessling et al., 2018b) and quality (Emery Thompson et al., 2012, 2009; Fürtbauer et al., 2020; Kurihara et al., 2020; Nurmi et al., 2018). Moreover, uCP levels are positively linked to energy intake, particularly from carbohydrates and proteins (Emery Thompson and Knott, 2008; Henquin et al., 2006; Hoogwerf et al., 1986). However, in spite of favorable feeding conditions, uCP levels can decline in reaction to an increase in energy 
expenditure induced, for example, by infections (Emery Thompson et al., 2009). The energetic expense associated with physical activity or lactation also typically induce low uCP levels (Sacco et al., 2021; Frisch et al., 1984; Blix et al., 1982; Dias et al., 2018; Emery Thompson et al., 2012). uCP concentration therefore rises in reaction to energy intake and declines with energy expenditure. These uCP level fluctuations illustrate the fact that insulin production and the induced amount of energy stored are modulated according to energy balance.

\subsection{Thyroid hormones}

The thyroid gland is part of the neuroendocrine system and specifically belongs to the HPT axis (hypothalamic-pituitary-thyroid axis). The stimulation of this gland induces the release of thyroid hormones into the bloodstream. These hormones are involved in mammalian growth and development (Behringer et al., 2014; Gobush et al., 2014; Keogh et al., 2013; Parra et al., 1980; Yousef and Luick, 1971). Additionally, thyroid hormones have a fundamental role to play in energy metabolism since they act as regulators of metabolic rate (Kim, 2008; Hulbert, 2000). Triiodothyronine (T3) is considered the biologically most active form of thyroid hormones and its production induces an increase in metabolic activity and thus in the associated energy expenditure (Kim, 2008; Rosenbaum et al., 2000). The regulation of this hormone is a crucial physiological adaptation in the face of energetic challenges (Chatzitomaris et al., 2017).

First, when coping with a decrease in energy intake, T3 typically decreases which lowers the metabolic rate and saves energy (Eales, 1988; Flier et al., 2000). This decline in T3 in relation to low energy intake has been shown in food-restriction experiments (Deschner et al., 2020; Fontana et al., 2006; Brecchia et al., 2006; Blake et al., 1991; Blum et al., 1980; Harlow and Seal, 1981; Merimee and Fineberg, 1976; Schaebs et al., 2016), and further supported in studies assessing energy intake in wild species (Jesmer et al., 2017). Second, a rise in T3 production has been reported in situations inducing an increase in metabolic demands such as physical activity (Hackney et al., 2012), mating (Cristóbal-Azkarate et al., 2016) or pregnancy (Chatzitomaris et al., 2017; Dias et al., 2017; Glinoer, 1997). Lastly, as mentioned earlier, the metabolic expense of energy is dissipated as heat. By modulating metabolic rate and energy expenditure, thyroid hormones are therefore involved in heat generation, i.e. thermogenesis (Bianco et al., 2005; Dauncey, 1990; Laurberg et al., 2005; Silva, 2006). The link between thyroid activity and ambient temperature was introduced more than a century ago (Mills, 1918). Since 
then experimental and field studies have provided evidence that heat exposure typically triggers a decline in thyroid hormones (El-Nouty et al., 1978; Sejian et al., 2014), whereas cold exposure induces the opposite effect, i.e. a rise in thyroid activity (Bauman and Turner, 1967; Kaethner and Good, 1975) and in T3 concentration (El-Nouty et al., 1978; Gale, 1975; Oki and Atkinson, 2004). In conclusion, T3 functions as an endocrine control of 'fuel consumption' by modulating the metabolic rate and expense of energy in relation to nutritional status and metabolic demands.

\subsection{Glucocorticoids}

The adaptive response to homeostasis-threatening situations induces the release of the metabolic hormone class of glucocorticoids (e.g. cortisol or corticosterone) and is commonly referred to as the stress response (first introduced as the "general adaptation syndrome": Selye, 1946; Charmandari et al., 2005; McDougall-Shackleton et al., 2019). Glucocorticoids are secreted in the adrenal glands along the HPA axis (hypothalamic-pituitary-adrenal axis) and they are the primary mediators of allostasis, i.e. processes maintaining stability (homeostasis) through changes (Romero et al., 2009; McEwen and Wingfield, 2003). These hormones act as inhibitors of body functions that are not immediately essential for survival (e.g. digestion, growth or reproduction; Sapolsky et al., 2000; Charmandari et al., 2005) and in doing so, glucocorticoids redirect energy allocation. They also increase energy availability by impeding glucose absorption and promoting energy mobilization from energy stores (through gluconeogenesis and lipolysis; Exton et al., 1972). Overall, glucocorticoids trigger an increase in readily available energy (i.e. blood glucose level) in the face of a psychological stressor (Creel et al., 2013) or, more importantly here, an energetic challenge.

An increase in glucocorticoids has been reported in animals facing a decrease in environmental resources both in terms of quantity (Champoux et al., 1993; McLarnon et al., 2015; Conn et al., 1995; Malcolm et al., 2014) and quality (Chapman et al., 2015; Foerster et al., 2012; Pokharel et al., 2019). Therefore a decline in nutritional status, induced by low energy intake, commonly leads to a rise in glucocorticoids to mobilize energy stores in times of shortage (Laver et al., 2020; Lodge et al., 2013; Jeanniard du Dot et al., 2009). In addition, increasing energy availability through a rise in glucocorticoids has been observed in times of heightened energy expenditure. For example, physical activity (Girard and Garland, 2002; 
Hackney et al., 2012; Markham et al., 2015), female reproductive states (Dunn et al., 2013; Emery Thompson et al., 2010; Dantzer et al., 2010; Goymann et al., 2001; Laver et al., 2020), cold ambient temperatures (de Bruijn and Romero, 2018) or infections (Behie and Pavelka, 2013) can induce high glucocorticoid concentrations. Overall, the endocrine control of energy allocation and availability through glucocorticoid production is a physiological adaptation in response to fluctuating energetic needs and energy balance.

Insulin, thyroid hormones and glucocorticoids are hormones involved in energy metabolism and the modulation in their production is adaptive to various energetic challenges. They have a large influence on survival as their dysfunction or absence can lead to death (Katsarou et al., 2017; Triandafillou et al., 1982; Darlington et al., 1990). Importantly, besides $\mathrm{uCP}, \mathrm{T} 3$ and glucocorticoids can be measured non-invasively through urine as their urinary concentrations correlate with circulating levels (Burke and Eastman, 1974; Crockett et al., 1993). This hormonal assessment from a non-invasively collected matrix such as urine has revolutionized studies on energetics (i.e. studies investigating mechanisms involved in different components of energy metabolism such as energy acquisition, energy storage or energy utilization). The urinary concentrations of $\mathrm{uCP}, \mathrm{T} 3$ and glucocorticoids provide a gateway to the evaluation of energy balance and physiological adaptations in response to energetic challenges. Specifically, while uCP allows an evaluation of overall energy balance, T3 and glucocorticoids bring a complementary energetic picture with regards to metabolic rate (energy expenditure) and energy mobilization, respectively. Therefore, assessing and integrating these hormones is a powerful approach when studying energetics and this will be detailed in the next section.

\section{This thesis}

\subsection{Thesis aim}

Behavioral and physiological adaptations contribute to the support of metabolic needs and alleviate the costs energetic challenges can have on fitness. These adaptations are various and might act in concert in supporting energy demands, body maintenance and survival in challenging times (Nie et al., 2015). However, to date few studies have provided an integrative approach by considering, for example, how energetic challenges can simultaneously impact (i) several hormones involved in energy metabolism or (ii) both behavior and hormones. Such 
investigations are needed to shed light on complementary adaptations that have emerged concomitantly and to assess on a fine-scale energetic conditions induced by different challenges among mammals. This integrative approach will allow a better evaluation of the magnitude of the energetic costs of various challenges which will lend valuable insight into the way such energetic constraints might have driven life history traits in different species. The main aim of this dissertation is to investigate physiological and behavioral responses to various energetic challenges in order to provide an integrative picture of the set of adaptations acting in concert when coping with a challenging situation.

Specifically, the first aim of this thesis is to combine several energetic markers to assess the physiological reaction to different energetic challenges. While most studies have provided insights on how energetic challenges affect one specific biomarker of energy balance (e.g. Dias et al., 2018; Fürtbauer et al., 2020; Laver et al., 2020), very few have taken the path of combining several markers. Simultaneously assessing several energetic markers offers a promising approach to look from different windows at the core sustaining an individual's life, i.e. its energy metabolism. This way, we can tease apart several determinants of an individual's energy condition (e.g. energy assimilation, energy expenditure, energy mobilization) and investigate their respective, and complementary, shifts in reaction to energetic challenges (Emery Thompson, 2016b). For example, assessing glucocorticoids alongside another energetic marker such as thyroid hormones would parse the respective contribution to energy mobilization and energy expenditure and therefore help in determining the energetic condition of an individual. Specifically, an increase in glucocorticoids (i.e. rise in energy mobilization) would be indicative of an energy deficit when combined with a decrease in thyroid hormones (i.e. reduced metabolic rate and energy expenditure), while it would illustrate heightened energy demands while combined with a rise in thyroid hormones.

To date only a handful of studies have jointly assessed glucocorticoids with thyroid hormones. These studies aimed at understanding foraging strategies (Jesmer et al., 2017), disentangling psychological stressor from energetic challenge (Ayres et al., 2012; Joly et al., 2015; Pritchard et al., 2020; Vynne et al., 2014) or investigating the effects of various energetic challenges on individuals' energetic condition (Dias et al., 2017). Some provided evidence that food availability or energy intake did not influence thyroid hormone or glucocorticoid levels (Pritchard et al., 2020) while others found an increase only in thyroid hormones (Dias et al., 2017) or in both hormones (Jesmer et al., 2017). The discrepancy of the few results available illustrates the need for further investigation in understanding how thyroid hormones and 
glucocorticoids are affected by energetic challenges in different species. This dissertation aims at contributing to this growing body of research by jointly assessing thyroid hormones and glucocorticoids and examining how they react to various energetic challenges.

The second aim of this thesis is to combine a physiological marker with behavior to assess the energetic impact of a major challenge faced by female mammals. Reproduction has provided a stimulating field of research for studies on energetics. Numerous studies have examined the energetic costs of female reproduction through a behavioral (e.g. Clutton-Brock et al., 2009; Korine et al., 2004; Muruthi et al., 1991) or physiological (e.g. Gesquiere et al., 2018; Gholib et al., 2018; Grueter et al., 2014) approach. Although these studies have largely contributed to enlightening the behavioral or hormonal shifts associated with the substantial costs of female reproduction, their results typically lead to new questions or extrapolation. For example, when no differences in $\mathrm{uCP}$ levels are found between females at different reproductive states, does it mean that reproduction is not costly enough to trigger changes in female energy balance? Probably not. It rather suggests that reproducing females have likely adopted behavioral shifts to buffer these costs and maintain similar uCP levels to nonreproducing females (Fürtbauer et al., 2020; Grueter et al., 2014). Such cases illustrate the importance of combining a behavioral approach with hormonal assessment in order to further investigate how energetic costs can potentially be offset or buffered by behavioral shifts (Girard-Buttoz et al., 2014). Therefore, this dissertation also aims at providing an additional study to the limited corpus of research investigating the energetic costs of female reproduction from both a physiological and a behavioral perspective.

In conclusion, with this dissertation, the effects of several energetic challenges are investigated through a multifaceted prism: either by combining two energetic markers or by combining behavior with an energetic marker. Species living in a seasonal habitat are a model of choice for such studies on energetics as they typically experience various challenges in relation to fluctuations in environmental conditions.

\subsection{Study species}

The population of Assamese macaques (Macaca assamensis) at Phu Khieo Wildlife Sanctuary in Thailand provides a good model for studying the behavioral and physiological impact of energetic challenges. First, they live in a habitat exhibiting two distinct seasons: a 
cold dry season (from November to February; Figure 1) and a hot rainy season (from March to October), in which minimum ambient temperature reaches $5{ }^{\circ} \mathrm{C}$ and $23{ }^{\circ} \mathrm{C}$, respectively (Richter et al., 2016). The habitat is also characterized by repeated patterns of fluctuating resource availability and this in spite of a large variability between years (Heesen et al., 2013; and see Figure 1 to visualize fluctuations in fruit availability during one year). Fruit availability appears to be a determinant of energy intake and activity patterns in this population (Heesen et al., 2013; Richter et al., 2016). Therefore, changes in ambient temperatures, in energy intake and in physical activity might represent three potential energetic challenges that females have adapted to cope with and they might individually trigger shifts in energy metabolism.

Second, as in all mammalian species, another major energetic challenge experienced by females is reproduction. Peak of lactation is synchronized with a peak of fruit availability (Heesen et al., 2013). Fruit availability also modulates conception rates (Heesen et al., 2013). As females seem to rely both on exogenous and endogenous cues to conceive, the population has been described as relaxed-income breeders (Heesen et al., 2013). Additionally, females bear visible costs when reproducing since lactating females exhibit poor physical condition (Heesen et al., 2013), suggesting a decline in their energetic condition. At the onset of the mating season, which spans from October to February (Figure 1; Fürtbauer et al., 2010), a female's energetic condition will determine whether or not she will conceive in the respective mating season. Females who gave birth late in the previous year will typically skip a year and exhibit a two-year interbirth interval (Fürtbauer et al., 2010). This indicates that females need some time to recover from their previous reproductive investment before being able to conceive again. The energetic costs of reproduction are clearly illustrated in this population and motivates further investigation on that regard, in terms of physiological and behavioral shifts potentially occurring during the reproductive cycle.

Third, female Assamese macaques exhibit a stable dominance hierarchy characterized by conflict avoidance and feeding tolerance between females with strong social bonds (Heesen et al., 2014). This may explain why, in spite of the contest feeding competition induced by the distribution and quality of food items in their habitat (Heesen et al., 2013; Schülke et al., 2011), dominance rank is not a determinant of energy intake, reproductive success and glucocorticoid levels in this population (Heesen et al., 2013; Fürtbauer et al., 2014). This is advantageous when studying energetics as social rank can therefore be discarded from any potential drivers of female energetic condition. Moreover, in addition to fruits, Assamese macaques rely on many other food items to fulfill their nutritional requirements (Heesen et al., 2013; Schülke et al., 
2011). Such diversity in the diet is common among primate species (Milton, 1984; Lambert and Rothman, 2015) and is a stimulating feature for studies investigating potential shift in dietary composition in relation to energetic challenges. Lastly, energetic markers can be assessed noninvasively in this population as studies have previously validated the assessment of uCP, T3 and cortisol from urine samples in macaques species (Girard-Buttoz et al., 2011; Sadoughi et al., 2021; Bahr et al., 2000).

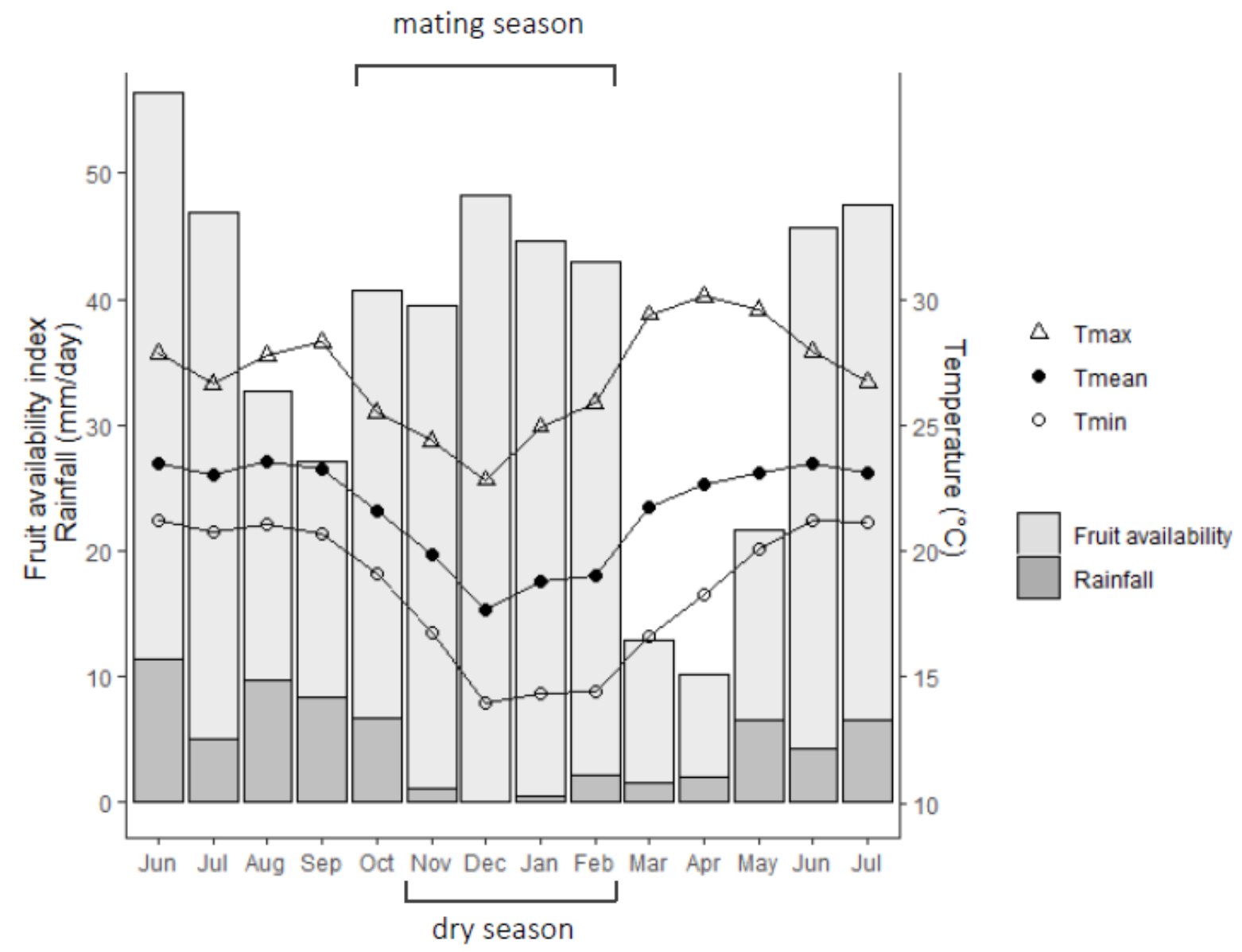

Figure 1. Variation in monthly average of fruit availability, rainfall, mean ambient temperature (Tmean), maximum ambient temperature (Tmax) and minimum ambient temperature (Tmin) through one year (from June 2017 to July 2018).

In conclusion, female reproduction, seasonal fluctuations in energy intake, physical activity and ambient temperature are potential energetic challenges that female Assamese macaques have adapted to. These challenges may trigger shifts in behavior, especially in feeding 
behavior, and potentially induce modulations in uCP, T3 and cortisol production. The concomitant investigation of behavioral and physiological responses to energetic challenges would therefore be particularly relevant and informative, especially for species living in a seasonal habitat, such as Assamese macaque.

\subsection{Thesis content}

To investigate energetics in wild female Assamese macaques, I focused on four potential energetic challenges experienced by this seasonal species: (i) a low energy intake assessed via behavioral and nutritional data, (ii) an increase in physical activity estimated from daily travel distances, (iii) thermogenesis when facing cold ambient temperatures and (iv) reproduction (gestation and lactation). I studied how these challenges may impact female activity budget, feeding behavior and/or energy metabolism. To do so, I assessed uCP, T3 and cortisol levels from urine samples. With the aim of providing an integrative picture of the behavioral and physiological consequences of various energetic challenges, I conducted my investigation through two main chapters (Figure 2).

In the second chapter of this thesis, I combined the assessment of two energetic markers, T3 and cortisol, and investigated how the four energetic challenges may individually drive the production of these hormones. This first study aims at disentangling the physiological adaptations involved in metabolic rate and energy mobilization in response to different challenges.

In the third chapter, I focused on one challenge, i.e. reproduction, and I investigated the energetic costs of gestation and lactation through the behavioral and physiological shifts they may induce. Specifically, in addition to measuring uCP levels, I assessed females' activity budget and dissected several components of their feeding behavior in order to compare all these different metrics across females in different reproductive states. This second study will help in understanding different and complementary coping mechanisms in females facing the substantial energetic demands of reproduction. 
PHYSIOLOGY

T3

cortisol
BEHAVIOR

UCP activity budget

Chapter 3:

Chapter 2:

combining two energetic markers to investigate physiological responses to various energetic challenges in Assamese macaque

energy intake

physical activity

cold ambient temperatures

reproduction feeding behavior

Figure 2. Visualization of the content of chapters 2 and 3 of this thesis. 



\section{CHAPTER 2}

\section{Triiodothyronine and cortisol levels in the face of energetic challenges from reproduction, thermoregulation and food intake in female macaques}

Sonia Touitou ${ }^{\mathrm{a}, \mathrm{b}, \mathrm{d}}$, Michael Heistermann ${ }^{\mathrm{c}}$, Oliver Schülke ${ }^{\mathrm{a}, \mathrm{b}, \mathrm{d},{ }^{\dagger}}$, Julia Ostner ${ }^{\mathrm{a}, \mathrm{b}, \mathrm{d},{ }^{\dagger}}$

a. Department of Behavioral Ecology, University of Göttingen, Germany

b. Leibniz ScienceCampus Primate Cognition, Göttingen, Germany

c. Endocrinology Laboratory, German Primate Centre, Göttingen, Germany

d. Primate Social Evolution Group, German Primate Centre, Göttingen, Germany

† These authors contributed equally to this work

Hormones and Behavior (2021)

Available online at https://doi.org/10.1016/j.yhbeh.2021.104968 


\section{Abstract}

Energy availability drives an individual's fitness and can be affected by diverse energetic challenges. The assessment of hormones involved in metabolic activity and energy mobilization provides a gateway to the study of physiological adaptations in response to changes in energy availability. Here, we investigated immunoreactive urinary total triiodothyronine (UTT3, thyroid hormone secreted through the hypothalamus-pituitary-thyroid axis and regulating the basal metabolic rate) alongside glucocorticoids (i.e. urinary cortisol, uCort, secreted through the hypothalamus-pituitary-adrenal axis and mediating energy mobilization) in wild female Assamese macaques (Macaca assamensis). Combining more than 2,900 h of behavioral data from 42 adult females with physiological data from 382 urine samples, we evaluated both uTT3 and uCort in relation to potential energetic challenges encountered by a female, namely fluctuations in energy intake, travel distance, reproductive state and minimum ambient temperature. As predicted, levels of both hormones changed in response to variation in energy intake with a tendency toward a positive effect on UTT3 and a significant negative effect on uCort levels. Unexpectedly, neither hormone was influenced by variation in travel distance. Reproductive state affected both hormones with higher levels of uTT3 and uCort in the second half of gestation. Finally, a decrease of minimum temperature triggered an increase in uCort but unexpectedly not in uTT3. Collectively, our results highlight the respective contribution of two endocrine axes when facing energetic challenges and the underlying metabolic strategies to cope with them. Overall, assessing thyroid hormones together with glucocorticoids provides an integrative picture in the evaluation of an individual's energy status.

\section{Key words}

Thyroid hormones; Glucocorticoids; Energy intake; Energy expenditure; Travel distance; Reproduction; Ambient temperature; Primate; Energy mobilization; Metabolic activity 


\section{CHAPTER 3}

The effect of reproductive state on activity budget, feeding behavior, and urinary C-peptide levels in wild female Assamese macaques

Sonia Touitou ${ }^{\mathrm{a}, \mathrm{b}, \mathrm{d}}$, Michael Heistermann ${ }^{c}$, Oliver Schülke ${ }^{\mathrm{a}, \mathrm{b}, \mathrm{d}, \dagger}$, Julia Ostner $^{\mathrm{a}, \mathrm{b}, \mathrm{d},{ }^{\dagger}}$

a. Department of Behavioral Ecology, University of Göttingen, Germany

b. Leibniz ScienceCampus Primate Cognition, Göttingen, Germany

c. Endocrinology Laboratory, German Primate Centre, Göttingen, Germany

d. Primate Social Evolution Group, German Primate Centre, Göttingen, Germany

† These authors contributed equally to this work

Behavioral Ecology and Sociobiology (accepted) 


\section{Abstract}

The source of maternal energy supporting reproduction (i.e. stored or incoming) is an important factor determining different breeding strategies (capital, income or mixed) in female mammals. Key periods of energy storage and allocation might induce behavioral and physiological shifts in females, and investigating their distribution throughout reproduction helps in determining vulnerable phases shaping female reproductive success. Here, we examined the effects of reproductive state on activity budget, feeding behavior, and urinary Cpeptide (uCP) levels, a physiological marker of energy balance, in 43 wild female Assamese macaques (Macaca assamensis). Over a 13-month study period, we collected 96,266 instantaneous records of activity and 905 urine samples. We found that early lactating females and non-gestating - non-lactating females follow an energy-saving strategy consisting of resting more at the expense of feeding and consuming mostly fruits which contributed to enhancing their energy intake and feeding efficiency. We found an opposite pattern in gestating and late lactating females who feed more at the expense of resting and consume mostly seeds, providing a fiber-rich diet. Storing food into cheek pouches increased throughout gestation while it decreased all along lactation. Lastly, we found the highest $\mathrm{uCP}$ levels during late gestation. Our results reflect different feeding adaptations in response to the energetic costs of reproduction and suggest a critical role of fat accumulation before conception and metabolizing fat during gestation and lactation. Overall, our study provides an integrative picture of the energetics of reproduction in a seasonal species and contributes to our understanding of the diversity of behavioral and physiological adaptations shaping female reproductive success.

\section{Key words}

Reproduction; Activity budget; Diet composition; Energy intake; Feeding efficiency; Urinary C-peptide 


\section{CHAPTER 4}

\section{General discussion}

The overall aim of this thesis was to contribute to the understanding of the physiological and behavioral responses to energetic challenges in mammalian females. I investigated how energy-demanding situations affected female hormone levels, activity budget and feeding behavior. This integrative approach allowed the evaluation of different sets of complementary adaptations that emerged in the face of various challenging situations. Female Assamese macaques (Macaca assamensis) provided a good model for the purpose of my research as they have to cope with different potential energetic challenges, naturally occurring in their seasonal habitat in Thailand (e.g. fluctuations in fruit availability and ambient temperature). I collected behavioral and nutritional data together with urine samples. From the latter, I assessed three different physiological markers of energy metabolism: glucocorticoid (cortisol) metabolite levels, and, for the first time in this species, urinary C-peptide of insulin (uCP) and thyroid hormone (triiodothyronine, or T3) metabolite levels. In the first study (Chapter 2), I combined markers of energy mobilization (cortisol) and metabolic rate (T3) to jointly investigate their modulation in response to potential energy-costly situations. The results showed that depending on the undergoing energetic challenge, the induced rise in cortisol will be combined with either an increase or a decrease in T3 levels. In the second study (Chapter 3), I focused on one specific energetic challenge, namely reproduction, and examined its effect both on female behavior (activity budget and feeding behavior) and energy balance (uCP levels). The results revealed both behavioral and physiological adaptations throughout the reproductive cycle. An overview of the results from chapters 2 and 3 are depicted below (Figure $1)$.

In this general discussion, I first combine the results of chapters 2 and 3 in order to provide an overview of the energetic picture in female Assamese macaques. Second, I integrate the results of the present thesis into the growing body of research on energetics. I specifically review the state of the art regarding the three energetic markers in primates. Third, I suggest future research directions for forthcoming studies on energetics and highlight the importance of addressing research questions on energetics through a multifaceted approach. I stress the value of integrative approaches consisting in measuring several physiological markers and 
adding behavior into the energetic picture. Fourth, I present research implications with regards to wildlife conservation.

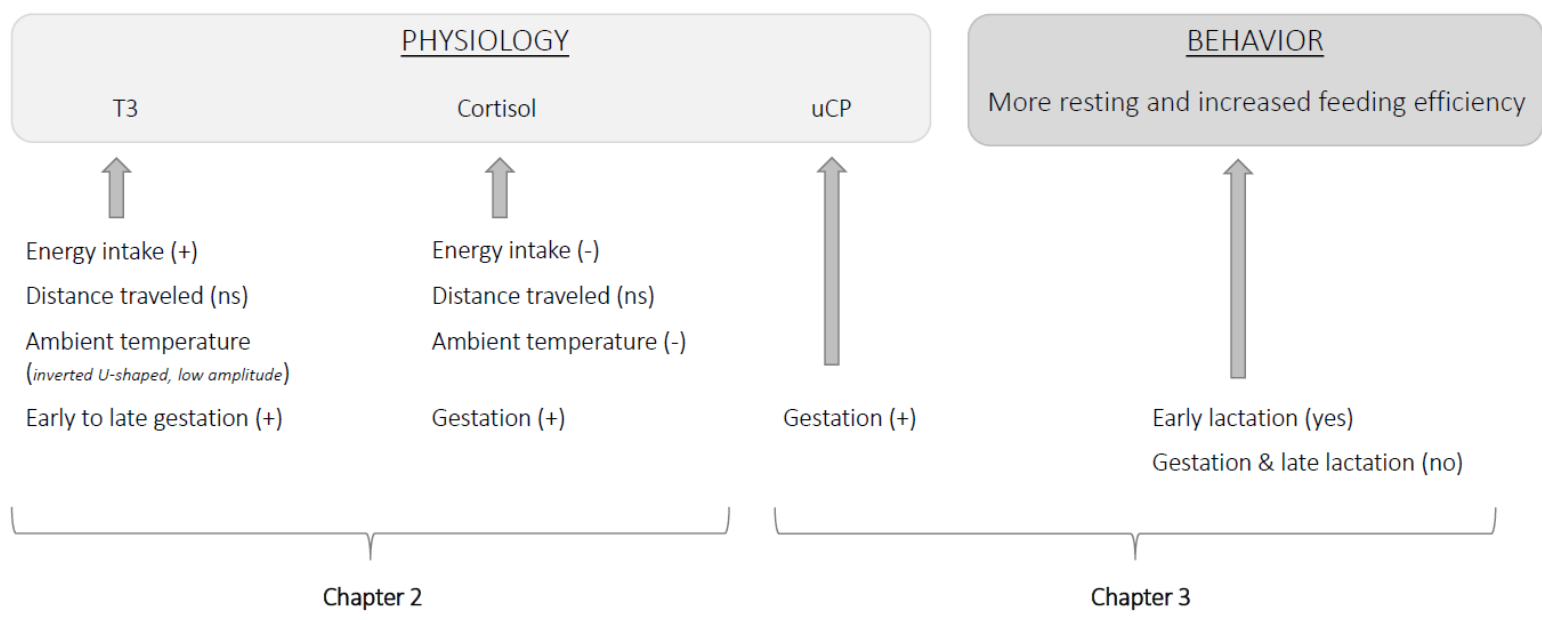

Figure 1. Overview of the results. Direction of effects of various challenges is indicated in parentheses.

$(+)$ : induces a significant increase (trend in the case of the effect of energy intake on T3 levels)

(-): induces a significant decrease

(ns): non-significant effect

\section{Energetics in female Assamese macaques}

\subsection{Energy intake}

In times of low energy intake, female Assamese macaques mobilize their fat stores, as illustrated by the increase in glucocorticoid (cortisol) level (Chapter 2). They simultaneously tend to lower their metabolic rate as suggested by a decline in T3 levels, in order to conserve energy (Chapter 2). Interestingly, when controlling for female reproduction and travel distance, variation in fruit availability does not influence female uCP levels and thus energy balance (Chapter 3). Two options could explain these comparable levels of uCP as fruit availability changes. First, it might be that the physiological responses involving energy mobilization from fat stores and reduction in energy expenditure by slowing down metabolic rate are good coping mechanisms when fruit availability is low, i.e. when energy intake decreases (Heesen et al., 2013). Second, it may be that the high levels of glucocorticoids as energy intake decreases trigger insulin resistance (Zhou et al., 2016; Geer et al., 2014). This 
potential modulation in insulin sensitivity would therefore impede the interpretation of uCP levels and the inference of energy balance as energy intake fluctuates. While I could not disentangle these two possibilities, I could still highlight that energy intake gets low enough to trigger a physiological response in female Assamese macaques. Whether or not this affects their energy balance remains unclear.

\subsection{Female reproduction}

Female Assamese macaques exhibit an increase in energy demands over the course of gestation as illustrated by an increase in both glucocorticoids and T3 (Chapter 2). In late gestation, females mobilize their fat stores and have a faster metabolism. Females therefore spend energy by drawing upon their energy reserves and by supporting an increased metabolic activity. In addition, late gestating females become more resistant to insulin, as illustrated by their high uCP levels (Chapter 3). Insulin resistance might participate in fulfilling the energetic demands of gestation. This symptom, comparable with a mild form of gestational diabetes, keeps energy intake away from maternal uptake. Readily available energy can instead be spared for the fetus needs while the mother relies on lipid oxidation (Butte, 2000). This metabolic shift toward lipid oxidation is also supported by the increase of glucocorticoids during gestation (Chapter 2). Interestingly, gestating females do not follow a behavioral energy saving strategy as they do not spend more time resting and do not enhance their feeding efficiency (Chapter 3). Taken together, the results from chapters 2 and 3 highlight that physiological, and not behavioral, responses mainly contribute to the energetic support of gestation.

With the present dissertation, I also highlight another energetic pattern during lactation in Assamese macaques. Lactating females do not exhibit any physiological signs of undergoing energetic deficit. Their T3, glucocorticoid and uCP levels are indeed similar to nongestating - non-lactating females' (Chapters 2 and 3). Early lactating females follow a behavioral energy-saving strategy consisting in spending more time resting at the expense of feeding and being more efficient when feeding. This behavioral coping mechanism seems sufficient enough not to require additional physiological support. In contrast to gestating females, early lactating females rely particularly on behavioral, and not physiological, responses to offset the costs of lactation. 
With this dissertation, I provide evidence that female Assamese macaques do not exhibit low energy balance during reproduction. Their relaxed-income breeding system, with female fat reserves modulating the ability to conceive (Heesen et al., 2013), together with physiological and behavioral shifts during gestation and lactation (Chapters 2 and 3) might efficiently overcome the energetic costs of reproduction.

\subsection{Ambient temperature and travel distances}

Cold ambient temperature faced by female Assamese macaques does not seem to be challenging enough to trigger thermogenesis through an increase in T3 (Chapter 2). However, a decline in ambient temperature does induce an increase in glucocorticoid levels (Chapter 2). The fact that the study population does not face a long-lasting and extreme cold might explain why a glucocorticoid release is enough to overcome the energetic costs of thermoregulation.

Lastly, from chapters 2 and 3 it appears that T3, glucocorticoid and uCP levels are not affected by travel distances (and either by traveling time in the case of T3 and glucocorticoids; Chapter 2). This absence of physiological responses suggest that female Assamese macaques do not have to overcome high energy expenditure induced by walking travel distances.

\subsection{Future investigations}

From this dissertation it appears that among the energetic challenges investigated, fluctuations in energy intake and reproduction are the costliest ones as they respectively induce the activation of two endocrine axes and a combination of physiological and behavioral responses. This dissertation provides an important step toward the evaluation of the energetic challenges faced by the study population and a better understanding of the physiological and behavioral coping mechanisms involved. Two gaps of knowledge remain to be filled in future studies. First, it would be very informative to know more on potential behavioral shifts in response to other challenges than reproduction. A female may decrease her behavioral energy expenditure by allocating less time into foraging and/or resting more when energy intake is limited. Behavioral thermoregulation (e.g. huddling), especially during cold nights, may also help to overcome low ambient temperatures. These behavioral adaptations might mitigate the energetic costs of low energy intake and thermoregulation. Second, as physiological data 
accumulates, I encourage future studies to test the potential physiological and behavioral effect of interacting energetic challenges. For example, females at different stages of the reproductive cycle may exhibit different magnitudes in their physiological responses to a similar challenge (Foerster et al., 2012; Dias et al., 2017). The absence of a strong synchrony in reproduction patterns in Assamese macaques would allow such investigations as females do not experience the same environmental conditions at the same time within their respective cycle. Investigating the potential effect of interacting energetic challenges would require a large data set encompassing several years with physiological data for the same female giving birth at different time within the mating season across years.

This thesis adds to the growing body of literature on energetic markers and provide some directions for future investigations in Assamese macaques. Next, I will integrate my findings into the broader picture of energetics in wild populations. I will specifically focus on primates as they have been the study model of most studies on energetics. The following interpretation and synthesis should hold on a broader mammalian taxonomic level.

\section{Overview of energetic marker use in primates}

Table 1 summarizes the results of different studies on energetics (including this thesis) assessing non-invasively uCP, T3 or glucocorticoid levels in primates. From this table, it appears that physiological responses to energetic challenges in primates do not always coincide and that several gaps and uncertainties remain to be addressed in the future. I will provide a brief review for each marker below.

2.1. UCP

2.1.1. uCP and energy balance, energy intake, food intake

The relevance of $\mathrm{uCP}$ as a physiological marker of energy balance in non-human primates emerged from feeding experiments in bonobos and macaque species, showing a positive association between uCP levels and food access or food dietary content (see Table 1; studies \# 4; 18; 19). 


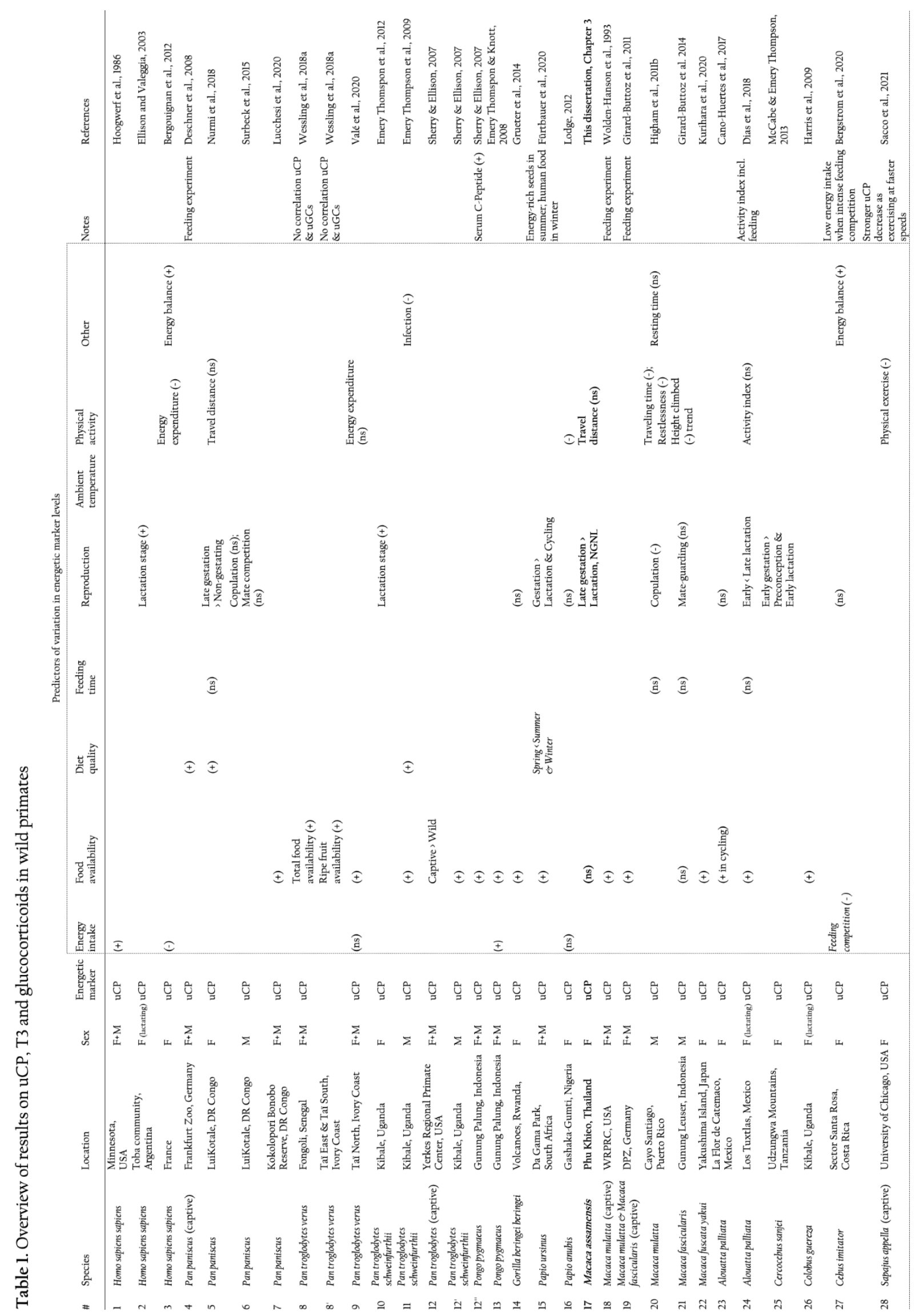




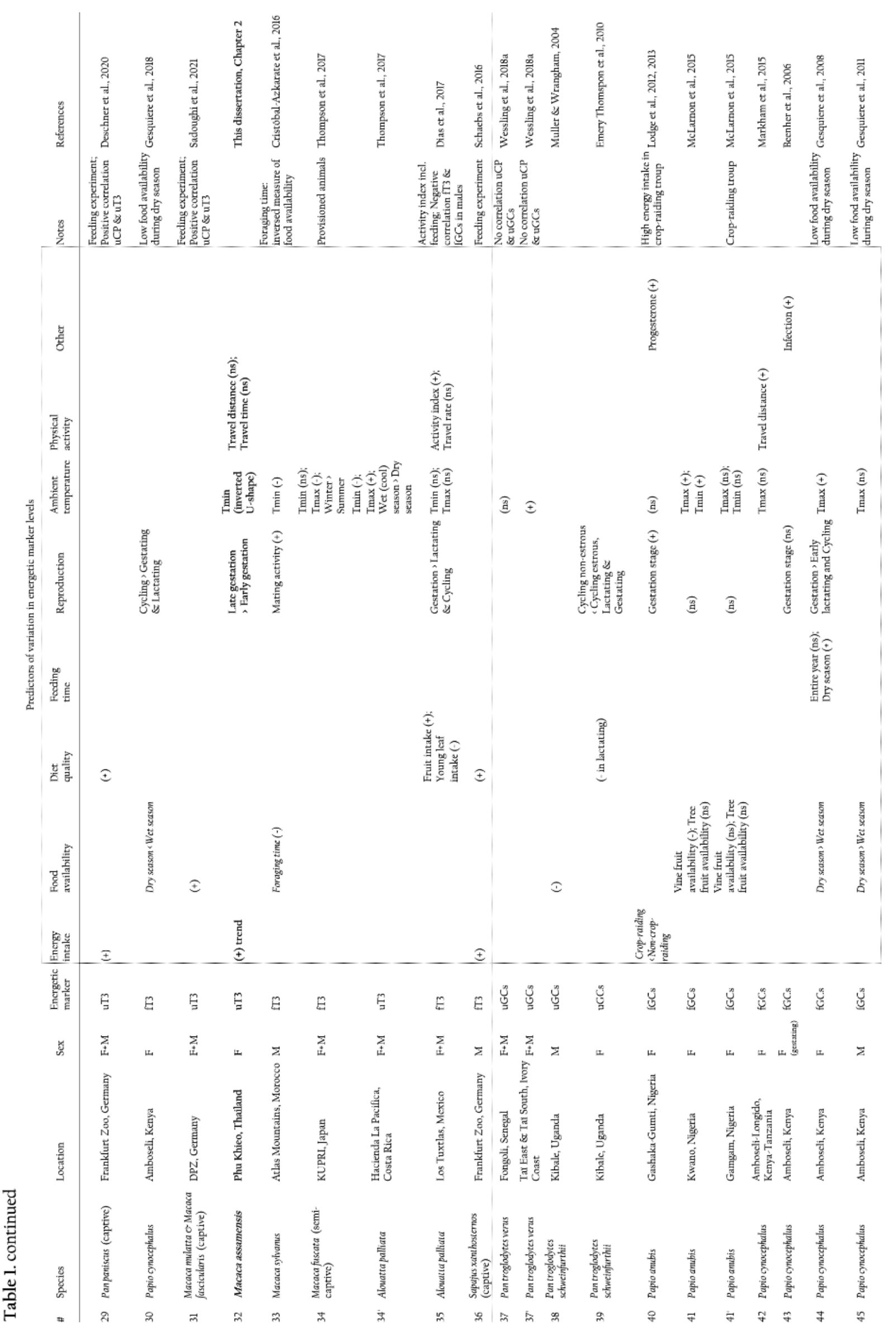




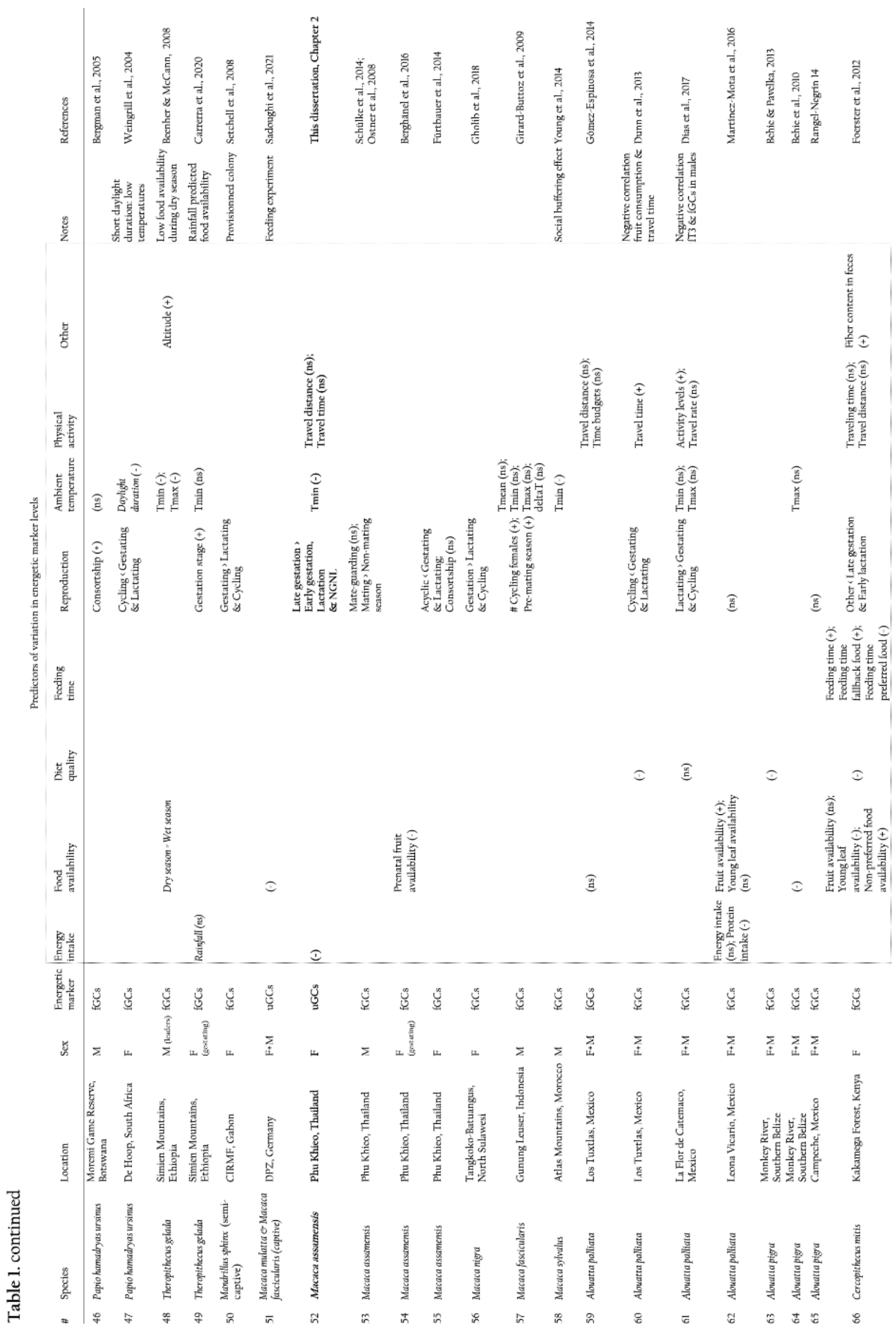




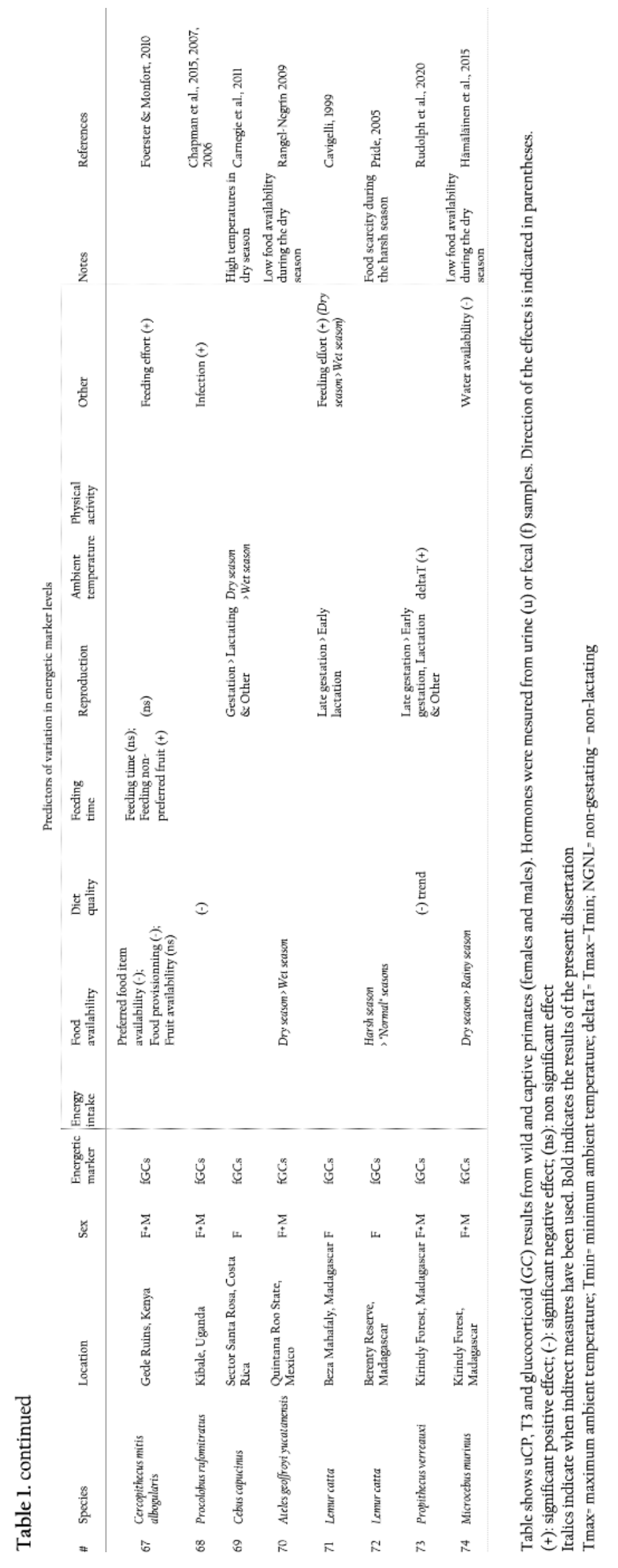


Since then, the use of uCP to assess energy balance in wild primates has become a stimulating field of research. Recently, a positive association found between uCP levels and energy balance assessed from nutritional and behavioral data in capuchin monkeys has provided evidence of the usefulness of uCP assessment in the wild (\# 27).

Regarding energy intake, several studies have investigated its effect on uCP levels in wild species. To date, only one has assessed energy intake and found a positive relationship with uCP levels in wild orangutans (\# 13). The other studies used indirect measures of energy intake and nutritional condition: diet quality, feeding time and food availability. uCP seems to be positively predicted by diet quality in bonobos, chimpanzees and chacma baboons (\# 5; 11; 15) and to be independent from feeding time as suggested by consistent findings from studies on macaques and howler monkeys (\# 5; 20; 21; 24). Lastly, fourteen of the twenty-eight uCP studies investigated the link between uCP levels and food availability in wild populations and mixed results were found. Twelve reported a positive relationship while two studies conducted on female Assamese macaques (this dissertation; \# 17) and on males long-tailed macaques (\# 21) found an absence of patterns. With the current limited body of research, I would suggest that for females, the discrepancy of results between uCP levels and food availability could be explained by breeding strategies.

An absence of a relationship between uCP and food availability was found in female Assamese macaques who are relaxed-income breeders. These females therefore not only rely on their accumulated fat stores to reproduce but also on exogenous clues (e.g. daylight duration). The positive association between $\mathrm{UCP}$ and food availability was found in female apes, chacma baboons, howler monkeys and colobus, i.e. primate species that are typical capital or nonseasonal breeders (Brockman and van Schaik, 2005; Knott, 2001; Polo and Colmenares, 2016; Emery Thompson and Wrangham, 2008; Di Bitetti and Janson, 2000; Teichroeb and Sicotte, 2008). In these species, females reproduce as soon as their energetic condition allow them to do so and they are therefore particularly dependent upon food abundance to invest in reproduction. The preponderant role of endogenous cues in driving reproduction in capital and non-seasonal breeders might explain why energy balance and thus uCP levels are tightly linked to food availability in these species. The fact that an absence of relationship between uCP and food availability was found in a relaxed-income breeder, while a positive relationship was found in capital and non-seasonal breeders might be the consequence of the stronger influence of food abundance fluctuation on the endocrine response in the latter (Brockman and van 
Schaik, 2005). This has to remain speculative as studies are very scarce. More investigations on female relaxed-income breeders such as muriquis, marmosets or rhesus macaques (Brockman and van Schaik, 2005) would be valuable to move the question forward.

\subsubsection{UCP and female reproduction}

Among the eight studies investigating the effect of different stages of the female reproductive cycle on $\mathrm{uCP}$, four studies found comparable $\mathrm{uCP}$ levels throughout the reproductive cycle in gorillas, olive baboons (Papio anubis), howler and capuchin monkeys (\# $14 ; 16 ; 23 ; 27)$. The four others found a different pattern, with female bonobos, chacma baboons, Assamese macaques (this dissertation) and Sanje mangabeys (Cercocebus sanjei) exhibiting high uCP levels during gestation (\# 5; 15; 17; 25). The reason why some females exhibit high uCP levels during gestation while others do not is unclear. Although this increase of uCP during gestation in female primates seem not to be consistent, two factors might explain this rise in uCP levels. First, in capital breeders, high uCP levels during gestation can be due to the accumulation of fat stores that may not only occur prior conception but also during gestation, as suggested by Brockman and van Schaik (2005). So a change in uCP levels might be related to changes in feeding behavior and fat accumulation prior and during gestation in capital breeding females. Second, high levels of uCP in gestating females can be induced by insulin resistance. A potential way to tease apart these two sources driving an increase in uCP would be to differentiate early and late gestation as insulin resistance typically arises in the later stages of gestation (Spellacy and Goetz, 1963; Cousins et al., 1980). High levels of uCP in late gestation likely illustrates insulin resistance (as found in Assamese macaques; \# 17) whereas high uCP in early stages might be related with capital breeding (as found in Sanje mangabeys; \# 25). A case where gestating females exhibit high uCP levels in chacma baboons with no differences between early and late stages also illustrates the possibility of a mixed strategy, with fat accumulation during gestation and a progressive insulin resistance (\# 15).

Lactation is the most costly stage of reproduction in female mammals (Gittleman and Thompson, 1988). In spite of this, all studies comparing uCP levels between lactating and cycling primates reported no difference between these two states (\# 14; 15; 16; 17; 23; 25; 27). Behavioral coping mechanisms have been suggested to offset the energetic costs of lactation. Only two of these studies (including this dissertation) investigated the effects of reproduction 
both on female uCP levels and behavior and were therefore able to evaluate (and confirm; as found in this dissertation) behavioral mechanisms offsetting the costs of reproduction on energy balance in wild primates (\# 17; 23).

\subsection{3. uCP and physical activity}

Only nine of the twenty-eight uCP studies examined the effect of energy expenditure through physical activities on $\mathrm{UCP}$ levels in primates. A decrease in $\mathrm{UCP}$ with physical expense was reported in two controlled experimental studies (\# 3; 28). Two field studies conducted on males found a similar pattern, with uCP levels decreasing as traveling time or height climbed increased (\# 20; 21). In contrary, two other field studies showed that female uCP level was not affected by travel distances (\# 5; 17), suggesting that walking distances may not be energetically challenging enough to induce a decrease in energy balance. A potential difference between the effect of physical activities on male and female uCP levels within the same population would need further investigation. It may be that males expend more energy than females during a physical activity as they typically have larger body size and the energy expenditure of traveling is a function of body mass (Valé et al., 2020). Males may therefore be more likely to exhibit a decrease in their uCP levels in response to a physical expense.

\subsubsection{Potential caveats with uCP}

One field study reported no pattern between uCP levels and thoroughly assessed energy intake and expenditure (\# 9). I would propose two potential explanations. First, this absence of relationship could simply highlight the fact that energy intake and expenditure are both very complicated to assess reliably in wild species. Assessing uCP levels would therefore be a useful tool to alleviate this issue and be able to assess energy balance in wild species (as suggested in \# 9). Second, uCP is maybe more complicated to interpret than we think as energy intake and expenditure are not the only drivers of uCP levels. As seen earlier, insulin sensitivity is not static and influences uCP levels. Changes in insulin sensitivity does not occur solely during gestation as physical activity might also enhance insulin sensitivity (Bergouignan et al., 2012). For example, energy intake in subjects who have to exercise induces relatively less insulin production than subject who do not exercise, stressing the enhanced insulin sensitivity in 
exercising subjects (Bergouignan et al., 2012). This flexibility in insulin sensitivity can therefore lead to unexpected correlations between energy intake and uCP levels (\# 3). In addition, some studies have suggested that uCP might be more sensitive to energy expenditure than intake (Emery Thompson et al., 2009; Higham et al., 201lb).

\subsubsection{Next steps with uCP}

Studies on $\mathrm{UCP}$ has provided evidence that this energetic marker can capture signals of energy intake and energy expenditure. Most importantly, uCP responds to energy intake and expenditure in opposite directions and therefore provides a direct assessment of energy balance. However, we need more studies in order to understand to what extent uCP is associated with energy intake and how diet composition and/or physical expense can potentially add noise to the relationship. The next important question to tackle with regards to $\mathrm{uCP}$ is whether fluctuations in physical expense could affect insulin sensitivity and thus, the extent to which uCP responds to energy intake. I encourage future studies to investigate a potential effect of an interaction between energy intake and expenditure on uCP levels in wild primates.

\subsection{T3}

\subsubsection{T3 and energy intake, food intake}

My thesis (Chapter 2) is the first study investigating the relationship between energy intake and T3 in a wild primate (\# 32). Other investigations were conducted through feeding experiments in captive primates (\# 29; 31; 36). In line with their results, I found that T3 tended to rise as energy intake increased. T3 level appears to capture energy intake in wild primates and this would deserve additional support from future studies conducted in other wild primates.

It also appears that a reduction in T3 levels is initiated in response to one food item (probably the most nutritive one) becoming scarce as suggested by a study in mantled howlers assessing T3 from fecal samples (\# 35). However, as found in humans, it may also be that diet composition, specifically carbohydrate (e.g. fibers) and protein content, modifies the gut 
microbiota and transit time which may affect metabolite composition in feces (David et al., 2014; Tanes et al., 2021; Milton and Demment, 1988; Wrick et al., 1983). As fruits are typically rich in carbohydrates and young leaves in proteins, it is possible that the difference in T3 response to nutrient content reported by Dias et al. (2017; \#35) is due to the gut microbiota activity. These potential influence of dietary composition has to be borne in mind when assessing T3 from fecal samples.

\subsubsection{T3 and female reproduction}

Studies examining the effect of reproduction on female T3 levels are very scarce and show a lack of consistency in their results. Female Assamese macaques and howler monkeys exhibit an increase in T3 levels during gestation (\# 32; 35) while baboons exhibit an opposite pattern with low T3 levels during gestation and lactation (\# 30). It may be that the degree of seasonal fluctuations of food availability is a driver of these metabolic differences. Contrary to Assamese macaques and howler monkeys, baboons live in a very pervasive habitat with major differences between dry and rainy seasons in terms of food availability. Not exhibiting a general increase in circulating T3 during reproduction may be a metabolic strategy sparing energy when living a habitat with important environmental constraints (Gesquiere et al., 2018). This is an emerging field of research that deserves further investigation in order to better understand different metabolic strategies in response to reproduction in female primates and how this can be related to ecological pressures.

\subsubsection{T3 and ambient temperature}

To date only four studies (including this dissertation), investigated the effect of ambient temperature on T3 in wild primate species. Tropical species such as Assamese macaques and howler monkeys do not experience extreme variations in temperature and this might explain why they do not exhibit an increase of T3 as ambient temperature decreases (\# 32; 35; but see 34). Species living at higher latitudes such as Japanese and Barbary macaques experience much stronger amplitudes of thermal fluctuation across seasons. This might therefore explain why these macaque species exhibit an increase of $\mathrm{T} 3$ as ambient temperature decreases (\# 33; 34). 


\subsubsection{T3 and physical activity}

Lastly, this dissertation provides the second investigation regarding the link between physical activity and T3 levels in a wild primate. As found in howler monkeys, T3 levels in Assamese macaques are not affected by variation in traveling time (or travel distance; \# 32; 35).

\subsubsection{Next steps with T3}

Contrary to uCP, T3 levels increase in response to both energy intake and expenditure and therefore do not provide an assessment of energy balance. Instead, the non-invasive assessment of T3 lends itself as a very promising tool in order to better understand metabolic strategies in energetically challenging times. A more widespread use of this energetic marker in the future will help in determining shifts in metabolic rate in response to thermoregulatory needs in species experiencing different magnitude of cold or heat stress in their natural habitats. I also encourage future studies to assess T3 in order to evaluate potential changes in energy expenditure with regards to physical expense.

\subsection{Glucocorticoids}

\subsubsection{Glucocorticoids and energy intake, food intake}

Only a handful of studies (including this dissertation) investigated glucocorticoid output in relation to caloric intake in a wild primate species (\# 40; 52; 62). Interestingly and contrary to expectations, one study found that fecal glucocorticoid level was not negatively associated with energy intake but with protein intake (\# 62). In addition, an increase in diet quality (high fruit consumption) appears to induce a decrease in glucocorticoid concentrations (\# 39,60;63;66;68; 73). Feeding on less preferred food items induces an increase in glucocorticoids (\# 66; 67). Besides highlighting a potential impact of a poor nutritional condition, the increase in fecal glucocorticoid levels in times of low protein intake and lowquality diet could also highlight a possible effect of nutrient content in gut microbiota and in fecal glucocorticoid metabolite output (David et al., 2014; Dantzer et al., 2016). As for fecal T3, more investigations are needed to disentangle the effect of energy intake from nutrient intake on fecal glucocorticoid metabolites. Future studies could for example control for specific 
nutrient intake when investigating the effect of total energy intake on energetic markers assessed in fecal samples.

The effect of food availability on glucocorticoids has been extensively investigated. In most species an increase in food availability induces a decline in glucocorticoid levels (\# 38; 41; $64 ; 67)$. Some studies provided evidence that it is the availability of specific food item that predict glucocorticoid output (\# 41; 66; 67). When preferred food items become available, intergroup encounters and resource defense can also induce a rise in glucocorticoids through social stress and lead to a positive relationship between food availability and glucocorticoid levels (\# 62).

\subsubsection{Glucocorticoids and female reproduction}

To date, different patterns regarding glucocorticoid levels during reproductive cycle have been stressed. Although few inconsistencies within species can be acknowledged, evidence of an increase in glucocorticoids in gestating and/or lactating females have been provided in a wide variety of primate species (\# 44; 47; 50; 52; 55; 56; 60; 61; 66; 69; 71; 73). During gestation, an increase of glucocorticoid concentrations can be induced by several factors. Besides a potential effect of heightened maternal needs during gestation, the increase of glucocorticoid concentrations can also be explained by an increase in cortisol binding proteins (cortisol-binding-globulin; Demey-Ponsart et al., 1982; Nenke et al., 2017) and/or a stimulation of the maternal HPA-axis by the placental production of corticotropin-releasing hormone (McLean and Smith, 1999; Mastorakos and Ilias, 2003).

\subsubsection{Glucocorticoids and ambient temperature}

There is a lot of discrepancy regarding the effect of ambient temperature on glucocorticoid levels in wild primates. Some species, including female Assamese macaques, exhibit an increase in glucocorticoids as minimum ambient temperature decreases which illustrates a physiological reaction to ambient cold (\# 48; 52; 58). Evidence of a heat stress has also been highlighted in some primate species (especially in savannah habitats), as illustrated by a positive correlation between ambient temperature and glucocorticoid levels (\# 37; 41; 44). 
Potential differences in physiological response between males and females within a population would need further investigation (\# 44; 45).

\subsubsection{Glucocorticoids and physical activity}

Lastly regarding the relationship between physical expense and glucocorticoid release in wild primates, only few studies have tackled this question and different patterns have been found. Traveling seems energetically expensive enough to trigger an increase in glucocorticoid levels in some populations (\# 42;60). However, in other primate populations, traveling does not induce a glucocorticoid response (\# 52; 59; 66).

\subsubsection{Next steps with glucocorticoids}

Assessing glucocorticoids lends itself useful to evaluate which challenges require energy mobilization in a wild population. Contrary to $\mathrm{uCP}$ and T3, glucocorticoids are nonspecific as they respond to psychological stressors in addition to energetic challenges which can add noise to a signal. In spite of this, the relevance of assessing glucocorticoid metabolite levels in future studies on energetics is apparent in order to understand some inconsistencies in the results found so far. This marker of energy mobilization should particularly receive more attention with regards to thermoregulation and physical expense in wild primates.

\subsection{Conclusion}

Data start to accumulate in the burgeoning field of research that is the study of energetics through non-invasive markers of energy metabolism. This lends valuable insight into the evaluation of challenges and physiological coping mechanisms in different classes of wild primates living under different environmental pressures. Table 1 highlights the overall need for more data on uCP, T3 and glucocorticoid levels in wild primates. The use of noninvasive markers of energy have been particularly investigated in apes as they represent half of uCP studies and a quarter of T3 studies. On the contrary, other primate species are underrepresented in Table 1 . I therefore encourage future studies to focus on strepsirrhine and 
platyrrhine families (apart from howlers). In addition, I strongly recommend future studies to address research questions on energetics through integrative approaches since they promote the interpretation of results on energetic markers. I will present these recommendations below.

\section{Future research directions and recommendations for studies on energetics}

In this dissertation I used powerful approaches consisting in the combination of several energetic markers, the combination of energetic markers and behavior, and the assessment of several potential energetic challenges. Such holistic and integrative approaches are scarcely used in studies on energetics. For example, only few studies in Table 1 have concomitantly assessed several energetic markers (this dissertation; Dias et al., 2017; Wessling et al., 2018). Integrative approaches represent a next important step in studies on energetics as they have proven useful in many situations.

3.1. An integrative physiological approach: importance of combining several physiological markers

The endocrine system is complex given the myriad of factors driving hormonal production and cross-talks between endocrine axes (Widmaier, 1992). It is therefore particularly challenging to investigate an individual's physiological state as a whole. Measuring several hormones at once alleviates this issue and provides a major advance in studies on physiology in wild species.

Studies pairing cortisol with another hormone levels such as estrogen, progesterone or testosterone have allowed a better understanding of the association between different endocrine pathways and reproductive function (Foley et al., 2001), health (Muehlenbein and Watts, 2010), bonding behaviors (Rincon et al., 2020) or maternal behavior (Bardi et al., 2003). For example, studies initially provided evidence that maternal behavior can be driven by low postpartum cortisol levels (Bahr et al., 1998) and high estrogen levels (Maestripieri and Zehr, 1998). Later, a more integrative study combining the measurement of these two hormones showed that one single hormone is not enough to predict maternal behavior as it is the 
cortisol/estrogen ratio that explain whether a mother will be more or less responsive to her newborn's needs (Bardi et al., 2003).

Regarding energetics, pairing glucocorticoid and thyroid hormone levels proves relevant for different purposes. First, based only on glucocorticoid levels, it is impossible to parse out the relative contribution of nutritional and psychological factors to glucocorticoid modulations. As thyroid hormones are affected by nutritional, yet not psychological stressors in mammals (Behringer et al., 2018), combining thyroid and glucocorticoid measurement helps in disentangling psychological stressors (induced for example by human disturbance or predation) from a nutritional deficit (Ayres et al., 2012; Dias et al., 2017; Joly et al., 2015; Pritchard et al., 2020; Vynne et al., 2014). For instance, Ayres et al. (2012) showed that a population of killer whales (Orcinus orca) was more affected by a nutritional deficit than by a psychological stressor as modulations of both glucocorticoid and thyroid hormone levels were induced by prey availability.

Second, assessing glucocorticoids together with thyroid hormones helps in revealing foraging strategies in wild species (Jesmer et al., 2017). In moose (Alces alces), Jesmer et al. (2017) found that glucocorticoids can be unexpectedly positively correlated with energy intake, in a similar way as thyroid hormone. The authors suggested that this atypical hormone-energy relationship in large bodied mammals might illustrate their state-dependent foraging strategy, i.e. they increase energy intake as their energy reserves decrease. As energy reserves slowly change in relation to energy intake in large mammals, high levels of glucocorticoids (low energy reserves) can be found together with high thyroid hormone level (high energy intake; Jesmer et al., 2017).

Lastly, modulations in energy mobilization and energy expenditure in response to various challenges can be disentangled by jointly assessing glucocorticoids and thyroid hormones (Chapter 2; Dias et al., 2017) which allows a fine-scale estimation of individual energetic status. This joint assessment helps in evaluating whether challenges induce energy deficit, illustrated by high glucocorticoid levels and low thyroid hormone levels (e.g. low energy intake: Chapter 2); or substantial energetic demands, illustrated by high levels of both glucocorticoids and thyroid hormones (e.g. late pregnancy: Chapter 2; activity rate: Dias et al., 2017; molting: Gobush et al., 2014). Therefore, the simultaneous assessment of glucocorticoids and thyroid hormones have enhanced our ability to determine a specific source of stress, foraging strategies and energetic status in wild species. 
Pairing these two hormones would also enable to address unanswered questions or uncertainties raised by previous research. I will provide three examples of such contexts in which the joint assessment of thyroid hormones and glucocorticoids would promote the interpretation of previous findings. First, many studies reported an increase in glucocorticoid levels during gestation (\# 40; 44; 50; 56; 69; 71; 73). It would be informative to know whether this increase in glucocorticoids is only due to the physiological shifts induced by gestation, such as the placental influence on the maternal HPA-axis (McLean and Smith, 1999) or whether it is confounded with a rise in maternal energetic demands, that would be captured by a concomitant increase in thyroid hormones (as found in Assamese macaque: Chapter 2). Second, some studies reported a rise of glucocorticoids during low food availability (\# 38; 64; Dantzer et al., 2016), in unprotected habitats (Rangel-Negrín et al., 2014) or in low-ranking gestating females (Carrera et al., 2020). These authors could not determine whether this release in glucocorticoids was induced by psychological stressors or nutritional shortage. This uncertainty can be addressed by assessing thyroid hormones in addition to glucocorticoids. Third, some energetic challenges are non-independent (e.g. food availability and travel distances) leading to difficulties when investigating the source of an increase in glucocorticoids (Dunn et al., 2013). Assessing thyroid hormones in addition to glucocorticoids would help in determining whether a rise in glucocorticoids is due to heightened energy demands (illustrated by a parallel increase in T3) or to an energy deficit (illustrated by a parallel decline in T3). With these few examples in mind, it becomes apparent that assessing these two energetic markers at once is relevant in many situations and would contribute to filling some gaps of knowledge that previous studies could not entirely tackle by assessing a single marker.

Therefore, I would strongly encourage future studies on energetics to assess whenever possible more than one non-invasive energetic marker and to consider measuring glucocorticoids and thyroid hormones as this approach provides one of the most integrative pictures of the physiological and energetic state in wild animals. To my knowledge, only one non-invasive study assessed the concurrent levels of glucocorticoids and thyroid hormones with a third hormone, progesterone (Vynne et al., 2014). The authors found that although maned wolves (Chrysocyon brachyurus) experienced some psychological stress (rise in glucocorticoid levels) when chasing rodents in agricultural fields, this negative influence of anthropogenic disturbance was likely outweighed by nutritional (high thyroid hormone levels) and fitness (high levels of progesterone) benefits associated with cropland access. This 
is a promising approach for future studies aiming at investigating the link between energetic status and reproductive function in wild species. Other studies on energetics used blood samples to measure glucocorticoids and thyroid hormones together with other hormones involved in energy metabolism (e.g. leptin, aldosterone, insulin like growth factor l: Keogh et al., 2013; Jeanniard du Dot et al., 2009; St. Aubin et al., 1996). These studies provide stimulating ideas for potential physiological markers that would be worth validating in non-invasively collected matrices as they may be used in addition to glucocorticoids and thyroid hormones in field-friendly studies on energetics.

3.2. An integrative physiological and behavioral approach: relevance of combining a physiological marker with behavior

An additional way toward a more comprehensive investigation of the energetic costs of a challenge is to pair physiological markers with behavior. Examining the effects of a challenging situation through the behavioral window contributes to the assessment of energetic costs from the potential behavioral shifts used to offset them. Looking at the same time through the physiological window helps in determining whether the behavioral shifts are enough to cope with the challenge or whether a physiological reaction is also needed. This 'double-window' observation is a useful integrative approach to quantify the magnitude of the costs induced by an energetic challenge. The relevance of this approach is particularly apparent when investigating adaptations in response to substantial energy demands.

I want to bring attention to the fact that an absence of physiological responses to a challenge does not always mean an absence of costs. Looking only from a physiological side could lead to a substantial underestimation of the costs induced by a challenge. A complementary behavioral approach allows disentangling whether there are no costs or whether these costs are somehow offset. A behavioral coping mechanism is an integral part of the set of adaptations to a challenging situation and should be considered and assessed whenever possible as it might mitigate the hormonal response. In addition, in a similar way behavior can influence hormone levels in a challenging situation, the hormonal response can also induce behavioral shifts. For example, evidence shows that glucocorticoid levels can affect foraging behaviors (Chmura et al., 2016; Zhang et al., 2020; la Fleur, 2006; Tataranni et al., 1996). A physiological and a behavioral response to a challenge can be interlinked, with one 
influencing the intensity of the other. Assessing at once both the hormonal and behavioral responses to a challenge is therefore crucial as they can act in concert as coping mechanisms and modulate one another. Although to date such an integrative approach has been scarcely used, few studies provide evidence of the importance of watching physiological consequences under the light of behavioral ones and vice versa. These studies shed more light on the energetic costs of infections (\# 11), food scarcity (\# 26), mate guarding (\# 21) or female reproduction (this dissertation; \# 17; 23).

This dissertation shows that the assessment of behavioral responses to reproduction enhances the interpretation of physiological responses. It allows a better evaluation of the costs of reproduction and the coping mechanisms involved. Female Assamese macaques exhibit an increase in energy demands over the course of gestation (Chapter 2) and some of the energetic requirements of gestation are fulfilled through a physiological adaptation involving insulin resistance and fat store use rather than compensatory behavioral shifts (Chapter 3). A different pattern is expressed during lactation, as energy-saving behavioral adaptations during early stages (Chapter 3) contribute to offsetting the energetic costs of lactation as illustrated by similar levels of uCP, T3 and cortisol levels in lactating and non-gestating - non-lactating females (Chapters 2 and 3). Therefore, simultaneously assessing behavioral and physiological responses to reproduction allowed the determination of the coping mechanisms involved at different stages of the reproductive cycle (physiological adaptation during gestation and behavioral adaptation during lactation). Comparing the results found in Assamese macaques with the ones coming from the handful of studies investigating the behavioral and physiological effects of female reproduction helps in evaluating the costs of reproduction. Specifically, reproducing females can maintain similar uCP levels to other females by exhibiting substantial (Assamese macaques: this dissertation), very weak (olive baboons: \# 16) or no shifts (mantled howlers: \# 23) in activity budget. The energetic costs of reproduction therefore require different intensities in behavioral shifts in order to be offset.

I would like to raise awareness on the fact that potential behavioral shifts to offset the energetic costs induced by a challenge do not always coincide with the emergence of this energetic challenge. This adds complexity in linking a challenge to the set of coping mechanisms that have emerged in response to it as these mechanisms are not necessarily expressed all together. A behavioral shift can be exhibited prior to a challenge. Seasonality in energetic challenges can be associated with predictability in the occurrence of future challenges. Species can typically 'get ready' for an incoming mating season or dry season by 
storing energy that will soon be required. In such cases, compensatory behavioral shifts can be expressed in anticipation of a challenge-to-be. In this dissertation, investigating behavior in non-gestating - non-lactating females, i.e. before a future energetic investment in reproduction, tackles this potential 'anticipation' of future costs. The results showed, as found in other female mammals, that behavioral shifts consisting in storing and saving energy prior reproduction is an integrative part of the breeding strategy in female Assamese macaques (Chapter 3; Miller et al., 2006). Similarly, male rhesus macaques (Macaca mulatta) build-up and conserve energy during the birth season to be energetically prepared for the next demanding mating season (Higham et al., 201lb). A behavioral shift prior to a challenge has therefore to be considered as it might adapt fat reserves at the onset of a challenging situation. These fat stores will contribute to the ability of animals to offset incoming energetic costs. They also influence animals' physiological state (Girard-Buttoz et al., 2011). A behavioral 'anticipation' is therefore important to bear in mind when assessing the energetic costs of a challenge and determining the associated coping mechanisms.

With this dissertation, I highlight the importance of combining several non-invasive physiological markers and combining physiological markers with behavior. I encourage future studies on energetics to use such holistic approaches in order to provide a more comprehensive investigation of the different mechanisms expressed in wild species to cope with energetic challenges. This would help in alleviating the complexity of teasing apart several adaptations acting in concert and in determining their relative importance in the face of different energetic challenges. Besides the complexity associated with the evaluation of behavioral and physiological adaptations to different energetic challenges, I would like to acknowledge the fact that the assessment of these energetic challenges is also complex. Below I present some usual pitfalls that must be considered when assessing energetic challenges.

\subsection{The challenge of assessing challenges}

Controlled experimental studies can easily impose a specific energetic challenge on animals and therefore clearly assess its behavioral and physiological consequences (e.g. feeding restriction experiments: Deschner et al., 2020; Girard-Buttoz et al., 2011; Laver et al., 2020; Sadoughi et al., 2021). It is of course a very different story in the wild. Investigating the isolated effects of one specific energetic challenge in wild species is particularly difficult, as it requires 
the assessment of all other potential factors to control for their respective effects. While some potential energetic challenges can be effortlessly assessed (e.g. ambient temperature), others require more time and labor in their evaluation.

Energy intake is one of the most challenging factors to quantify. For that reason, a large majority of studies on energetics uses indirect measurements of energy intake. However, caution should be taken when doing so, especially when no relationship between energy intake and potential proxies has been established previously in a population. Feeding time can be an inaccurate indirect assessment of energy intake insofar as there remains uncertainty regarding what individuals feed on, how nutritional it is and how fast they eat it, i.e. parameters driving energy intake (Conklin-Brittain et al., 2006; Kurihara et al., 2020; Schülke et al., 2006). The inadequacy of feeding time to assess nutritional condition is particularly evident by the absence of relationship with uCP (\# 5; 20; 21; 24) and the inconsistencies in glucocorticoid results (\# 44;66;67). Feeding time could have an opposite effect on glucocorticoids depending on season (\# 44) and on what food item is being consumed (\# 66; 67). These different effects of feeding time on glucocorticoids highlight the importance of considering what the individuals is feeding on rather than crude feeding time.

Similarly, food availability can be a misleading proxy of energy intake as individuals might compensate for an absence of preferred food items by modifying their diet composition and consuming fallback food items for example (Lambert and Rothman, 2015; Wessling et al., 2018a). In some species food availability is not a determinant of energy intake (Martínez-Mota et al., 2016). Moreover, food availability can be a proxy for other factors such as feeding competition (Martínez-Mota et al., 2016; Pride, 2005), foraging time (Majolo et al., 2013) or daily path length (Harris et al., 2009). In such cases, a physiological response to variation of food availability might illustrate a psychological stress or energy expenditure in addition to energy intake.

Quantifying energy intake per se is therefore crucial as it decreases uncertainty due to any potential confounding effects associated with an indirect measure. Although a direct assessment of energy intake is labor intensive and requires rich feeding and nutritional data, it is necessary in studies on energetics in populations for which no established proxy is available. To date, in addition to this dissertation, few studies have managed to measure energy intake in wild populations (Heesen et al., 2013; Emery Thompson and Knott, 2008; Knott, 1998; Koch et al., 2017; Kurihara et al., 2020; Lodge, 2012; Martínez-Mota et al., 2016; Valé et al., 2020). 
Investigating the effects of various and thoroughly assessed energetic challenges on concomitant adaptations in a wild population is fundamental when addressing research questions on energetics. Holistic and ecologically relevant approaches help in determining the energetic pressures faced by a population in its natural habitat and what behavioral and physiological coping mechanisms are associated with these challenges. This would have relevant research implications, particularly with regards to wildlife conservation.

\section{Research implication on climate change effects and wildlife conservation}

Studies on energetics allow us to determine what challenges are energetically costly and how these costs can be behaviorally and physiologically offset in wild species. An energetic challenge is particularly costly when it induces a response that almost reaches the limit of the physiological capacity of a population (e.g. dive duration when foraging is limited by oxygen stores in marine mammals; Williams et al., 2011). The aggravation of an already-costly challenge could have severe consequences on the vulnerability of the population and its ability to keep inhabiting its home range. Assessing behavioral and physiological responses to energetic challenges provides a useful toolbox for conservation purposes especially with regards to climate change and human disturbance (Reed et al., 2011). The effects of climate change in a population lead to the emergence of new energetic challenges and aggravations of already existing ones. In addition to its direct heat consequence, climate change has other indirect consequences such as aridity, home range restriction or bottlenecks in energy supply (Gibert, 2019; Moritz et al., 2008). These consequences limit population dynamics and induce distribution shifts and disease risks (Previtali et al., 2009; White, 2008; Rosalino et al., 2019; Humphries et al., 2004; Gallana et al., 2013).

Studies on energetics have a predictive power regarding how populations would respond in the face of new and changing environmental challenges and how their life history traits will be altered by climate change (Bozinovic and Pörtner, 2015; Chevin et al., 2010; Fuller et al., 2016; Isaac, 2009; Pacifici et al., 2018; Wingfield et al., 1997). Glucocorticoids have been used as the main tool in predicting future challenges (Wikelski and Cooke, 2006). This hormone can however be complicated to interpret when assessed alone in conservation studies (Busch and Hayward, 2009). For that reason, integrating physiological markers and specifically the combination of glucocorticoids with thyroid hormone is a tool used in studies on energetics aiming at monitoring energetic challenges in wild populations and guiding 
conservation decisions (Ayres et al., 2012; Gobush et al., 2014; Jesmer et al., 2017; Joly et al., 2015; Vynne et al., 2014). In addition, predicting species vulnerability in the face of climate change and accordingly planning relevant conservation actions would markedly benefit from integrative studies on energetics combining physiology and behavior (Cooke et al., 2015; Hetem et al., 2014; Németh et al., 2013). Anticipating which and how species would likely suffer first from climate change and enhanced energetic challenges is a crucial and needed step toward an improved wildlife population management (Tédonzong et al., 2020; LeDee et al., 2021).

I therefore encourage researchers to address questions on energetics through integrative approaches such as the ones presented in this dissertation. This would not only provide a better assessment of individual energetic condition but also yield valuable materiel to protect vulnerable populations as they are facing climate change and human disturbance. The relevance of integrative studies on energetics lay emphasis on the importance of building bridges between scientific fields. Collaborations between endocrinologists, ethologists, evolutionary biologists and conservation biologists (among others) would promote integrative studies on energetics. 


\section{SUMMARY}

Energy is a key requirement of life. It is involved in life history traits such as body maintenance, growth and reproduction. Energy is a limiting resource and therefore has to be strategically allocated. When facing an energetic challenge (e.g. low food availability), an individual energy balance, i.e. the difference between energy intake and expenditure, is likely to decrease, leading to shifts in energy-allocation strategies. Such challenging situations can bear drastic fitness consequences and two important adaptations have emerged in order to offset these energetic costs. First, individuals can modify their behavior to maximize energy intake and/or decrease energy expenditure. By adapting their feeding behavior and activity budget, individuals can therefore compensate the costs induced by energetic challenges. Second, physiological adaptations also participate in overcoming such costs. Major hormones such as insulin, thyroid hormones and glucocorticoids are involved in energy metabolism since they regulate energy assimilation, energy expenditure (through metabolic rate) and energy store mobilization. Their concentrations are typically modulated in times of energy deficit or heightened energy demands. A considerable advantage of these hormones is that they can be assessed non-invasively from urine samples.

Behavioral and physiological shifts contribute to offsetting energetic costs. However, to date few studies have used an integrative approach investigating how such adaptations can act in concert when facing an energetic challenge. Such investigations are needed to determine complementary adaptations that have emerged concomitantly and to assess on a fine-scale energetic conditions induced by different challenges among mammals. In addition, this integrative approach will allow a better evaluation of the magnitude of the energetic costs of various challenges which will lend valuable insight into the way such energetic constraints might have driven life history traits in different species.

In this thesis, I aim at investigating the behavioral and physiological responses to potential energetic challenges faced by female Assamese macaques (Macaca assamensis) in their seasonal natural habitat. I specifically examined the effects of cold ambient temperature, physical activity, low energy intake and female reproduction on female behavior and hormone levels. I collected behavioral and nutritional data and assessed urinary C-peptide (uCP, a 
marker of insulin production), triiodothyronine (T3, a thyroid hormone) and cortisol (one of the main glucocorticoids in vertebrates) levels.

The results showed that the four energetic challenges triggered a specific combination of physiological and behavioral responses. First, low ambient temperatures induced a rise in cortisol but no rise in T3. This likely illustrates the fact that ambient temperatures did not decrease low enough or for long enough to trigger thermogenesis through an increase in T3 levels. A rise in cortisol alone might therefore be enough for female to cope with cold temperatures. Second, travel distance was not associated with a cortisol or a T3 response, suggesting that walking distances are not very energetically demanding in females. Third, a rise in cortisol was paired with a decline in T3 when energy intake is low. Energy intake can therefore be limited enough for females to mobilize their fat stores and reduce their metabolic rate in order to support their energetic needs and save energy, respectively. Fourth, a rise in cortisol was combined with a rise in T3 during late gestation, illustrating elevated energy requirements at this stage of the reproductive cycle. In addition, uCP levels were also high in late gestation which is likely induced by insulin resistance and maternal metabolic shifts in order to spare readily available energy to the fetus needs. The interpretation of similar levels of cortisol, T3 and uCP between lactating and non-gestating - non-lactating females were promoted by the integration of behavioral responses. Contrary to the other reproducing females, early lactating females follow a behavioral energy-conserving strategy (they rest more and feed efficiently), which might offset the energetic costs of lactation.

This dissertation contributes to the growing body of literature in the use of noninvasive markers of energy. Integrating my findings with the other reported ones, I also highlight some uncertainty and inconsistencies and suggest some directions for future investigations. Lastly, my dissertation provides a powerful integrative approach when investigating energetic costs. I shed light on the importance of tackling research questions on energetics through a multifaceted prism by considering both physiological and behavioral responses, since one promotes the interpretation of the other. 


\section{REFERENCES}

Agetsuma, N., Nakagawa, N., 1998. Effects of habitat differences on feeding behaviors of Japanese monkeys: Comparison between Yakushima and Kinkazan. Primates 39, 275289. https://doi.org/10.1007/BF02573077

Albani, A., Cutini, M., Germani, L., Riley, E.P., Ngakan, P.O., Carosi, M., 2020. Activity budget, home range, and habitat use of moor macaques (Macaca maura) in the karst forest of South Sulawesi, Indonesia. Primates 61, 673-684. https://doi.org/10.1007/s10329-020-00811-8

Altmann, J., Alberts, S., 2005. Growth rates in a wild primate population: Ecological influences and maternal effects. Behavioral Ecology and Sociobiology 57, 490-501. https://doi.org/10.1007/s00265-004-0870-x

Altmann, J., Alberts, S.C., 2003. Variability in reproductive success viewed from a life-history perspective in baboons. American Journal of Human Biology 15, 401-409. https://doi.org/10.1002/ajhb.10157

Amato, K.R., Leigh, S.R., Kent, A., Mackie, R.I., Yeoman, C.J., Stumpf, R.M., Wilson, B.A., Nelson, K.E., White, B.A., Garber, P.A., 2015. The gut microbiota appears to compensate for seasonal diet variation in the wild black howler monkey (Alouatta pigra). Microbial Ecology 69, 434-443. https://doi.org/10.1007/s00248-014-0554-7

Anestis, S.F., Breakey, A.A., Beuerlein, M.M., Bribiescas, R.G., 2009. Specific gravity as an alternative to creatinine for estimating urine concentration in captive and wild chimpanzee (Pan troglodytes) samples. American Journal of Primatology 71, 130-135. https://doi.org/10.1002/ajp.20631

Appleby, M.C., 1980. Social rank and food access in red deer stags. Behaviour 74, 294-309. Archie, E.A., Altmann, J., Alberts, S.C., 2014. Costs of reproduction in a long-lived female primate: injury risk and wound healing. Behavioral Ecology and Sociobiology 68, 11831193. https://doi.org/10.1007/s00265-014-1729-4

Armitage, K., Blumstein, D., Woods, B., 2003. Energetics of hibernating yellow-bellied marmots (Marmota flaviventris). Comparative biochemistry and physiology. Part A, Molecular \& integrative physiology 134, 101-14. https://doi.org/10.1016/S10956433(02)00219-2

Arnold, W., Ruf, T., Kuntz, R., 2006. Seasonal adjustment of energy budget in a large wild mammal, the Przewalski horse (Equus ferus przewalskii) II. Energy expenditure. Journal of Experimental Biology 209, 4566-4573. https://doi.org/10.1242/jeb.02536

Ayres, K.L., Booth, R.K., Hempelmann, J.A., Koski, K.L., Emmons, C.K., Baird, R.W., BalcombBartok, K., Hanson, M.B., Ford, M.J., Wasser, S.K., 2012. Distinguishing the impacts of inadequate prey and vessel traffic on an endangered killer whale (Orcinus orca) population. PLOS ONE 7, e36842. https://doi.org/10.1371/journal.pone.0036842

Baayen, H., Davidson, D., Bates, D., 2008. Mixed-effects modeling with crossed random effects for subjects and items. Journal of Memory and Language 59, 390-412. https://doi.org/10.1016/j.jml.2007.12.005

Bădescu, I., Katzenberg, M.A., Watts, D.P., Sellen, D.W., 2017. A novel fecal stable isotope approach to determine the timing of age-related feeding transitions in wild infant chimpanzees. American Journal of Physical Anthropology 162, 285-299. https://doi.org/10.1002/ajpa.23116

Bahr, N.I., Palme, R., Möhle, U., Hodges, J.K., Heistermann, M., 2000. Comparative aspects of the metabolism and excretion of cortisol in three individual nonhuman primates. 
General and Comparative Endocrinology 117, 427-438.

https://doi.org/10.1006/gcen.1999.7431

Bahr, N.I., Pryce, C.R., Döbeli, M., Martin, R.D., 1998. Evidence from urinary cortisol that maternal behavior is related to stress in gorillas. Physiology \& Behavior 64, 429-437. https://doi.org/10.1016/S0031-9384(98)00057-2

Baniel, A., Amato, K.R., Beehner, J.C., Bergman, T.J., Mercer, A., Perlman, R.F., Petrullo, L., Reitsema, L., Sams, S., Lu, A., Snyder-Mackler, N., 2021. Seasonal shifts in the gut microbiome indicate plastic responses to diet in wild geladas. Microbiome 9, 26. https://doi.org/10.1186/s40168-020-00977-9

Baracos, V.E., Whitmore, W.T., Gale, R., 1987. The metabolic cost of fever. Canadian Journal of Physiology and Pharmacology 65, 1248-1254. https://doi.org/10.1139/y87-199

Bardi, M., Shimizu, K., Barrett, G., Borgognini-Tarli, S., Huffman, M., 2003. Peripartum cortisol levels and mother-infant interactions in Japanese macaques. American Journal of Physical Anthropology 120, 298-304. https://doi.org/10.1002/ajpa.10150

Barr, D.J., 2013. Random effects structure for testing interactions in linear mixed-effects models. Frontiers in Psychology 4. https://doi.org/10.3389/fpsyg.2013.00328

Barrett, L., Halliday, J., Henzi, P., 2006. The ecology of motherhood: The structuring of lactation costs by chacma baboons. Journal of Animal Ecology 75, 875-86. https://doi.org/10.1111/j.1365-2656.2006.01105.x

Barrette, C., Vandal, D., 1986. Social rank, dominance, antler size, and access to food in snowbound wild woodland caribou. Behaviour 97, 118-145. https://doi.org/10.1163/156853986X00342

Bartoń, K., 2018. Package "MuMIn". Model selection and model averaging based on information criteria. R package version 1.42.1.

Bates, D., Mächler, M., Bolker, B., Walker, S., 2015. Fitting linear mixed-effects models using lme4. Journal of Statistical Software 67, 1-48. https://doi.org/10.18637/jss.v067.i01

Bauman, T.R., Turner, C.W., 1967. The effect of varying temperatures on thyroid activity and the survival of rats exposed to cold and treated with L-thyroxine or corticosterone. Journal of Endocrinology 37, 355-359. https://doi.org/10.1677/joe.0.0370355

Beehner, J.C., McCann, C., 2008. Seasonal and altitudinal effects on glucocorticoid metabolites in a wild primate (Theropithecus gelada). Physiology \& Behavior 95, 508514. https://doi.org/10.1016/j.physbeh.2008.07.022

Beehner, J.C., Nguyen, N., Wango, E.O., Alberts, S.C., Altmann, J., 2006. The endocrinology of pregnancy and fetal loss in wild baboons. Hormones and Behavior 49, 688-699. https://doi.org/10.1016/j.yhbeh.2005.12.016

Behie, A.M., Pavelka, M.S.M., 2013. Interacting roles of diet, cortisol levels, and parasites in determining population density of belizean howler monkeys in a hurricane damaged forest fragment, in: Marsh, L.K., Chapman, C.A. (editors), Primates in fragments: Complexity and resilience, developments in primatology: Progress and prospects. Springer, New York, NY, 447-456. https://doi.org/10.1007/978-1-4614-8839-2_30

Behie, A.M., Pavelka, M.S.M., Chapman, C.A., 2010. Sources of variation in fecal cortisol levels in howler monkeys in Belize. American Journal of Primatology 72, 600-606. https://doi.org/10.1002/ajp.20813

Behringer, V., Deimel, C., Hohmann, G., Negrey, J., Schaebs, F.S., Deschner, T., 2018. Applications for non-invasive thyroid hormone measurements in mammalian ecology, growth, and maintenance. Hormones and Behavior 105, 66-85. https://doi.org/10.1016/j.yhbeh.2018.07.011

Behringer, V., Deschner, T., Murtagh, R., Stevens, J.M.G., Hohmann, G., 2014. Age-related changes in thyroid hormone levels of bonobos and chimpanzees indicate heterochrony 
in development. Journal of Human Evolution 66, 83-88.

https://doi.org/10.1016/j.jhevol.2013.09.008

Bennett, P.M., Harvey, P.H., 1985. Brain size, development and metabolism in birds and mammals. Journal of Zoology 207, 491-509. https://doi.org/10.11l1/j.14697998.1985.tb04946.x

Bentley, G.R., 1999. Aping our ancestors: Comparative aspects of reproductive ecology. Evolutionary Anthropology: Issues, News, and Reviews 7, 175-185. https://doi.org/10.1002/(SICI)1520-6505(1999)7:5<175::AID-EVAN3〉3.0.CO;2-4

Bercovitch, F.B., 1987. Female weight and reproductive condition in a population of olive baboons (Papio anubis). American Journal of Primatology 12, 189-195. https://doi.org/10.1002/ajp.1350120206

Bergeron, P., Careau, V., Humphries, M.M., Réale, D., Speakman, J.R., Garant, D., 201l. The energetic and oxidative costs of reproduction in a free-ranging rodent. Functional Ecology 25, 1063-1071. https://doi.org/10.1111/j.1365-2435.2011.01868.x

Berghänel, A., Heistermann, M., Schülke, O., Ostner, J., 2016. Prenatal stress effects in a wild, long-lived primate: predictive adaptive responses in an unpredictable environment.

Proceedings of the Royal Society B: Biological Sciences 283, 20161304. https://doi.org/10.1098/rspb.2016.1304

Bergman, T., Beehner, J., Cheney, D., Seyfarth, R.M., Whitten, P.L., 2005. Correlates of stress in free-ranging male chacma baboons, Papio hamadryas ursinus. Animal Behaviour 70, 703-713. https://doi.org/10.1016/j.anbehav.2004.12.017

Bergouignan, A., Habold, C., Rudwill, F., Gauquelin-Koch, G., Normand, S., Simon, C., Blanc, S., 2012. Urinary C-peptide is not an accurate bioindicator of energy balance in humans. Obesity 20, 683-688. https://doi.org/10.1038/oby.2011.116

Bergstrom, M.L., Hogan, J.D., Melin, A.D., Fedigan, L.M., 2019. The nutritional importance of invertebrates to female Cebus capucinus imitator in a highly seasonal tropical dry forest. American Journal of Physical Anthropology 170, 207-216. https://doi.org/10.1002/ajpa.23913

Bergstrom, M.L., Kalbitzer, U., Campos, F.A., Melin, A.D., Emery Thompson, M., Fedigan, L.M., 2020. Non-invasive estimation of the costs of feeding competition in a neotropical primate. Hormones and Behavior 118, 104632. https://doi.org/10.1016/j.yhbeh.2019.104632

Bianco, A.C., Maia, A.L., da Silva, W.S., Christoffolete, M.A., 2005. Adaptive activation of thyroid hormone and energy expenditure. Bioscience Reports 25, 191-208. https://doi.org/10.1007/s10540-005-2885-6

Blake, N.G., Eckland, D.J., Foster, O.J., Lightman, S.L., 1991. Inhibition of hypothalamic thyrotropin-releasing hormone messenger ribonucleic acid during food deprivation. Endocrinology 129, 2714-2718. https://doi.org/10.1210/endo-129-5-2714

Blix, P.M., Boddie-Willis, C., Landau, R.L., Rochman, H., Rubenstein, A.H., 1982. Urinary Cpeptide: an indicator of beta-cell secretion under different metabolic conditions. Journal of Clinical Endocrinology \& Metabolism 54, 574-580. https://doi.org/10.1210/jcem-54-3-574

Blum, J.W., Gingins, M., Vitins, P., Bickel, H., 1980. Thyroid hormone levels related to energy and nitrogen balance during weight loss and regain in adult sheep. Acta Endocrinologica 93, 440-447. https://doi.org/10.1530/acta.0.0930440

Bolker, B.M., 2008. Ecological models and data in R. Princeton University Press, NJ, USA

Borries, C., Larney, E., Kreetiyutanonf, K., Koenig, A., 2002. The diurnal primate community in a dry evergreen forest in Phu Khieo Wildlife Sanctuary, Northeast Thailand. Natural History Bulletin of the Siam Society 50, 75-88. 
Borries, C., Larney, E., Lu, A., Ossi, K., Koenig, A., 2008. Costs of group size: lower developmental and reproductive rates in larger groups of leaf monkeys. Behavioral Ecology 19, 1186-1191. https://doi.org/10.1093/beheco/arn088

Borries, C., Lu, A., Ossi-Lupo, K., Larney, E., Koenig, A., 2011. Primate life histories and dietary adaptations: A comparison of asian colobines and macaques. American Journal of Physical Anthropology 144, 286-299. https://doi.org/10.1002/ajpa.21403

Bozinovic, F., Pörtner, H.-O., 2015. Physiological ecology meets climate change. Ecology and Evolution 5, 1025-1030. https://doi.org/10.1002/ece3.1403

Brecchia, G., Bonanno, A., Galeati, G., Federici, C., Maranesi, M., Gobbetti, A., Zerani, M., Boiti, C., 2006. Hormonal and metabolic adaptation to fasting: effects on the hypothalamic-pituitary-ovarian axis and reproductive performance of rabbit does. Domestic Animal Endocrinology 31, 105-122. https://doi.org/10.1016/j.domaniend.2005.09.006

Brent, L.J.N., Semple, S., Dubuc, C., Heistermann, M., MacLarnon, A., 2011. Social capital and physiological stress levels in free-ranging adult female rhesus macaques. Physiology \& Behavior 102, 76-83. https://doi.org/10.1016/j.physbeh.2010.09.022

Brockman, D.K., van Schaik, C.P., 2005. Seasonality and reproductive function, in: van Schaik, C.P., Brockman, D.K. (editors), Seasonality in primates: Studies of living and extinct human and non-human primates, Cambridge Studies in Biological and Evolutionary Anthropology. Cambridge University Press, Cambridge, UK, 269-306. https://doi.org/10.1017/CBO9780511542343.011

Bronson, F.H., 1985. Mammalian reproduction: an ecological perspective. Biology of Reproduction 32, 1-26. https://doi.org/10.1095/biolreprod32.1.1

Bronson, F.H., Marsteller, F.A., 1985. Effect of short-term food deprivation on reproduction in female mice. Biology of Reproduction 33, 660-667. https://doi.org/10.1095/biolreprod33.3.660

Brooks, M., E., Kristensen, K., van Benthem, K., J., Magnusson, A., Berg, C., W., Nielsen, A., Skaug, H., J., Mächler, M., Bolker, B., M., 2017. glmmTMB balances speed and flexibility among packages for zero-inflated generalized linear mixed modeling. The R Journal 9, 378. https://doi.org/10.32614/RJ-2017-066

Burger, J.R., Hou, C., Brown, J.H., 2019. Toward a metabolic theory of life history. PNAS 116, 26653-26661. https://doi.org/10.1073/pnas.1907702116

Burke, C.W., Eastman, C.J., 1974. Thyroid hormones. British Medical Bulletin 30, 93-99. https://doi.org/10.1093/oxfordjournals.bmb.a071175

Burns, C., Goodwin, B., Ostfeld, R., 2005. Prescription for longer life? Bot fly parasitism of the white-footed mouse. Ecology 86, 753-761. https://doi.org/10.1890/03-0735

Burr, W.A., Ramsden, D.B., Griffiths, R.S., Black, E.G., Hoffenberg, R., Meinhold, H., Wenzel, K.W., 1976. Effect of a single dose of dexamethasone on serum concentrations of thyroid hormones. Lancet 2, 58-61. https://doi.org/10.1016/s0140-6736(76)92283-2

Busch, D.S., Hayward, L.S., 2009. Stress in a conservation context: A discussion of glucocorticoid actions and how levels change with conservation-relevant variables. Biological Conservation 142, 2844-2853. https://doi.org/10.1016/j.biocon.2009.08.013

Butte, N. F., 2000. Carbohydrate and lipid metabolism in pregnancy: normal compared with gestational diabetes mellitus. American Journal of Clinical Nutrition 71, 1256S-61S. https://doi.org/10.1093/ajcn/71.5.1256s

Buyken, A.E., Kellerhoff, Y., Hahn, S., Kroke, A., Remer, T., 2006. Urinary C-peptide excretion in free-living healthy children is related to dietary carbohydrate intake but not to the dietary glycemic index. Journal of Nutrition 136, 1828-1833. https://doi.org/10.1093/jn/136.7.1828 
Buzzard, P., 2006. Cheek pouch use in relation to interspecific competition and predator risk for three guenon monkeys (Cercopithecus spp.). Primates 47, 336-41. https://doi.org/10.1007/s10329-006-0188-6

Cano-Huertes, B., Rangel-Negrín, A., Coyohua-Fuentes, A., Chavira-Ramírez, D.R., CanalesEspinosa, D., Dias, P.D., 2017. Reproductive energetics of female mantled howlers (Alouatta palliata). International Journal of Primatology. https://doi.org/10.1007/s10764017-9990-9

Careau, V., Thomas, D.W., Humphries, M.M., 2010. Energetic cost of bot fly parasitism in free-ranging eastern chipmunks. Oecologia 162, 303-312. https://doi.org/10.1007/s00442-009-1466-y

Carnegie, S.D., Fedigan, L.M., Ziegler, T.E., 2011. Social and environmental factors affecting fecal glucocorticoids in wild, female white-faced capuchins (Cebus capucinus). American Journal of Primatology 73, 861-869. https://doi.org/10.1002/ajp.20954

Carrera, S.C., Sen, S., Heistermann, M., Lu, A., Beehner, J.C., 2020. Low rank and primiparity increase fecal glucocorticoid metabolites across gestation in wild geladas. General and Comparative Endocrinology 293, 113494. https://doi.org/10.1016/j.ygcen.2020.113494

Cavigelli, S., 1999. Behavioural patterns associated with faecal cortisol levels in free-ranging female ring-tailed lemurs, Lemur catta. Animal Behaviour 57, 935-944. https://doi.org/10.1006/anbe.1998.1054

Champoux, M., Zanker, D., Levine, S., 1993. Food search demand effort effects on behavior and cortisol in adult female squirrel monkeys. Physiology \& Behavior. 54, 1091-1097. https://doi.org/10.1016/0031-9384(93)90330-i

Chapman, C.A., Saj, T.L., Snaith, T.V., 2007. Temporal dynamics of nutrition, parasitism, and stress in colobus monkeys: Implications for population regulation and conservation. American Journal of Physical Anthropology 134, 240-250. https://doi.org/10.1002/ajpa.20664

Chapman, C.A., Schoof, V.A.M., Bonnell, T.R., Gogarten, J.F., Calmé, S., 2015. Competing pressures on populations: long-term dynamics of food availability, food quality, disease, stress and animal abundance. Philosophical Transactions of the Royal Society of London B: Biological Sciences 370. https://doi.org/10.1098/rstb.2014.0112

Chapman, C.A., Wasserman, M.D., Gillespie, T.R., Speirs, M.L., Lawes, M.J., Saj, T.L., Ziegler, T.E., 2006. Do food availability, parasitism, and stress have synergistic effects on red colobus populations living in forest fragments? American Journal of Physical Anthropology 131, 525-534. https://doi.org/10.1002/ajpa.20477

Charmandari, E., Tsigos, C., Chrousos, G., 2005. Endocrinology of the stress response. Annual Review of Physiology 67, 259-284. https://doi.org/10.1146/annurev.physiol.67.040403.120816

Chatzitomaris, A., Hoermann, R., Midgley, J.E., Hering, S., Urban, A., Dietrich, B., Abood, A., Klein, H.H., Dietrich, J.W., 2017. Thyroid allostasis-adaptive responses of thyrotropic feedback control to conditions of strain, stress, and developmental programming. Frontiers in Endocrinology (Lausanne) 8. https://doi.org/10.3389/fendo.2017.00163

Chevalier, C., Stojanović, O., Colin, D.J., Suarez-Zamorano, N., Tarallo, V., Veyrat-Durebex, C., Rigo, D., Fabbiano, S., Stevanović, A., Hagemann, S., Montet, X., Seimbille, Y., Zamboni, N., Hapfelmeier, S., Trajkovski, M., 2015. Gut microbiota orchestrates energy homeostasis during cold. Cell 163, 1360-1374. https://doi.org/10.1016/j.cell.2015.11.004

Chevin, L.-M., Lande, R., Mace, G.M., 2010. Adaptation, plasticity, and extinction in a changing environment: Towards a predictive theory. PLOS Biology 8, el000357. https://doi.org/10.1371/journal.pbio.1000357 
Chmura, H.E., Wey, T.W., Blumstein, D.T., 2016. Assessing the sensitivity of foraging and vigilance to internal state and environmental variables in yellow-bellied marmots (Marmota flaviventris). Behavioral Ecology and Sociobiology 70, 1901-1910. https://doi.org/10.1007/s00265-016-2195-y

Cianni, G.D., Miccoli, R., Volpe, L., Lencioni, C., Prato, S.D., 2003. Intermediate metabolism in normal pregnancy and in gestational diabetes. Diabetes/Metabolism Research and Reviews 19, 259-270. https://doi.org/10.1002/dmrr.390

Clutton-Brock, T., Iason, G., Albon, S., Guinness, F., 2009. Effects of lactation on feeding behaviour and habitat use in wild red deer hinds (Cervus elaphus). Journal of Zoology 198, 227-236. https://doi.org/10.1111/j.1469-7998.1982.tb02072.x

Clutton-Brock, T.H., Albon, S.D., Guinness, F.E., 1989. Fitness costs of gestation and lactation in wild mammals. Nature 337, 260-262. https://doi.org/10.1038/337260a0

Coe, C.L., Lubach, G.R., 2014. Vital and vulnerable functions of the primate placenta critical for infant health and brain development. Frontiers in Neuroendocrinology 35, 439446. https://doi.org/10.1016/j.yfrne.2014.03.004

Coelho, A.M., 1974. Socio-bioenergetics and sexual dimorphism in primates. Primates 15 , 263-269. https://doi.org/10.1007/BF01742287

Conklin-Brittain, N., Knott, C., Wrangham, R.W., 2006. Energy intake by wild chimpanzees and orangutans: methodological considerations and a preliminary comparison, in: Hohmann, G., Robbins, M.M., Boesch, C. (editors), Feeding ecology in apes and other primates: Ecological, physical, and behavioral aspects. Cambridge University Press, Cambridge, UK, 445-471.

Conn, C.A., Kozak, W.E., Tooten, P.C., Niewold, T.A., Borer, K.T., Kluger, M.J., 1995. Effect of exercise and food restriction on selected markers of the acute phase response in hamsters. Journal of Applied Physiology 78, 458-465. https://doi.org/10.1152/jappl.1995.78.2.458

Cooke, S.J., Blumstein, D.T., Buchholz, R., Caro, T., Fernández-Juricic, E., Franklin, C.E., Metcalfe, J., O'Connor, C.M., Clair, C.C.S., Sutherland, W.J., Wikelski, M., 2015. Physiology, behavior, and conservation. Physiological and Biochemical Zoology. https://doi.org/10.1086/671165

Cooper, M.A., Chaitra, M.S., Singh, M., 2004. Effect of dominance, reproductive state, and group size on body mass in Macaca radiata. International Journal of Primatology 25, 165-178. https://doi.org/10.1023/B:IJOP.0000014648.12402.b6

Cothran, E.G., Chesser, R.K., Smith, M.H., Johns, P.E., 1987. Fat levels in female white-tailed deer during the breeding season and pregnancy. Journal of Mammalogy 68, 11l-118. https://doi.org/10.2307/1381053

Cousins, L., Rigg, L., Hollingsworth, D., Brink, G., Aurand, J., Yen, S.S., 1980. The 24-hour excursion and diurnal rhythm of glucose, insulin, and C-peptide in normal pregnancy. American Journal of Obstetrics and Gynecology 136, 483-488. https://doi.org/10.1016/0002-9378(80)90675-4

Cox, S., 2005. Energy, in: Caballero, B. (editors), Encyclopedia of Human Nutrition (Second Edition). Elsevier, Academic Press, USA, 106-114. https://doi.org/10.1016/B0-12226694-3/00103-4

Creel, S., Dantzer, B., Goymann, W., Rubenstein, D.R., 2013. The ecology of stress: effects of the social environment. Functional Ecology 27, 66-80. https://doi.org/10.1111/j.13652435.2012.02029.x

Cristóbal-Azkarate, J., Maréchal, L., Semple, S., Majolo, B., MacLarnon, A., 2016. Metabolic strategies in wild male Barbary macaques: evidence from faecal measurement of thyroid hormone. Biology Letters 12, 20160168. https://doi.org/10.1098/rsbl.2016.0168 
Crockett, C.M., Bowers, C.L., Sackett, G.P., Bowden, D.M., 1993. Urinary cortisol responses of longtailed macaques to five cage sizes, tethering, sedation, and room change.

American Journal of Primatology 30, 55-74. https://doi.org/10.1002/ajp.1350300105

Dantzer, B., McAdam, A.G., Palme, R., Fletcher, Q.E., Boutin, S., Humphries, M.M., Boonstra, R., 2010. Fecal cortisol metabolite levels in free-ranging North American red squirrels: Assay validation and the effects of reproductive condition. General and Comparative Endocrinology 167, 279-286. https://doi.org/10.1016/j.ygcen.2010.03.024

Dantzer, B., Santicchia, F., van Kesteren, F., Palme, R., Martinoli, A., Wauters, L.A., 2016. Measurement of fecal glucocorticoid metabolite levels in Eurasian red squirrels (Sciurus vulgaris): effects of captivity, sex, reproductive condition, and season. Journal of Mammalogy 97, 1385-1398. https://doi.org/10.1093/jmammal/gyw095

Darlington, D.N., Chew, G., Ha, T., Keil, L.C., Dallman, M.F., 1990. Corticosterone, but not glucose, treatment enables fasted adrenalectomized rats to survive moderate hemorrhage. Endocrinology 127, 766-772. https://doi.org/10.1210/endo-127-2-766

Dasilva, G.L., 1992. The western black-and-white colobus as a low-energy strategist: Activity budgets, energy expenditure and energy intake. Journal of Animal Ecology 61, 79-91. https://doi.org/10.2307/5511

Dauncey, M.J., 1990. Thyroid hormones and thermogenesis. Proceedings of the Nutrition Society 49, 203-215. https://doi.org/10.1079/PNS19900024

David, L.A., Maurice, C.F., Carmody, R.N., Gootenberg, D.B., Button, J.E., Wolfe, B.E., Ling, A.V., Devlin, A.S., Varma, Y., Fischbach, M.A., Biddinger, S.B., Dutton, R.J., Turnbaugh, P.J., 2014. Diet rapidly and reproducibly alters the human gut microbiome. Nature 505, 559-563. https://doi.org/10.1038/naturel2820

de Bruijn, R., Romero, L.M., 2018. The role of glucocorticoids in the vertebrate response to weather. General and Comparative Endocrinology 269, 11-32. https://doi.org/10.1016/j.ygcen.2018.07.007

Degroot, L.J., Hoye, K., 1976. Dexamethasone suppression of serum T3 and T4. Journal of Clinical Endocrinology \& Metabolism 42, 976-978. https://doi.org/10.1210/jcem-42-5976

Della Torre, S., Benedusi, V., Fontana, R., Maggi, A., 2014. Energy metabolism and fertility: a balance preserved for female health. Nature Reviews Endocrinology 10, 13-23. https://doi.org/10.1038/nrendo.2013.203

Demey-Ponsart, E., Foidart, J.M., Sulon, J., Sodoyez, J.C., 1982. Serum CBG, free and total cortisol and circadian patterns of adrenal function in normal pregnancy. Journal of Steroid Biochemistry and Molecular Biology 16, 165-169. https://doi.org/10.1016/00224731(82)90163-7

Dentice, M., Marsili, A., Zavacki, A., Larsen, P.R., Salvatore, D., 2013. The deiodinases and the control of intracellular thyroid hormone signaling during cellular differentiation. Biochimica et Biophysica Acta 1830, 3937-3945. https://doi.org/10.1016/j.bbagen.2012.05.007

Deschner, T., Hohmann, G., Ortmann, S., Schaebs, F.S., Behringer, V., 2020. Urinary total T3 levels as a method to monitor metabolic changes in relation to variation in caloric intake in captive bonobos (Pan paniscus). General and Comparative Endocrinology 285, 113290. https://doi.org/10.1016/j.ygcen.2019.113290

Deschner, T., Kratzsch, J., Hohmann, G., 2008. Urinary C-peptide as a method for monitoring body mass changes in captive bonobos (Pan paniscus). Hormones and Behavior 54, 620-626. https://doi.org/10.1016/j.yhbeh.2008.06.005

Devevey, G., Niculita-Hirzel, H., Biollaz, F., Yvon, C., Chapuisat, M., Christe, P., 2008.

Developmental, metabolic and immunological costs of flea infestation in the common 
vole. Functional Ecology 22, 1091-1098. https://doi.org/10.1111/j.13652435.2008.01493.x

Di Bitetti, M.S., Janson, C.H., 2000. When will the stork arrive? Patterns of birth seasonality in neotropical primates. American Journal of Primatology 50, 109-130. https://doi.org/10.1002/(SICI)1098-2345(200002)50:2<109::AID-AJP2>3.0.CO;2-W

Dias, P., Cano-Huertes, B., Coyohua-Fuentes, A., Chavira, D., Canales, D., Rangel-Negrín, A., 2018. Maternal condition and maternal investment during lactation in mantled howler monkeys. American Journal of Physical Anthropology 167, 178-184. https://doi.org/10.1002/ajpa.23626

Dias, P., Rangel-Negrín, A., Canales, D., 201l. Effects of Lactation on the time-budgets and foraging patterns of female black howlers (Alouatta pigra). American Journal of Physical Anthropology 145, 137-46. https://doi.org/10.1002/ajpa.21481

Dias, P.A.D., Coyohua-Fuentes, A., Canales-Espinosa, D., Chavira-Ramírez, R., RangelNegrín, A., 2017. Hormonal correlates of energetic condition in mantled howler monkeys. Hormones and Behavior 94, 13-20. https://doi.org/10.1016/j.yhbeh.2017.06.003

Dimitriadis, G., Mitrou, P., Lambadiari, V., Maratou, E., Raptis, S.A., 201l. Insulin effects in muscle and adipose tissue. Diabetes Research and Clinical Practice 93S, S52-59. https://doi.org/10.1016/S0168-8227(11)70014-6

Dobson, A.J., 2002. An introduction to generalized linear models, Second edition, Chapman \& Hall/CRC, Boca Raton, FL, USA.

Dobson, F.S., 1995. Regulation of population size: evidence from columbian ground squirrels. Oecologia 102, 44-5l. https://doi.org/10.1007/BF00333309

Drent, R.H., Daan, S., 1980. The prudent parent: energetic adjustments in avian breeding. Arde 55, 225-252. https://doi.org/10.5253/arde.v68.p225

Dufour, D.L., Sauther, M.L., 2002. Comparative and evolutionary dimensions of the energetics of human pregnancy and lactation. American Journal of Human Biology 14, 584-602. https://doi.org/10.1002/ajhb.10071

Dunbar, R.I.M., Dunbar, P., 1988. Maternal time budgets of gelada baboons. Animal Behaviour 36, 970-980. https://doi.org/10.1016/S0003-3472(88)80055-1

Dunn, J.C., Cristóbal-Azkarate, J., Schulte-Herbrüggen, B., Chavira, R., Veà, J.J., 2013. Travel time predicts fecal glucocorticoid levels in free-ranging howlers (Alouatta palliata). International Journal of Primatology 34, 246-259. https://doi.org/10.1007/s10764-0139657-0

Durnin, J.V.G.A., 1991. Energy requirements of pregnancy. Acta Paediatrica 80, 33-42. https://doi.org/10.11l1/j.1651-2227.1991.tbl8149.x

Eales, J.G., 1988. The influence of nutritional state on thyroid function in various vertebrates. Integrative and Comparative Biology 28, 35l-362. https://doi.org/10.1093/icb/28.2.351

East, M., Otto, E., Helms, J., Thierer, D., Cable, J., Hofer, H., 2015. Does lactation lead to resource allocation trade-offs in the spotted hyaena? Behavioral Ecology and Sociobiology 69, 805-814. https://doi.org/10.1007/s00265-015-1897-x

Edwards, P.D., Boonstra, R., 2018. Glucocorticoids and CBG during pregnancy in mammals: diversity, pattern, and function. General and Comparative Endocrinology 259, 122130. https://doi.org/10.1016/j.ygcen.2017.11.012

Ellison, P.T., 2003. Energetics and reproductive effort. American Journal of Human Biology 15, 342-35l. https://doi.org/10.1002/ajhb.10152

Ellison, P.T., 1990. Human ovarian function and reproductive ecology: New hypotheses. American Anthropologist 92, 933-952. https://doi.org/10.1525/aa.1990.92.4.02a00050 
Ellison, P.T., Valeggia, C.R., 2003. C-peptide levels and the duration of lactational amenorrhea. Fertility and Sterility 80, 1279-1280. https://doi.org/10.1016/S00150282(03)02158-7

El-Nouty, F.D., Yousef, M.K., Magdub, A.B., Johnson, H.D., 1978. Thyroid hormones and metabolic rate in burros, Equus asinus, and llamas, Lama glama: Effects of environmental temperature. Comparative Biochemistry and Physiology Part A: Physiology 60, 235237. https://doi.org/10.1016/0300-9629(78)90238-4

Emery Thompson, M., 2016a. C-peptide of Insulin, in: The International Encyclopedia of Primatology. American Cancer Society, 1-2. https://doi.org/10.1002/9781119179313.wbprim0159

Emery Thompson, M., 2016b. Energetics of feeding, social behavior, and life history in nonhuman primates. Hormones and Behavior 91, 84-96. https://doi.org/10.1016/j.yhbeh.2016.08.009

Emery Thompson, M., 2013. Comparative reproductive energetics of human and nonhuman primates. Annual Review of Anthropology 42, 287-304. https://doi.org/10.1146/annurev-anthro-092412-155530

Emery Thompson, M., Georgiev, A.V., 2014. The high price of success: Costs of mating effort in male primates. International Journal of Primatology 35, 609-627. https://doi.org/10.1007/s10764-014-9790-4

Emery Thompson, M., Knott, C., 2008. Urinary C-peptide of insulin as a non-invasive marker of energy balance in wild orangutans. Hormones and behavior 53, 526-35. https://doi.org/10.1016/j.yhbeh.2007.12.005

Emery Thompson, M., Muller, M.N., Kahlenberg, S.M., Wrangham, R.W., 2010. Dynamics of social and energetic stress in wild female chimpanzees. Hormones and Behavior 58, 440-449. https://doi.org/10.1016/j.yhbeh.2010.05.009

Emery Thompson, M., Muller, M.N., Wrangham, R.W., 2012. The energetics of lactation and the return to fecundity in wild chimpanzees. Behavioral Ecology 23, 1234-1241. https://doi.org/10.1093/beheco/ars107

Emery Thompson, M., Muller, M.N., Wrangham, R.W., Lwanga, J.S., Potts, K.B., 2009. Urinary C-peptide tracks seasonal and individual variation in energy balance in wild chimpanzees. Hormones and Behavior 55, 299-305. https://doi.org/10.1016/j.yhbeh.2008.11.005

Emery Thompson, M., Wrangham, R.W., 2008. Diet and reproductive function in wild female chimpanzees (Pan troglodytes schweinfurthii) at Kibale National Park, Uganda. American Journal of Physical Anthropology 135, 171-181. https://doi.org/10.1002/ajpa.20718

Emlen, J.M., 1966. The Role of Time and Energy in Food Preference. The American Naturalist $100,611-617$.

Exton, J.H., Friedmann, N., Wong, E.H., Brineaux, J.P., Corbin, J.D., Park, C.R., 1972. Interaction of glucocorticoids with glucagon and epinephrine in the control of gluconeogenesis and glycogenolysis in liver and of lipolysis in adipose tissue. Journal of Biological Chemistry 247, 3579-3588.

Fedak, M.A., Anderson, S.S., 1982. The energetics of lactation: accurate measurements from a large wild mammal, the grey seal (Halichoerus grypus). Journal of Zoology 198, 473-479. https://doi.org/10.11ll/jzo.1982.198.4.473

Festa-Bianchet, M., 1989. Individual differences, parasites, and the costs of reproduction for bighorn ewes (Ovis canadensis). Journal of Animal Ecology 58, 785-795. https://doi.org/10.2307/5124 
Festa-Bianchet, M., Côté, S.D., Hamel, S., Pelletier, F., 2019. Long-term studies of bighorn sheep and mountain goats reveal fitness costs of reproduction. Journal of Animal Ecology 88, 1118-1133. https://doi.org/10.1111/1365-2656.13002

Festa-Bianchet, M., Gaillard, J.-M., Jorgenson, J.T., 1998. Mass- and density-dependent reproductive success and reproductive costs in a capital breeder. The American Naturalist 152, 367. https://doi.org/10.2307/2463469

Finch, C.E., Rose, M.R., 1995. Hormones and the physiological architecture of life history evolution. The Quarterly Review of Biology 70, 1-52.

Flier, J.S., Harris, M., Hollenberg, A.N., 2000. Leptin, nutrition, and the thyroid: the why, the wherefore, and the wiring. Journal of Clinical Investigation 105, 859-861.

Foerster, S., Cords, M., Monfort, S.L., 2012. Seasonal Energetic Stress in a Tropical Forest Primate: Proximate causes and evolutionary implications. PLOS ONE 7, e50108. https://doi.org/10.1371/journal.pone.0050108

Foerster, S., Monfort, S.L., 2010. Fecal glucocorticoids as indicators of metabolic stress in female Sykes' monkeys (Cercopithecus mitis albogularis). Hormones and Behavior 58, 685-697. https://doi.org/10.1016/j.yhbeh.2010.06.002

Foley, C.A.H., Papageorge, S., Wasser, S.K., 2001. Noninvasive stress and reproductive measures of social and ecological pressures in free-ranging african elephants. Conservation Biology 15, 1134-1142.

Fontana, L., Klein, S., Holloszy, J.O., Premachandra, B.N., 2006. Effect of long-term calorie restriction with adequate protein and micronutrients on thyroid hormones. Journal of Clinical Endocrinology and Metabolism 91, 3232-3235. https://doi.org/10.1210/jc.20060328

Forhead, A.J., Fowden, A.L., 2014. Thyroid hormones in fetal growth and prepartum maturation. Journal of Endocrinology 221, R87-R103. https://doi.org/10.1530/JOE-140025

Forstmeier, W., Schielzeth, H., 201l. Cryptic multiple hypotheses testing in linear models: Overestimated effect sizes and the winner's curse. Behavioral Ecology and Sociobiology 65, 47-55. https://doi.org/10.1007/s00265-010-1038-5

Fowden, A.L., Li, J., Forhead, A.J., 1998. Glucocorticoids and the preparation for life after birth: Are there long-term consequences of the life insurance? Proceedings of the Nutrition Society 57, 113-122. https://doi.org/10.1079/pns19980017

Fox, J., Weisberg, S., 2018. An R Companion to Applied Regression. SAGE Publications, CA, USA.

Frisch, R.E., Hall, G.M., Aoki, T.T., Birnholz, J., Jacob, R., Landsberg, L., Munro, H., ParkerJones, K., Tulchinsky, D., Young, J., 1984. Metabolic, endocrine, and reproductive changes of a woman channel swimmer. Metabolism: Clinical and Experimental 33, 1106-llll. https://doi.org/10.1016/0026-0495(84)90095-7

Fuller, A., Mitchell, D., Maloney, S.K., Hetem, R.S., 2016. Towards a mechanistic understanding of the responses of large terrestrial mammals to heat and aridity associated with climate change. Climate Change Responses 3, 10. https://doi.org/10.1186/s40665-016-0024-1

Fürtbauer, I., Christensen, C., Bracken, A., O'Riain, M.J., Heistermann, M., King, A.J., 2020. Energetics at the urban edge: Environmental and individual predictors of urinary Cpeptide levels in wild chacma baboons (Papio ursinus). Hormones and Behavior 126, 104846. https://doi.org/10.1016/j.yhbeh.2020.104846

Fürtbauer, I., Heistermann, M., Schülke, O., Ostner, J., 2014. Low female stress hormone levels are predicted by same- or opposite-sex sociality depending on season in wild Assamese macaques. Psychoneuroendocrinology 48, 19-28. https://doi.org/10.1016/j.psyneuen.2014.05.022 
Fürtbauer, I., Schülke, O., Heistermann, M., Ostner, J., 2010. Reproductive and life history parameters of wild female Macaca assamensis. International Journal of Primatology 31, 501-517. https://doi.org/10.1007/s10764-010-9409-3

Gadgil, M., Bossert, W.H., 1970. Life historical consequences of natural selection. The American Naturalist 104, 1-24.

Gale, C.C., 1975. Endocrine and metabolic responses to cold in baboons. Federation Proceedings 34, 1685-1691.

Gallana, M., Ryser-Degiorgis, M.-P., Wahli, T., Segner, H., 2013. Climate change and infectious diseases of wildlife: Altered interactions between pathogens, vectors and hosts. Current Zoology 59, 427-437. https://doi.org/10.1093/czoolo/59.3.427

Gamo, Y., Bernard, A., Mitchell, S.E., Hambly, C., Jothery, A.A., Vaanholt, L.M., Król, E., Speakman, J.R., 2013. Limits to sustained energy intake. XVI. Body temperature and physical activity of female mice during pregnancy. Journal of Experimental Biology 216, 2328-2338. https://doi.org/10.1242/jeb.078410

Gardner, E.M., Beli, E., Clinthorne, J.F., Duriancik, D.M., 2011. Energy intake and response to infection with influenza. Annual Review of Nutrition 31, 353-367. https://doi.org/10.1146/annurev-nutr-081810-160812

Garza, C., 2005. Effect of infection on energy requirements of infants and children. Public Health Nutrition 8, 1187-1190. https://doi.org/10.1079/PHN2005804

Geer, E.B., Islam, J., Buettner, C., 2014. Mechanisms of glucocorticoid-induced insulin resistance: focus on adipose tissue function and lipid metabolism. Endocrinology and Metabolism Clinics of North America 43, 75-102. https://doi.org/10.1016/j.ecl.2013.10.005

Georgiev, A., 2012. Energetic costs of reproductive effort in male chimpanzees, $\mathrm{PhD}$ dissertation.

Gesquiere, L.R., Khan, M., Shek, L., Wango, T.L., Wango, E.O., Alberts, S.C., Altmann, J., 2008. Coping with a challenging environment: Effects of seasonal variability and reproductive status on glucocorticoid concentrations of female baboons (Papio cynocephalus). Hormones and Behavior 54, 410-416. https://doi.org/10.1016/j.yhbeh.2008.04.007

Gesquiere, L.R., Onyango, P.O., Alberts, S.C., Altmann, J., 2011. Endocrinology of year-round reproduction in a highly seasonal habitat: Environmental variability in testosterone and glucocorticoids in baboon males. American Journal of Physical Anthropology 144, 169-176. https://doi.org/10.1002/ajpa.21374

Gesquiere, L.R., Pugh, M., Alberts, S.C., Markham, A.C., 2018. Estimation of energetic condition in wild baboons using fecal thyroid hormone determination. General and Comparative Endocrinology 260, 9-17. https://doi.org/10.1016/j.ygcen.2018.02.004

Gholib, G., Agil, M., Supriatna, I., Purwantara, B., Lubis, T.M., Adam, M., Azhar, A., Engelhardt, A., 2018. Non-invasive monitoring of stress in females crested macaques (Macaca nigra): comparison of glucocorticoid levels during cycling, pregnancy, and lactation. Proceeding of the $8^{\text {th }}$ AIC: Health and Life Sciences 8.

Gibert, J.P., 2019. Temperature directly and indirectly influences food web structure. Scientific Reports 9, 5312. https://doi.org/10.1038/s41598-019-41783-0

Girard, I., Garland, T., 2002. Plasma corticosterone response to acute and chronic voluntary exercise in female house mice. Journal of Applied Physiology 92, 1553-1561. https://doi.org/10.1152/japplphysiol.00465.2001

Girard-Buttoz, C., Heistermann, M., Rahmi, E., Marzec, A., Agil, M., Fauzan, P.A., Engelhardt, A., 2014. Mate-guarding constrains feeding activity but not energetic status of wild male long-tailed macaques (Macaca fascicularis). Behavioral Ecology and Sociobiology 68, 583-595. https://doi.org/10.1007/s00265-013-1673-8 
Girard-Buttoz, C., Higham, J.P., Heistermann, M., Wedegärtner, S., Maestripieri, D., Engelhardt, A., 2011. Urinary C-Peptide Measurement as a Marker of Nutritional Status in Macaques. PLOS ONE 6, el8042. https://doi.org/10.1371/journal.pone.0018042

Girard-Buttoz, C., Heistermann, M., Krummel, S., Engelhardt, A., 2009. Seasonal and social influences on fecal androgen and glucocorticoid excretion in wild male long-tailed macaques (Macaca fascicularis). Physiology \& Behavior 98, 168-175. https://doi.org/10.1016/j.physbeh.2009.05.005

Gittleman, J., Thompson, S., 1988. Energy allocation in mammalian reproduction. Integrative and Comparative Biology 28, 863-875. https://doi.org/10.1093/icb/28.3.863

Glinoer, D., 1997. The regulation of thyroid function in pregnancy: Pathways of endocrine adaptation from physiology to pathology. Endocrine Reviews 18, 404-433. https://doi.org/10.1210/edrv.18.3.0300

Gobush, K.S., Booth, R.K., Wasser, S.K., 2014. Validation and application of noninvasive glucocorticoid and thyroid hormone measures in free-ranging hawaiian monk seals. General and Comparative Endocrinology 195, 174-182. https://doi.org/10.1016/j.ygcen.2013.10.020

Goering, H.K., Soest, P.J.V., 1970. Forage fiber analyses: Apparatus, reagents, procedures, and some a applications. Agricultural Research Service, U.S. Department of Agriculture.

Goland, R.S., Conwell, I.M., Warren, W.B., Wardlaw, S.L., 1992. Placental corticotropinreleasing hormone and pituitary-adrenal function during pregnancy. Neuroendocrinology 56, 742-749. https://doi.org/10.1159/000126302

Goldberg, G.R., Prentice, A.M., Coward, W.A., Davies, H.L., Murgatroyd, P.R., Sawyer, M.B., Ashford, J., Black, A.E., 1991. Longitudinal assessment of the components of energy balance in well-nourished lactating women. American Journal of Clinical Nutrition 54, 788-798. https://doi.org/10.1093/ajcn/54.5.788

Goldizen, A.W., Terborgh, J., Cornejo, F., Porras, D.T., Evans, R., 1988. Seasonal food shortage, weight loss, and the timing of births in saddle-back tamarins (Saguinus fuscicollis). Journal of Animal Ecology 57, 893-901. https://doi.org/10.2307/5099

Gómez-Espinosa, E., Rangel-Negrín, A., Chavira, D., Canales-Espinosa, D., Dias, P., 2014. The effect of energetic and psychosocial stressors on glucocorticoids in mantled howlers (Alouatta palliata). American Journal of Primatology 76. https://doi.org/10.1002/ajp.22240

Goodson, N.J., Stevens, D.R., Bailey, J.A., 1991. Effects of snow on foraging ecology and nutrition of bighorn sheep. Journal of Wildlife Management 55, 214-222. https://doi.org/10.2307/3809142

Gorbach, S.L., Schaefer, E.J., Woods, M., Longcope, C., Dwyer, J.T., Goldin, B.R., MorrillLaBrode, A., Dallal, G., 1989. Plasma lipoprotein cholesterol and endogenous sex hormones in healthy young women. Metabolism: Clinical and Experimental 38, 10771081. https://doi.org/10.1016/0026-0495(89)90043-7

Gould, L., Sussman, R.W., Sauther, M.L., 2003. Demographic and life-history patterns in a population of ring-tailed lemurs (Lemur catta) at Beza Mahafaly Reserve, Madagascar: A 15-year perspective. American Journal of Physical Anthropology 182-194.

Goymann, W., East, M.L., Wachter, B., Höner, O.P., Möstl, E., Van’t Holf, T.J., Hofer, H., 2001. Social, state-dependent and environmental modulation of faecal corticosteroid levels in free-ranging female spotted hyenas. Proceedings of the Royal Society of London B: Biological Sciences 268, 2453-2459. https://doi.org/10.1098/rspb.2001.1828 
Grassman, L., Tewes, M., Silvy, N., Kreetiyutanont, K., 2005. Ecology of three sympatric felids in a mixed evergreen forest in North-Central Thailand. Journal of Mammalogy 86, 2938. https://doi.org/10.1644/1545-1542(2005)086<0029:EOTSFI>2.0.CO;2

Grueter, C.C., Deschner, T., Behringer, V., Fawcett, K., Robbins, M.M., 2014. Socioecological correlates of energy balance using urinary C-peptide measurements in wild female mountain gorillas. Physiology \& Behavior 127, 13-19. https://doi.org/10.1016/j.physbeh.2014.01.009

Guillermo-Tuazon, M., Barba, C., van Raaij, J., Hautvast, J.G.A.J., 1992. Energy intake, energy expenditure, and body composition of poor rural philippine women throughout the first 6 mo of lactation. American Journal of Clinical Nutrition 56, 874-80. https://doi.org/10.1093/ajen/56.5.874

Hackney, A., Kallman, A., Hosick, K., Rubin, D., Battaglini, C., 2012. Thyroid hormonal responses to intensive interval versus steady-state endurance exercise sessions. Hormones (Athens, Greece) 11, 54-60. https://doi.org/10.1007/BF03401537

Hackney, A.C., Walz, E.A., 2013. Hormonal adaptation and the stress of exercise training: The role of glucocorticoids. Trends in Sport Sciences 20, 165-171.

Hall, K.D., Heymsfield, S.B., Kemnitz, J.W., Klein, S., Schoeller, D.A., Speakman, J.R., 2012. Energy balance and its components: Implications for body weight regulation. American Journal of Clinical Nutrition 95, 989-994. https://doi.org/10.3945/ajcn.112.036350

Hämäläinen, A., Heistermann, M., Kraus, C., 2015. The stress of growing old: Sex- and seasonspecific effects of age on allostatic load in wild grey mouse lemurs. Oecologia 178 , 1063-1075. https://doi.org/10.1007/s00442-015-3297-3

Hamel, S., Craine, J., Towne, G., 2012. Maternal allocation in bison: Co-occurrence of senescence, cost of reproduction, and individual quality. Ecological Applications 22, 1628-1639. https://doi.org/10.1890/1051-0761-22.5.1628

Hamel, S., Gaillard, J.-M., Yoccoz, N.G., Loison, A., Bonenfant, C., Descamps, S., 2010. Fitness costs of reproduction depend on life speed: Empirical evidence from mammalian populations. Ecology Letters 13, 915-935. https://doi.org/10.1111/j.14610248.2010.01478.x

Hanna, J.B., Schmitt, D., 201l. Locomotor energetics in primates: Gait mechanics and their relationship to the energetics of vertical and horizontal locomotion. American Journal of Physical Anthropology 145, 43-54. https://doi.org/10.1002/ajpa.21465

Hanya, G., 2004. Seasonal variations in the activity budget of Japanese macaques in the coniferous forest of Yakushima: Effects of food and temperature. American Journal of Primatology 63, 165-177. https://doi.org/10.1002/ajp.20049

Harlow, H.J., Seal, U.S., 1981. Changes in hematology and metabolites in the serum and urine of the badger, Taxidea taxus, during food deprivation. Canadian Journal of Zoology 59, 2123-2128. https://doi.org/10.1139/z81-289

Harris, T., 2006. Between-group contest competition for food in a highly folivorous population of black and white colobus monkeys (Colobus guereza). Behavioral Ecology and Sociobiology, 61, 317-329. https://doi.org/10.1007/s00265-006-0261-6

Harris, T., Chapman, C., Monfort, S., 2009. Small folivorous primate groups exhibit behavioral and physiological effects of food scarcity. Behavioral Ecology 21, 46-56. https://doi.org/10.1093/beheco/arpl50

Harrison, M.J.S., 1983. Age and sex differences in the diet and feeding strategies of the green monkey, Cercopithecus sabaeus. Animal Behaviour 31, 969-977. https://doi.org/10.1016/S0003-3472(83)80001-3 
Hayes, V.J., Henzi, S.P., Freedman, L., Gaynor, D., 1992. The differential use of cheek pouches in a troop of Papio ursinus. Primates 33, 477-500. https://doi.org/10.1007/BF02381151

Haynie, D.T., 2001. Biological Thermodynamics. Cambridge University Press, Cambridge, UK.

Hedeskov, C.J., 1980. Mechanism of glucose-induced insulin secretion. Physiological Reviews 60, 442-509. https://doi.org/10.1152/physrev.1980.60.2.442

Heesen, M., Rogahn, S., Macdonald, S., Ostner, J., Schülke, O., 2014. Predictors of food-related aggression in wild Assamese macaques and the role of conflict avoidance. Behavioral Ecology and Sociobiology 68. https://doi.org/10.1007/s00265-014-1792-x

Heesen, M., Rogahn, S., Ostner, J., Schülke, O., 2013. Food abundance affects energy intake and reproduction in frugivorous female Assamese macaques. Behavioral Ecology and Sociobiology 67. https://doi.org/10.1007/s00265-013-1530-9

Heldstab, S.A., van Schaik, C.P., Isler, K., 2017. Getting fat or getting help? How female mammals cope with energetic constraints on reproduction. Frontiers in Zoology 14, 29. https://doi.org/10.1186/s12983-017-0214-0

Henquin, J.-C., Dufrane, D., Nenquin, M., 2006. Nutrient Control of Insulin Secretion in isolated normal human islets. Diabetes 55, 3470-3477. https://doi.org/10.2337/db060868

Herrera, E., Heymann, E., 2004. Does mom need more protein? Preliminary observations on differences in diet composition in a pair of red titi monkeys (Callicebus cupreus). Folia primatologica 75, 150-3. https://doi.org/10.1159/000078304

Hetem, R.S., Fuller, A., Maloney, S.K., Mitchell, D., 2014. Responses of large mammals to climate change. Temperature (Austin) 1, 115-127. https://doi.org/10.4161/temp.29651

Higham, J.P., Girard-Buttoz, C., Engelhardt, A., Heistermann, M., 20lla. Urinary C-peptide of insulin as a non-invasive marker of nutritional status: Some practicalities. PLOS ONE 6, e22398. https://doi.org/10.1371/journal.pone.0022398

Higham, J.P., Heistermann, M., Maestripieri, D., 201lb. The energetics of male-male endurance rivalry in free-ranging rhesus macaques, Macaca mulatta. Animal Behaviour 81, 1001-1007. https://doi.org/10.1016/j.anbehav.2011.02.001

Hill, D.A., 1997. Seasonal variation in the feeding behavior and diet of Japanese macaques (Macaca fuscata yakui) in lowland forest of Yakushima. American Journal of Primatology 43, 305-322. https://doi.org/10.1002/(SICI)10982345(1997)43:4<305::AID-AJP2>3.0.CO;2-0

Hill, D.A., Agetsuma, N., 1995. Supra-annual variation in the influence of Myrica rubra fruit on the behavior of a troop of Japanese macaques in Yakushima. American Journal of Primatology 35, 241-250. https://doi.org/10.1002/ajp.1350350307

Hill, J.W., Elmquist, J.K., Elias, C.F., 2008. Hypothalamic pathways linking energy balance and reproduction. American Journal Of Physiology-Endocrinology And Metabolism 294, E827-832. https://doi.org/10.1152/ajpendo.00670.2007

Hinde, K., Milligan, L.A., 2011. Primate milk: Proximate mechanisms and ultimate perspectives. Evolutionary Anthropology: Issues, News, and Reviews 20, 9-23. https://doi.org/10.1002/evan.20289

Hofer, H., East, M.L., 2003. Behavioral processes and costs of co-existence in female spotted hyenas: A life history perspective. Evolutionary Ecology 17, 315-331. https://doi.org/10.1023/A:1027352517231

Holand, O., Weladji, R., Gjøstein, H., Jouko, K., Smith, M., Nieminen, M., Røed, K., 2004. Reproductive effort in relation to maternal social rank in reindeer (Rangifer tarandus). Behavioral Ecology and Sociobiology 57, 69-76. https://doi.org/10.1007/s00265-0040827-0 
Hoogwerf, B.J., Goetz, F.C., 1983. Urinary C-peptide: A simple measure of integrated insulin production with emphasis on the effects of body size, diet, and corticosteroids. Journal of Clinical Endocrinology and Metabolism 56, 60-67. https://doi.org/10.1210/jcem-56-1-60

Hoogwerf, B.J., Laine, D.C., Greene, E., 1986. Urine C-peptide and creatinine (Jaffe Method) excretion in healthy young adults on varied diets: Sustained effects of varied carbohydrate, protein, and meat content. American Journal of Clinical Nutrition 43, 350-360. https://doi.org/10.1093/ajcn/43.3.350

Hou, C., Zuo, W., Moses, M.E., Woodruff, W.H., Brown, J.H., West, G.B., 2008. Energy uptake and allocation during ontogeny. Science 322, 736-739. https://doi.org/10.1126/science.1162302

Hu, M., Eviston, D., Hsu, P., Mariño, E., Chidgey, A., Santner-Nanan, B., Wong, K., Richards, J.L., Yap, Y.A., Collier, F., Quinton, A., Joung, S., Peek, M., Benzie, R., Macia, L., Wilson, D., Ponsonby, A.-L., Tang, M.L.K., O'Hely, M., Daly, N.L., Mackay, C.R., Dahlstrom, J.E., Vuillermin, P., Nanan, R., 2019. Decreased maternal serum acetate and impaired fetal thymic and regulatory $\mathrm{T}$ cell development in preeclampsia. Nature Communications 10, 3031. https://doi.org/10.1038/s41467-019-10703-1

Hulbert, A.J., 2000. Thyroid hormones and their effects: A new perspective. Biological Reviews 75, 519-631. https://doi.org/10.1111/j.1469-185X.2000.tb00054.x

Hulbert, A.J., Else, P.L., 2000. Mechanisms underlying the cost of living in animals. Annual Review of Physiology 62, 207-235. https://doi.org/10.1146/annurev.physiol.62.1.207

Hulbert, J.A., Else, P.L., 2004. Basal metabolic rate: History, composition, regulation, and usefulness. Physiological and Biochemical Zoology. https://doi.org/10.1086/422768

Humphries, M.M., Umbanhowar, J., McCann, K.S., 2004. Bioenergetic prediction of climate change impacts on northern mammals. Integrative and Comparative Biology 44, 152162. https://doi.org/10.1093/icb/44.2.152

Isaac, J.L., 2009. Effects of climate change on life history: Implications for extinction risk in mammals. Endangered Species Research 7, 115-123. https://doi.org/10.3354/esr00093

Isbell, L., 1991. Contest and scramble competition: Patterns of female aggression and ranging behavior among primates. Behavioral Ecology 2, 143-155.

https://doi.org/10.1093/beheco/2.2.143

Ivanov, K., 2006. The development of the concepts of homeothermy and thermoregulation. Journal of Thermal Biology 31, 24-29. https://doi.org/10.1016/j.jtherbio.2005.12.005

Jack, L.J., Kahl, S., St Germain, D.L., Capuco, A.V., 1994. Tissue distribution and regulation of 5'-deiodinase processes in lactating rats. Journal of Endocrinology 142, 205-215. https://doi.org/10.1677/joe.0.1420205

Jaeger, B.C., Edwards, L.J., Das, K., Sen, P.K., 2017. An R2 statistic for fixed effects in the generalized linear mixed model. Journal of Applied Statistics 44, 1086-1105. https://doi.org/10.1080/02664763.2016.1193725

Janson, C., 1985. Aggresive competition and individual food consumption in wild brown capuchin monkeys (Cebus apella). Behavioral Ecology and Sociobiology 18, 125-138. https://doi.org/10.1007/BF00299041

Janson, C.H., Chapman, C.A., 2000. Primate resources and the determination of primate community structure, in: Fleagle, J.G., Janson, C.H., Reed, K. (editors), Primate Communities. Cambridge University Press, Cambridge, UK, 237-267.

Jasienska, G., 2020. Costs of reproduction and ageing in the human female. Philosophical Transactions of the Royal Society B: Biological Sciences 375, 20190615. https://doi.org/10.1098/rstb.2019.0615

Jasienska, G., 2003. Energy metabolism and the evolution of reproductive suppression in the human female. Acta Biotheoretica 51, 1-18. https://doi.org/10.1023/a:1023035321162 
Jastroch, M., Giroud, S., Barrett, P., Geiser, F., Heldmaier, G., Herwig, A., 2016. Seasonal control of mammalian energy balance: Recent advances in the understanding of daily torpor and hibernation. Journal of Neuroendocrinology 28. https://doi.org/10.11ll/jne.12437

Jeanniard du Dot, T., Rosen, D.A.S., Richmond, J.P., Kitaysky, A.S., Zinn, S.A., Trites, A.W., 2009. Changes in glucocorticoids, IGF-I and thyroid hormones as indicators of nutritional stress and subsequent refeeding in Steller sea lions (Eumetopias jubatus). Comparative Biochemistry and Physiology - Part A: Molecular \& Integrative Physiology 152, 524-534. https://doi.org/10.1016/j.cbpa.2008.12.010

Jesmer, B., Goheen, J., Monteith, K., Kauffman, M., 2017. State-dependent behavior alters endocrine-energy relationship: Implications for conservation and management. Ecological Applications 27. https://doi.org/10.1002/eap.1608

Johnson, G.S., Elizondo, R.S., 1979. Thermoregulation in Macaca mulatta: a thermal balance study. Journal of Applied Physiology 46, 268-277. https://doi.org/10.1152/jappl.1979.46.2.268

Joly, K., Wasser, S.K., Booth, R., 2015. Non-invasive assessment of the interrelationships of diet, pregnancy rate, group composition, and physiological and nutritional stress of barren-ground caribou in late winter. PLoS ONE 10, e0127586. https://doi.org/10.1371/journal.pone.0127586

Jönsson, K.I., 1997. Capital and income breeding as alternative tactics of resource use in reproduction. Oikos 78, 57-66. https://doi.org/10.2307/3545800

Kaethner, M.M., Good, B.F., 1975. Seasonal thyroid activity in the tammar wallaby, Macropus eugenii (Desmarest). Australian Journal of Zoology 23, 363-369. https://doi.org/10.1071/zo9750363

Kanakis, I., Alameddine, M., Scalabrin, M., van 't Hof, R.J., Liloglou, T., Ozanne, S.E., Goljanek-Whysall, K., Vasilaki, A., 2020. Low protein intake compromises the recovery of lactation-induced bone loss in female mouse dams without affecting skeletal muscles. FASEB Journal 34, 11844-11859. https://doi.org/10.1096/fj.202001131R

Katsarou, A., Gudbjörnsdottir, S., Rawshani, A., Dabelea, D., Bonifacio, E., Anderson, B.J., Jacobsen, L.M., Schatz, D.A., Lernmark, Å., 2017. Type 1 diabetes mellitus. Nature Reviews Disease Primers 3, 1-17. https://doi.org/10.1038/nrdp.2017.16

Kelm, D.H., Helversen, O. von, 2007. How to budget metabolic energy: Torpor in a small neotropical mammal. Journal of Comparative Physiology B 177, 667-677. https://doi.org/10.1007/s00360-007-0164-5

Keogh, M.J., Atkinson, S., Maniscalco, J.M., 2013. Body condition and endocrine profiles of Steller sea lion (Eumetopias jubatus) pups during the early postnatal period. General and Comparative Endocrinology 184, 42-50. https://doi.org/10.1016/j.ygcen.2012.12.016

Key, C., Ross, C., 1999. Sex differences in energy expenditure in non-human primates. Proceedings of the Royal Society of London B: Biological Sciences 266, 2479-2485. https://doi.org/10.1098/rspb.1999.0949

Kim, B., 2008. Thyroid hormone as a determinant of energy expenditure and the basal metabolic rate. Thyroid 18, 141-144. https://doi.org/10.1089/thy.2007.0266

Kirkwood, J.K., Underwood, S.J., 1984. Energy requirements of captive cotton-top tamarins (Saguinus oedipus oedipus). Folia Primatologica (Basel) 42, 180-187. https://doi.org/10.1159/000156160

Kitabchi, A.E., 1977. Proinsulin and C-peptide: A review. Metabolism 26, 547-587. https://doi.org/10.1016/0026-0495(77)90099-3 
Knott, C., 2001. Female reproductive ecology of the apes: Implications for human evolution, in: Ellison, P.T. (editor), Reproductive ecology and human evolution. De Gruyter, NY, USA, 429-463

Knott, C., M.E, T., Wich, S., 2009. The ecology of reproduction in wild orangutans, in: Wich, S., Utami Atmoko, S. S., Setia, T. M., van Schaik, C. (editors), Orangutans: Geographic variation in behavioral ecology and conservation. Oxford University Press, USA, 171188. https://doi.org/10.1093/acprof:oso/9780199213276.003.0011

Knott, C.D., 1998. Changes in orangutan caloric intake, energy balance, and ketones in response to fluctuating fruit availability. International Journal of Primatology 19, 1061-1079. https://doi.org/10.1023/A:1020330404983

Koch, F., Ganzhorn, J.U., Rothman, J.M., Chapman, C.A., Fichtel, C., 2017. Sex and seasonal differences in diet and nutrient intake in Verreaux's sifakas (Propithecus verreauxi). American Journal of Primatology 79, 1-10. https://doi.org/10.1002/ajp.22595

Koenig, A., Borries, C., Chalise, M., Winkler, P., 1997. Ecology, nutrition, and timing of reproductive events in an asian primate, the Hanuman langur (Presbytis entellus). J Zool 243:215-235. https://doi.org/10.11l1/J.1469-7998.1997.TB02778.X

Koenig, A., Borries, C, Suarez, S.A., Kreetiyutanont, K., 2004. Socio-ecology of phayre's leaf monkeys (Trachypithecus phayrei) at Phu Khieo widlife Sanctuary. Journal of Wildlife in Thailand 12, 150-163.

Kohrs, M.B., Kerr, G.R., Harper, A.E., 1980. Effects of a low protein diet during pregnancy of the rhesus monkey. III Growth of infants. American Journal of Clinical Nutrition 33, 625-630. https://doi.org/10.1093/ajcn/33.3.625

Koivula, M., Koskela, E., Mappes, T., Oksanen, T.A., 2003. Cost of reproduction in the wild: Manipulation of reproductive effort in the bank vole. Ecology 84, 398-405. https://doi.org/10.1890/0012-9658(2003)084[0398:CORITW]2.0.CO;2

Korine, C., Speakman, J., Arad, Z., 2004. Reproductive energetics of captive and free-ranging egyptian fruit bats (Rousettus aegyptiacus). Ecology 85, 220-230. https://doi.org/10.1890/02-0632

Kruszynska, Y.T., Home, P.D., Hanning, I., Alberti, K.G.M.M., 1987. Basal and 24-h C-peptide and insulin secretion rate in normal man. Diabetologia 30, 16-21. https://doi.org/10.1007/BF01788901

Kumsuk, M., Kreetiyutanont, K., Suvannakorn, V., Sangounyat, N., 1999. Diversity of wildlife vertebrates in Phu Khieo Wildlife Sanctuary, Chaiyaphum Province Wildlife Conservation Division, Natural Resources Conservation Office, Royal Forest Department, Bangkok, 124.

Kurihara, Y., Hanya, G., 2015. Comparison of feeding behavior between two different-sized groups of Japanese macaques (Macaca fuscata yakui): Feeding competition in Japanese macaques. American journal of primatology 77. https://doi.org/10.1002/ajp.22429

Kurihara, Y., Kinoshita, K., Shiroishi, I., Hanya, G., 2020. Seasonal variation in energy balance of wild Japanese macaques (Macaca fucata yakui) in a warm-temperate forest: A preliminary assessment in the coastal forest of Yakushima. Primates 61. https://doi.org/10.1007/s10329-020-00797-3

Kusina, J., Pettigrew, J., Sower, A., White, M., Crooker, B., Hathaway, M., 1999. Effect of protein intake during gestation and lactation on the lactational performance of primiparous sows. Journal of Animal Science 77, 931-41. https://doi.org/10.2527/1999.774931x

Kuznetsova, A., Brockhoff, P.B., Christensen, R.H.B., 2017. lmerTest Package: Tests in Linear Mixed Effects Models. Journal of Statistical Software 82.

https://doi.org/10.18637/jss.v082.il3 
la Fleur, S.E., 2006. The effects of glucocorticoids on feeding behavior in rats. Physiology \& Behavior 89, 110-114. https://doi.org/10.1016/j.physbeh.2006.01.028

Lambert, J., 201l. Primate nutritional ecology: Feeding biology and diet at ecological and evolutionary scales, in: Campbell, C.J., Fuentes, A., MacKinnon, K.C., Bearder, S.K., Stumpf, R.M. (editors), Primates in Perspective. Oxford University Press, Oxford, UK, 512-522

Lambert, J.E., 2005. Competition, predation, and the evolutionary significance of the cercopithecine cheek pouch: The case of Cercopithecus and Lophocebus. American Journal of Physical Anthropology 126, 183-192. https://doi.org/10.1002/ajpa.10440

Lambert, J.E., Rothman, J.M., 2015. Fallback foods, optimal diets, and nutritional targets: Primate responses to varying food availability and quality. Annual Review of Anthropology 44, 493-512. https://doi.org/10.1146/annurev-anthro-102313-025928

Langley-Evans, S.C., Welham, S.J.M., Sherman, R.C., Jackson, A.A., 1996. Weanling rats exposed to maternal low-protein diets during discrete periods of gestation exhibit differing severity of hypertension. Clinical Science 91, 607-615. https://doi.org/10.1042/cs0910607

Lassek, W.D., Gaulin, S.J.C., 2006. Changes in body fat distribution in relation to parity in american women: A covert form of maternal depletion. American Journal of Physical Anthropology 131, 295-302. https://doi.org/10.1002/ajpa.20394

Laurberg, P., Andersen, S., Karmisholt, J., 2005. Cold adaptation and thyroid hormone metabolism. Hormone and Metabolic Research 37, 545-549. https://doi.org/10.1055/s2005-870420

Laver, P.N., Ganswindt, A., Ganswindt, S.B., Alexander, K.A., 2020. Effect of food limitation and reproductive activity on fecal glucocorticoid metabolite levels in banded mongooses. BMC Ecology 20, 12. https://doi.org/10.1186/sl2898-020-00280-z

LeDee, O.E., Handler, S.D., Hoving, C.L., Swanston, C.W., Zuckerberg, B., 2021. Preparing wildlife for climate change: How far have we come? Journal of Wildlife Management 85, 7-16. https://doi.org/10.1002/jwmg.21969

Lee, P.C., 1987. Nutrition, fertility and maternal investment in primates. Journal of Zoology 213, 409-422. https://doi.org/10.1111/j.1469-7998.1987.tb03717.x

Lee, P.C., Majluf, P., Gordon, I.J., 1991. Growth, weaning and maternal investment from a comparative perspective. Journal of Zoology 225, 99-114. https://doi.org/10.1111/j.14697998.1991.tb03804.x

Li, Y., Liu, H., Zhang, L., Yang, Y., Lin, Y., Zhuo, Y., Fang, Z., Che, L., Feng, B., Xu, S., Li, J., $\mathrm{Wu}, \mathrm{D} ., 2019$. Maternal dietary fiber composition during gestation induces changes in offspring antioxidative capacity, inflammatory response, and gut microbiota in a sow model. International Journal of Molecular Sciences 21. https://doi.org/10.3390/ijms21010031

Liggins, G.C., 1994. The role of cortisol in preparing the fetus for birth. Reproduction, Fertility and Development 6, 141-150. https://doi.org/10.1071/rd9940141

Lochmiller, R.L., Deerenberg, C., 2000. Trade-offs in evolutionary immunology: Just what is the cost of immunity? Oikos 88, 87-98. https://doi.org/10.1034/j.16000706.2000.880110.x

Lodge, E., 2012. Energetics and life-history of olive baboons in the Gashaka Gumti National Park.PhD dissertation

Lodge, E., Ross, C., Ortmann, S., MacLarnon, A.M., 2013. Influence of diet and stress on reproductive hormones in nigerian olive baboons. General and Comparative Endocrinology 191, 146-154. https://doi.org/10.1016/j.ygcen.2013.06.016 
Logan, M., Sanson, G., 2003. The effects of lactation on the feeding behaviour and activity patterns of free-ranging female koalas (Phascolarctos cinereus Goldfuss). Australian Journal of Zoology 5l. https://doi.org/10.1071/ZO03017

Loh, K., Zhang, L., Brandon, A., Wang, Q., Begg, D., Qi, Y., Fu, M., Kulkarni, R., Teo, J., Baldock, P., Brüning, J.C., Cooney, G., Neely, G., Herzog, H., 2017. Insulin controls food intake and energy balance via NPY neurons. Molecular Metabolism 6, 574-584. https://doi.org/10.1016/j.molmet.2017.03.013

López, M., Alvarez, C.V., Nogueiras, R., Diéguez, C., 2013. Energy balance regulation by thyroid hormones at central level. Trends in Molecular Medicine 19, 418-427. https://doi.org/10.1016/j.molmed.2013.04.004

Lucchesi, S., Cheng, L., Deschner, T., Mundry, R., Wessling, E.G., Surbeck, M., 2020. Better together? How intergroup associations affect energy balance and feeding behavior in wild bonobos. Behavioral Ecology and Sociobiology 75, 2. https://doi.org/10.1007/s00265-020-02943-9

Lyman, C.P., 1954. Activity, Food consumption and hoarding in hibernators. Journal of Mammalogy 35, 545-552. https://doi.org/10.2307/1375580

MacArthur, R.H., Pianka, E.R., 1966. On optimal use of a patchy environment. The American Naturalist 100, 603-609.

Maestripieri, D., Zehr, J.L., 1998. Maternal responsiveness increases during pregnancy and after estrogen treatment in macaques. Hormones and Behavior 34, 223-230. https://doi.org/10.1006/hbeh.1998.1470

Magomedova, L., Cummins, C.L., 2016. Glucocorticoids and metabolic control. Handbook of Experimental Pharmacology 233, 73-93. https://doi.org/10.1007/164_2015_1

Majolo, B., Lehmann, J., Vizioli, A., Schino, G., 2012. Fitness-related benefits of dominance in primates. American Journal of Physical Anthropology 147, 652-60. https://doi.org/10.1002/ajpa.22031

Majolo, B., McFarland, R., Young, C., Qarro, M., 2013. The effect of climatic factors on the activity budgets of barbary macaques. International Journal of Primatology 34, 500514. https://doi.org/10.1007/s10764-013-9678-8

Malcolm, K.D., McShea, W.J., Garshelis, D.L., Luo, S.-J., Van Deelen, T.R., Liu, F., Li, S., Miao, L., Wang, D., Brown, J.L., 2014. Increased stress in asiatic black bears relates to food limitation, crop raiding, and foraging beyond nature reserve boundaries in China. Global Ecology and Conservation 2, 267-276. https://doi.org/10.1016/j.gecco.2014.09.010

Markham, A.C., Gesquiere, L.R., Alberts, S.C., Altmann, J., 2015. Optimal group size in a highly social mammal. PNAS 112, 14882-14887. https://doi.org/10.1073/pnas.1517794112

Marlowe, F.W., Berbesque, J.C., 2009. Tubers as fallback foods and their impact on Hadza hunter-gatherers. American Journal of Physical Anthropology 140, 751-758. https://doi.org/10.1002/ajpa.21040

Marshall, A.J., Boyko, C.M., Feilen, K.L., Boyko, R.H., Leighton, M., 2009. Defining fallback foods and assessing their importance in primate ecology and evolution. American Journal of Physical Anthropology 140, 603-614. https://doi.org/10.1002/ajpa.21082

Marshall, A.J., Wrangham, R.W., 2007. Evolutionary Consequences of Fallback Foods. International Journal of Primatology 28, 1219. https://doi.org/10.1007/s10764-007-92185

Martin, R., 1996. Scaling of the mammalian brain: the maternal energy hypothesis. Physiology 1l, 149-156. https://doi.org/10.1152/physiologyonline.1996.11.4.149

Martínez-Mota, R., Righini, N., Palme, R., 2016. Fluctuations in daily energy intake do not cause physiological stress in a neotropical primate living in a seasonal forest. Oecologia 182, 973-984. https://doi.org/10.1007/s00442-016-3739-6 
Mastorakos, G., Ilias, I., 2003. Maternal and fetal hypothalamic-pituitary-adrenal axes during pregnancy and postpartum. Annals of the New York Academy of Sciences 997, 136149. https://doi.org/10.1196/annals.1290.016

McCabe, G.M., Emery Thompson, M., 2013. Reproductive seasonality in wild Sanje mangabeys (Cercocebus sanjei), Tanzania: Relationship between the capital breeding strategy and infant survival. Behaviour 150, 1399-1429. https://doi.org/10.1163/1568539X-00003102

McCabe, G.M., Fedigan, L.M., 2007. Effects of reproductive status on energy intake, ingestion rates, and dietary composition of female Cebus capucinus at Santa Rosa, Costa Rica. International Journal of Primatology 28, 837-85l. https://doi.org/10.1007/s10764-0079159-z

McCallister, J.M., Smith, T.E., Elwood, R.W., 2004. Validation of urinary cortisol as an indicator of hypothalamic-pituitary-adrenal function in the bearded emperor tamarin (Saguinus imperator subgrisescens). American Journal of Primatology 63, 17-23. https://doi.org/10.1002/ajp.20033

McCullagh, P., Nelder, J.A., 1989. Generalized Linear Models. Chapman \& Hall, London, UK. McDougall-Shackleton, S.A., Bonier, F., Romero, L.M., Moore, I.T., 2019. Glucocorticoids and "stress" are not synonymous. Integrative Organismal Biology 1. https://doi.org/10.1093/iob/obz017

McEwen, B.S., Wingfield, J.C., 2003. The concept of allostasis in biology and biomedicine. Hormones and Behavior 43, 2-15. https://doi.org/10.1016/s0018-506x(02)00024-7

McFarland, R., 1996. Female primates: Fat or fit?, in: Morbeck, M.E., Galloway, A., Zihlman, A. (editors), The evolving female. Princeton University Press, NJ, USA, 163-176.

McLarnon, A.M., Sommer, V., Goffe, A.S., Higham, J.P., Lodge, E., Tkaczynski, P., Ross, C., 2015. Assessing adaptability and reactive scope: Introducing a new measure and illustrating its use through a case study of environmental stress in forest-living baboons. General and Comparative Endocrinology 215, 10-24. https://doi.org/10.1016/j.ygcen.2014.09.022

McLean, M., Smith, R., 1999. Corticotropin-releasing hormone in human pregnancy and parturition. Trends in Endocrinology \& Metabolism 10, 174-178. https://doi.org/10.1016/s1043-2760(98)00146-5

Mduma, S.A.R., Sinclair, A.R.E., Hilborn, R., 1999. Food regulates the Serengeti wildebeest: A 40-year record. Journal of Animal Ecology 68, 1101-1122. https://doi.org/10.1046/j.13652656.1999.00352.x

Meistas, M.T., Rendell, M., Margolis, S., Kowarski, A.A., 1982. Estimation of the secretion rate of insulin from the urinary excretion rate of $C$-peptide: Study in obese and diabetic subjects. Diabetes 31, 449-453. https://doi.org/10.2337/diab.31.5.449

Melani, F., Rubenstein, A.H., Oyer, P.E., Steiner, D.F., 1970. Identification of proinsulin and Cpeptide in human serum by a specific immunoassay. PNAS 67, 148-155. https://doi.org/10.1073/pnas.67.1.148

Mellado, M., Rodríguez, A., Villarreal, J.A., Olvera, A., 2005. The effect of pregnancy and lactation on diet composition and dietary preference of goats in a desert rangeland. Small Ruminant Research 58, 79-85. https://doi.org/10.1016/j.smallrumres.2004.07.014

Melzer, K., Schutz, Y., Boulvain, M., Kayser, B., 2009. Pregnancy-related changes in activity energy expenditure and resting metabolic rate in Switzerland. European Journal of Clinical Nutrition 63, 1185-1191. https://doi.org/10.1038/ejcn.2009.49

Merimee, T.J., Fineberg, E.S., 1976. Starvation-induced alterations of circulating thyroid hormone concentrations in man. Metabolism 25, 79-83. https://doi.org/10.1016/00260495(76)90162-1 
Miller, K.E., Bales, K.L., Ramos, J.H., Dietz, J.M., 2006. Energy intake, energy expenditure, and reproductive costs of female wild golden lion tamarins (Leontopithecus rosalia). American Journal of Primatology 68, 1037-1053. https://doi.org/10.1002/ajp.20306

Miller, R.C., Brindle, E., Holman, D.J., Shofer, J., Klein, N.A., Soules, M.R., O'Connor, K.A., 2004. Comparison of specific gravity and creatinine for normalizing urinary reproductive hormone concentrations. Clinical Chemistry 50, 924-932. https://doi.org/10.1373/clinchem.2004.032292

Mills, C.A., 1918. Effects of external temperature, morphine, quinine and strychnine on thyroid activity. American Journal of Physiology-Legacy Content. https://doi.org/10.1152/ajplegacy.1918.46.4.329

Milton, K., 1984. The role of food-processing factors in primate food choice, in: Rodman, P.S., Cant, J.G.H. (editors), Adaptations for Foraging in Nonhuman Primates. Columbia University Press, New York, 249-279.

Milton, K., Demment, M.W., 1988. Digestion and passage kinetics of chimpanzees fed high and low fiber diets and comparison with human data. Journal of Nutrition 118, $1082-$ 1088. https://doi.org/10.1093/jn/118.9.1082

Moritz, C., Patton, J.L., Conroy, C.J., Parra, J.L., White, G.C., Beissinger, S.R., 2008. Impact of a century of climate change on small-mammal communities in Yosemite National Park, USA. Science 322, 261-264. https://doi.org/10.1126/science.1163428

Muehlenbein, M.P., Ancrenaz, M., Sakong, R., Ambu, L., Prall, S., Fuller, G., Raghanti, M.A., 2012. Ape conservation physiology: Fecal glucocorticoid responses in wild Pongo pygmaeus morio following human visitation. PLOS ONE 7, e33357. https://doi.org/10.1371/journal.pone.0033357

Muehlenbein, M.P., Watts, D.P., 2010. The costs of dominance: Testosterone, cortisol and intestinal parasites in wild male chimpanzees. BioPsychoSocial Medicine 4, 21. https://doi.org/10.1186/1751-0759-4-21

Muller, M.N., Wrangham, R.W., 2004. Dominance, cortisol and stress in wild chimpanzees (Pan troglodytes schweinfurthii). Behavioral Ecology and Sociobiology 55, 332-340.

Munro, C., Stabenfeldt, G., 1985. Development of a cortisol enzyme immunoassay in plasma [abstract]. Clinical Chemistry 31, 956.

Murray, C.M., Lonsdorf, E.V., Eberly, L.E., Pusey, A.E., 2009. Reproductive energetics in freeliving female chimpanzees (Pan troglodytes schweinfurthii). Behavioral Ecology 20, 121l1216. https://doi.org/10.1093/beheco/arpll4

Muruthi, P., Altmann, J., Altmann, S., 1991. Resource base, parity, and reproductive condition affect females' feeding time and nutrient intake within and between groups of a baboon population. Oecologia 87, 467-472. https://doi.org/10.1007/BF00320408

Nakajima, A., Kaga, N., Nakanishi, Y., Ohno, H., Miyamoto, J., Kimura, I., Hori, S., Sasaki, T., Hiramatsu, K., Okumura, K., Miyake, S., Habu, S., Watanabe, S., 2017. Maternal high fiber diet during pregnancy and lactation influences regulatory $\mathrm{T}$ cell differentiation in offspring in mice. Journal of Immunology 199, 3516-3524. https://doi.org/10.4049/jimmunol.1700248

National Research Council, 2003a. Carbohydrates and fiber, in: Nutrient requirements of nonhuman primates: Second revised edition. The National Academies Press, Washington, DC, USA, 58-74. https://doi.org/10.17226/9826

National Research Council, 2003b. Protein, in: Nutrient requirements of nonhuman primates: Second revised edition. The National Academies Press, Washington, DC, USA, 75-86. https://doi.org/10.17226/9826

National Research Council, 2003c. Fats and fatty acids, in: Nutrient requirements of nonhuman primates: Second revised edition. The National Academies Press, Washington, DC, USA, 87-93. https://doi.org/10.17226/9826 
National Research Council, 2003d. Minerals, in: Nutrient requirements of nonhuman primates: Second revised edition. The National Academies Press, Washington, DC, USA, 94-112. https://doi.org/10.17226/9826

National Research Council, 2003e. Vitamins, in: Nutrient requirements of nonhuman primates: Second revised edition. The National Academies Press, Washington, DC, USA, 113-149. https://doi.org/10.17226/9826

Németh, Z., Bonier, F., MacDougall-Shackleton, S.A., 2013. Coping with uncertainty: Integrating physiology, behavior, and evolutionary ecology in a changing world. Integrative and Comparative Biology 53, 960-964. https://doi.org/10.1093/icb/ict089

Nenke, M.A., Zeng, A., Meyer, E.J., Lewis, J.G., Rankin, W., Johnston, J., Kireta, S., Jesudason, S., Torpy, D.J., 2017. Differential effects of estrogen on corticosteroid-binding globulin forms suggests reduced cleavage in pregnancy. Journal of the Endocrine Society l, 202-210. https://doi.org/10.1210/js.2016-1094

Neuhaus, P., 2000. Weight comparisons and litter size manipulation in columbian ground squirrels (Spermophilus columbianus) show evidence of costs of reproduction. Behavioral Ecology and Sociobiology 48, 75-83. https://doi.org/10.1007/s002650000209

Neumann C, Duboscq J, Dubuc C, Ginting A, Maulana A, Agil M, Widdig A, Engelhardt A (2011) Assessing dominance hierarchies: Validation and advantages of progressive evaluation with Elo-rating. Anim Behav 82:911-921 https://doi.org/10.1016/j.anbehav.2011.07.016

Nie, Y., Speakman, J.R., Wu, Q., Zhang, C., Hu, Y., Xia, M., Yan, L., Hambly, C., Wang, L., Wei, W., Zhang, J., Wei, F., 2015. Exceptionally low daily energy expenditure in the bamboo-eating giant panda. Science 349, 171-174. https://doi.org/10.1126/science.aab2413

Nieuwenhuis, R., Grotenhuis, M., Pelzer, B., 2012a. influence.ME: Tools for detecting influential data in mixed effects models. R Journal 4, 38-47. https://doi.org/10.32614/RJ-2012-011

Nievergelt, C.M., Martin, R.D., 1999. Energy intake during reproduction in captive common marmosets (Callithrix jacchus). Physiology \& Behavior 65, 849-854. https://doi.org/10.1016/s0031-9384(98)00249-2

Nurmi, N.O., Hohmann, G., Goldstone, L.G., Deschner, T., Schülke, O., 2018. The "tolerant chimpanzee" - towards the costs and benefits of sociality in female bonobos. Behavioral Ecology 29, 1325-1339. https://doi.org/10.1093/beheco/aryll8

Ocobock, C., 2016. Human energy expenditure, allocation, and interactions in natural temperate, hot, and cold environments. American Journal of Physical Anthropology 161, 667-675. https://doi.org/10.1002/ajpa.23071

Oftedal, O., Boness, D., Tedman, R., 1987. The behavior, physiology, and anatomy of lactation in the Pinnipedia. Current Mammalogy 13. https://doi.org/10.1007/978-1-4757-990956

Oftedal, O.T., 2000. Use of maternal reserves as a lactation strategy in large mammals. Proceedings of the Nutrition Society 59, 99-106. https://doi.org/10.1017/S0029665100000124

Oki, C., Atkinson, S., 2004. Diurnal patterns of cortisol and thyroid hormones in the Harbor seal (Phoca vitulina) during summer and winter seasons. General and Comparative Endocrinology 136, 289-297. https://doi.org/10.1016/j.ygcen.2004.01.007

Ostner, J., Schülke, O., 2018. Linking sociality to fitness in primates: A call for mechanisms, in: Naguib, M., Barrett, L., Healy, S.D., Podos, J., Simmons, L.W., Zuk, M. (editors), Advances in the Study of Behavior. Academic Press, London, UK, 127-175. https://doi.org/10.1016/bs.asb.2017.12.001 
Ostner, J., Heistermann, M., Schülke, O., 2008. Dominance, aggression and physiological stress in wild male Assamese macaques (Macaca assamensis). Hormones and Behavior 54, 613-9. https://doi.org/10.1016/j.yhbeh.2008.05.020

Pacifici, M., Visconti, P., Rondinini, C., 2018. A framework for the identification of hotspots of climate change risk for mammals. Global Change Biology 24, 1626-1636. https://doi.org/10.11l1/gcb.13942

Parra, A., Villalpando, S., Junco, E., Urquieta, B., Alatorre, S., García-Bulnes, G., 1980. Thyroid gland function during childhood and adolescence. Acta Endocrinologica (Copenhagen) 93, 306-341.

Payne, P.R., Wheeler, E.F., 1968. Comparative nutrition in pregnancy and lactation. Proceedings of the Nutrition Society 27, 129-138. https://doi.org/10.1079/PNS19680037

Perrin, N., Sibly, R.M., 1993. Dynamic models of energy allocation and investment. Annual Review of Ecology and Systematics 24, 379-410. https://doi.org/10.1146/annurev.es.24.110193.002115

Pokharel, S.S., Singh, B., Seshagiri, P.B., Sukumar, R., 2019. Lower levels of glucocorticoids in crop-raiders: Diet quality as a potential 'pacifier' against stress in free-ranging asian elephants in a human-production habitat. Animal Conservation 22, 177-188. https://doi.org/10.1111/acv.12450

Polo, P., Colmenares, F., 2016. Seasonality of reproductive events and early mortality in a colony of hamadryas baboons (Papio hamadryas hamadryas) over a 30-year period: Capital breeding and life history patterns in a food-provisioned population seasonally thermally stressed. American Journal of Primatology 78, 1149-1164. https://doi.org/10.1002/ajp.22570

Pond, C.M., 1977. The significance of lactation in the evolution of mammals. Evolution 31, 177199. https://doi.org/10.2307/2407556

Powell, R.A., Leonard, R.D., 1983. Sexual dimorphism and energy expenditure for reproduction in female fisher Martes pennanti. Oikos 40, 166-174. https://doi.org/10.2307/3544579

Prentice, A.M., Prentice, A., 1988. Energy costs of lactation. Annual Review of Nutrition 8, 63-79.

Previtali, M.A., Lima, M., Meserve, P.L., Kelt, D.A., Gutiérrez, J.R., 2009. Population dynamics of two sympatric rodents in a variable environment: Rainfall, resource availability, and predation. Ecology 90, 1996-2006. https://doi.org/10.1890/08-0405.1

Pride, R.E., 2005. Optimal group size and seasonal stress in ring-tailed lemurs (Lemur catta). Behavioral Ecology 16, 550-560. https://doi.org/10.1093/beheco/ari025

Pritchard, C.E., Palme, R., Langkilde, T., 2020. Glucocorticoid and triiodothyronine concentrations do not correlate with behavior in vicuñas (Vicugna vicugna). General and Comparative Endocrinology 286, 113299. https://doi.org/10.1016/j.ygcen.2019.113299

Pyke, G., 2019. Optimal foraging theory: An introduction. Encyclopedia of Animal Behavior 1ll-117. https://doi.org/10.1016/B978-0-12-809633-8.01156-0

Pyke, G., Pulliam, H., Charnov, E., 1977. Optimal Foraging: A selective review of theory and tests. The Quarterly Review of Biology 52. https://doi.org/10.1086/409852

R Core Team, 2020. R: A language and environment for statistical computing. R foundation for statistical computing, Vienna, Austria. https://www.R-project.org/.

R Core Team, 2018. R: A language and environment for statistical computing. R foundation for statistical computing, Vienna, Austria. https://www.R-project.org/.

Rangel-Negrín, A., Coyohua-Fuentes, A., Chavira, R., Canales-Espinosa, D., Dias, P.A.D., 2014. Primates living outside protected habitats are more stressed: The case of black howler 
monkeys in the Yucatán peninsula. PLOS ONE 9, ell2329.

https://doi.org/10.1371/journal.pone.0112329

Rangel-Negrín, A., Alfaro, J.L., Valdez, R.A., Romano, M.C., Serio-Silva, J.C., 2009. Stress in Yucatan spider monkeys: Effects of environmental conditions on fecal cortisol levels in wild and captive populations. Animal Conservation 12, 496-502. https://doi.org/10.1111/j.1469-1795.2009.00280.x

Rashid, M., Ulijaszek, S.J., 1999. Daily energy expenditure across the course of lactation among urban bangladeshi women. American Journal of Physical Anthropology 110, 457-465. https://doi.org/10.1002/(SICI)1096-8644(199912)110:4<457::AID-

AJPA6>3.0.CO;2-X

Reed, T.E., Schindler, D.E., Waples, R.S., 201l. Interacting effects of phenotypic plasticity and evolution on population persistence in a changing climate. Conservation Biology 25, 56-63. https://doi.org/10.11l1/j.1523-1739.2010.01552.x

Richter, C., Heesen, M., Nenadić, O., Ostner, J., Schülke, O., 2016. Males matter: Increased home range size is associated with the number of resident males after controlling for ecological factors in wild Assamese macaques. American Journal of Physical Anthropology 159, 52-62. https://doi.org/10.1002/ajpa.22834

Ricklefs, R.E., Konarzewski, M., Daan, S., 1996. The Relationship between basal metabolic rate and daily energy expenditure in birds and mammals. The American Naturalist 147, 1047-1071. https://doi.org/10.1086/285892

Riek, A., Brinkmann, L., Gauly, M., Perica, J., Ruf, T., Arnold, W., Hambly, C., Speakman, J.R., Gerken, M., 2017. Seasonal changes in energy expenditure, body temperature and activity patterns in llamas (Lama glama). Scientific Reports 7, 7600. https://doi.org/10.1038/s41598-017-07946-7

Rimbach, R., Heymann, E.W., Link, A., Heistermann, M., 2013. Validation of an enzyme immunoassay for assessing adrenocortical activity and evaluation of factors that affect levels of fecal glucocorticoid metabolites in two New World primates. General and Comparative Endocrinology 191, 13-23. https://doi.org/10.1016/j.ygcen.2013.05.010

Rincon, A.V., Heistermann, M., Schülke, O., Ostner, J., 2020. Testosterone and cortisol are negatively associated with ritualized bonding behavior in male macaques.

Psychoneuroendocrinology 120, 104774. https://doi.org/10.1016/j.psyneuen.2020.104774

Rincon, A.V., Ostner, J., Heistermann, M., Deschner, T., 2019. Measuring urinary cortisol and testosterone levels in male barbary macaques: a comparison of EIA and LC-MS. General and Comparative Endocrinology 281, 117-125. https://doi.org/10.1016/j.ygcen.2019.05.017

Robbins, C., 1993a. Food resources and their utilization, in: Cunha, T.J. (editor), Wildlife Feeding and Nutrition. Academic Press, London, UK, 234-252.

Robbins, C., 1993b. Minerals, in: Cunha, T.J. (editor), Wildlife Feeding and Nutrition. Academic Press, London, UK, 30-68.

Robbins, C., 1993c. Vitamins, in: Cunha, T.J. (editor), Wildlife Feeding and Nutrition. Academic Press, London, UK, 69-68.

Roberts, S.B., Cole, T.J., Coward, W.A., 1985. Lactational performance in relation to energy intake in the baboon. American Journal of Clinical Nutrition 41, 1270-1276. https://doi.org/10.1093/ajcn/41.6.1270

Roberts, S.B., Paul, A.A., Cole, T.J., Whitehead, R.G., 1982. Seasonal changes in activity, birth weight and lactational performance in rural gambian women. Transactions of the Royal Society of Tropical Medicine and Hygiene 76, 668-678. https://doi.org/10.1016/0035-9203(82)90239-5 
Rödel, H.G., Valencak, T.G., Handrek, A., Monclús, R., 2016. Paying the energetic costs of reproduction: Reliance on postpartum foraging and stored reserves. Behavioral Ecology 27, 748-756. https://doi.org/10.1093/beheco/arv217

Roff, D.A., Fairbairn, D.J., 2007. The evolution of trade-offs: Where are we? Journal of Evolutionary Biology 20, 433-447. https://doi.org/10.1111/j.1420-9101.2006.01255.x

Romero, L.M., Dickens, M.J., Cyr, N.E., 2009. The reactive scope model - A new model integrating homeostasis, allostasis, and stress. Hormones and Behavior 55, 375-389. https://doi.org/10.1016/j.yhbeh.2008.12.009

Rosalino, L.M., Guedes, D., Cabecinha, D., Serronha, A., Grilo, C., Santos-Reis, M., Monterroso, P., Carvalho, J., Fonseca, C., Pardavila, X., Virgós, E., Hipólito, D., 2019. Climate and landscape changes as driving forces for future range shift in southern populations of the european badger. Scientific Reports 9, 3155. https://doi.org/10.1038/s41598-019-39713-1

Rose, L.M., 1994. Sex differences in diet and foraging behavior in white-faced capuchins (Cebus capucinus). International Journal of Primatology 15, 95-114. https://doi.org/10.1007/BF02735236

Rosenbaum, M., Hirsch, J., Murphy, E., Leibel, R.L., 2000. Effects of changes in body weight on carbohydrate metabolism, catecholamine excretion, and thyroid function. American Journal of Clinical Nutrition 71, 1421-1432. https://doi.org/10.1093/ajcn/71.6.1421

Rozin, P., 1976. The selection of foods by rats, humans, and other animals, in: Rosenblatt, J.S., Hinde, R.A., Shaw, E., Beer, C. (editors), Advances in the study of behavior. Academic Press, London, UK, 21-76. https://doi.org/10.1016/S0065-3454(08)60081-9

Rubenstein, A.H., Clark, J.L., Melani, F., Steiner, D.F., 1969. Secretion of proinsulin C-peptide by pancreatic $\beta$ cells and its circulation in blood. Nature 224, 697-699. https://doi.org/10.1038/224697a0

Rudolph, K., Fichtel, C., Heistermann, M., Kappeler, P.M., 2020. Dynamics and determinants of glucocorticoid metabolite concentrations in wild Verreaux's sifakas. Hormones and Behavior 124, 104760. https://doi.org/10.1016/j.yhbeh.2020.104760

Ruf, T., Geiser, F., 2015. Daily torpor and hibernation in birds and mammals. Biological reviews of the Cambridge Philosophical Society 90, 891-926. https://doi.org/10.1111/brv.12137

Sacco, A.J., Granatosky, M.C., Laird, M.F., Milich, K.M., 2021. Validation of a method for quantifying urinary C-peptide in platyrrhine monkeys. General and Comparative Endocrinology 300, 113644. https://doi.org/10.1016/j.ygcen.2020.113644

Sadoughi, B., Girard-Buttoz, C., Engelhardt, A., Heistermann, M., Ostner, J., 2021. Noninvasive assessment of metabolic responses to food restriction using urinary triiodothyronine and cortisol measurement in macaques. General and Comparative Endocrinology 306, 113736. https://doi.org/10.1016/j.ygcen.2021.113736

Saj, T.L., Sicotte, P., 2007. Scramble competition among Colobus vellerosus at Boabeng-Fiema, Ghana. International Journal of Primatology 28, 337-355. https://doi.org/10.1007/s10764-007-9125-9

Sapolsky, R.M., Romero, L.M., Munck, A.U., 2000. How do glucocorticoids influence stress responses? Integrating permissive, suppressive, stimulatory, and preparative actions. Endocrine Reviews 21, 55-89. https://doi.org/10.1210/edrv.21.1.0389

Sawada, A., Sakaguchi, E., Hanya, G., 2010. Digesta passage time, digestibility, and total gut fill in captive japanese macaques (Macaca fuscata): Effects food type and food intake level. International Journal of Primatology. https://doi.org/10.1007/s10764-010-9476-5 
Schaebs, F.S., Wolf, T.E., Behringer, V., Deschner, T., 2016. Fecal thyroid hormones allow for the noninvasive monitoring of energy intake in capuchin monkeys. Journal of Endocrinology 231, 1-10. https://doi.org/10.1530/JOE-16-0152

Schielzeth, H., 2010. Simple means to improve the interpretability of regression coefficients. Methods in Ecology and Evolution 1, 103-113. https://doi.org/10.11l1/j.2041210X.2010.00012.x

Schielzeth, H., Forstmeier, W., 2009. Conclusions beyond support: Overconfident estimates in mixed models. Behavioral Ecology 20, 416-420. https://doi.org/10.1093/beheco/arnl45

Schneider, J.E., 2004. Energy balance and reproduction. Physiology \& Behavior 81, 289-317. https://doi.org/10.1016/j.physbeh.2004.02.007

Schoener, T.W., 1971. Theory of feeding strategies. Annual Review of Ecology and Systematics 2, 369-404. https://doi.org/10.1146/annurev.es.02.110171.002101

Schülke, O., Chalise, M.K., Koenig, A., 2006. The importance of ingestion rates for estimating food quality and energy intake. American Journal of Primatology 68, 951-965. https://doi.org/10.1002/ajp.20300

Schülke, O., Pesek, D., Whitman, B.J., Ostner, J., 20ll. Ecology of Assamese macaques (Macaca assamensis) at Phu Phieo Wildlife sanctuary, Thailand 15.

Schülke, O., Heistermann, M., Ostner, J., 2014. Lack of evidence for energetic costs of mateguarding in wild male Assamese macaques (Macaca assamensis). International Journal of Primatology 35, 677-700. https://doi.org/10.1007/s10764-013-9748-y

Scotney, H., Symonds, M.E., Law, J., Budge, H., Sharkey, D., Manolopoulos, K.N., 2017. Glucocorticoids modulate human brown adipose tissue thermogenesis in vivo. Metabolism 70, 125-132. https://doi.org/10.1016/j.metabol.2017.01.024

Sealander, J.A., 1952. The relationship of nest protection and huddling to survival of Peromyscus at low temperature. Ecology 33, 63-71. https://doi.org/10.2307/1931252

Sejian, V., Singh, A.K., Sahoo, A., Naqvi, S.M.K., 2014. Effect of mineral mixture and antioxidant supplementation on growth, reproductive performance and adaptive capability of Malpura ewes subjected to heat stress. Journal of Animal Physiology and Animal Nutrition 98, 72-83. https://doi.org/10.1111/jpn.12037

Selye, H., 1946. The general adaptation syndrome and the diseases of adaptation. Journal of Clinical Endocrinology and Metabolism 6, 117-230. https://doi.org/10.1210/jcem-6-2117

Serio-Silva, J.C., Hernández-Salazar, L.T., Rico-Gray, V., 1999. Nutritional composition of the diet of Alouatta palliata mexicana females in different reproductive states. Zoo Biology 18, 507-513. https://doi.org/10.1002/(SICI)1098-2361(1999)18:6<507::AIDZOO5>3.0.CO;2-R

Setchell, J.M., Smith, T., Wickings, E.J., Knapp, L.A., 2010. Stress, social behaviour, and secondary sexual traits in a male primate. Hormones and Behavior 58, 720-728. https://doi.org/10.1016/j.yhbeh.2010.07.004

Setchell, J.M., Smith, T., Wickings, E.J., Knapp, L.A., 2008. Factors affecting fecal glucocorticoid levels in semi-free-ranging female mandrills (Mandrillus sphinx). American Journal of Primatology 70, 1023-1032. https://doi.org/10.1002/ajp.20594

Sherry, D.S., Ellison, P.T., 2007. Potential applications of urinary C-peptide of insulin for comparative energetics research. American Journal of Physical Anthropology 133, 771778. https://doi.org/10.1002/ajpa.20562

Silk, J.B., 1987. Activities and feeding behavior of free-ranging pregnant baboons. International Journal of Primatology 8, 593-613. https://doi.org/10.1007/BF02735779

Silva, J.E., 2006. Thermogenic mechanisms and their hormonal regulation. Physiological Reviews 86, 435-464. https://doi.org/10.1152/physrev.00009.2005 
Sjödin, A.M., Forslund, A.H., Westerterp, K.R., Andersson, A.B., Forslund, J.M., Hambraeus, L.M., 1996. The influence of physical activity on BMR. Medicine \& Science in Sports \& Exercise 28, 85-91. https://doi.org/10.1097/00005768-199601000-00018

Smithson, M., Verkuilen, J., 2006. A better lemon squeezer? Maximum-likelihood regression with beta-distributed dependent variables. Psychological methods 11, 54-71. https://doi.org/10.1037/1082-989X.11.1.54

Snaith, T., Chapman, C., 2005. Towards an ecological solution to the folivore paradox: Patch depletion as an indicator of within-group scramble competition in red colobus monkeys (Piliocolobus tephrosceles). Behavioral Ecology and Sociobiology 59, 185-190. https://doi.org/10.1007/s00265-005-0023-x

Sommer, F., Ståhlman, M., Ilkayeva, O., Arnemo, J.M., Kindberg, J., Josefsson, J., Newgard, C.B., Fröbert, O., Bäckhed, F., 2016. The gut microbiota modulates energy metabolism in the hibernating brown bear Ursus arctos. Cell Rep 14, 1655-1661. https://doi.org/10.1016/j.celrep.2016.01.026

Soumah, A.G., Yokota, N., 1991. Female rank and feeding strategies in a free-ranging provisioned troop of japanese macaques. Folia Primatologica 57, 191-200. https://doi.org/10.1159/000156586

Speakman, J.R., 2008. The physiological costs of reproduction in small mammals. Philosophical Transactions of the Royal Society B: Biological Sciences 363, 375-398. https://doi.org/10.1098/rstb.2007.2145

Speakman, J.R., Rowland, A., 1999. Preparing for inactivity: How insectivorous bats deposit a fat store for hibernation. Proceedings of the Nutrition Society 58, 123-131. https://doi.org/10.1079/pns19990017

Spellacy, W.N., Goetz, F.C., 1963. Plasma insulin in normal late pregnancy. New England Journal of Medicine 268, 988-991. https://doi.org/10.1056/NEJM196305022681805

St. Aubin, D., Ridgway, S., Wells, R., Rhinehart, H., 1996. Dolphin thyroid and adrenal hormones: Circulating levels in wild and semidomesticated Tursiops truncatus, and influence of sex, age, and season. Marine Mammal Science 12, 1-13. https://doi.org/10.11ll/j.1748-7692.1996.tb00301.x

Stearns, S.C., 1992. The Evolution of Life Histories. Oxford University Press, USA.

Stearns, S.C., 1989. Trade-Offs in Life-History Evolution. Functional Ecology 3, 259-268. https://doi.org/10.2307/2389364

Stearns, S.C., 1976. Life-history tactics: A review of the ideas. The Quarterly Review of Biology 5l, 3-47. https://doi.org/10.1086/409052

Stephenson, P.J., Racey, P.A., 1993. Reproductive energetics of the Tenrecidae (Mammalia: Insectivora). II. The Shrew-Tenrecs, Microgale spp. Physiological Zoology 66, 664-685.

Strack, A.M., Sebastian, R.J., Schwartz, M.W., Dallman, M.F., 1995. Glucocorticoids and insulin: reciprocal signals for energy balance. American Physiological Society Journal 268, R142-149. https://doi.org/10.1152/ajpregu.1995.268.1.Rl42

Stubbs, R.J., Tolkamp, B.J., 2006. Control of energy balance in relation to energy intake and energy expenditure in animals and man: an ecological perspective. British Journal of Nutrition 95, 657-676. https://doi.org/10.1079/BJN20041361

Surbeck, M., Deschner, T., Behringer, V., Hohmann, G., 2015. Urinary C-peptide levels in male bonobos (Pan paniscus) are related to party size and rank but not to mate competition. Hormones and Behavior 71, 22-30. https://doi.org/10.1016/j.yhbeh.2015.03.007

Tanes, C., Bittinger, K., Gao, Y., Friedman, E.S., Nessel, L., Paladhi, U.R., Chau, L., Panfen, E., Fischbach, M.A., Braun, J., Xavier, R.J., Clish, C.B., Li, H., Bushman, F.D., Lewis, J.D., $\mathrm{Wu}, \mathrm{G} . \mathrm{D} ., 2021$. Role of dietary fiber in the recovery of the human gut microbiome and 
its metabolome. Cell Host \& Microbe 29, 394-407.e5.

https://doi.org/10.1016/j.chom.2020.12.012

Tantasuparuk, W., Dalin, A.-M., Lundeheim, N., Kunavongkrit, A., Einarsson, S., 2001. Body

weight loss during lactation and its influence on weaning-to-service interval and ovulation rate in Landrace and Yorkshire sows in the tropical environment of Thailand. Animal Reproduction Science 65, 273-81. https://doi.org/10.1016/S03784320(00)00218-9

Tardif, S.D., 1997. The Bioenergetics of Parental Behavior and the Evolution of Alloparental Care in Marmosets and Tamarins, in: French, J.A., Solomon, N.G. (Es.), Cooperative Breeding in Mammals. Cambridge University Press, Cambridge, UK, 11-33. https://doi.org/10.1017/CBO9780511574634.003

Tataranni, P.A., Larson, D.E., Snitker, S., Young, J.B., Flatt, J.P., Ravussin, E., 1996. Effects of glucocorticoids on energy metabolism and food intake in humans. American Journal of Physiology-Endocrinology and Metabolism 271, E317-E325. https://doi.org/10.1152/ajpendo.1996.271.2.E317

Taylor, C.R., Heglund, N.C., Maloiy, G.M., 1982. Energetics and mechanics of terrestrial locomotion. I. Metabolic energy consumption as a function of speed and body size in birds and mammals. Journal of Experimental Biology 97, 1-21.

Tédonzong, L.R.D., Willie, J., Makengveu, S.T., Lens, L., Tagg, N., 2020. Variation in behavioral traits of two frugivorous mammals may lead to differential responses to human disturbance. Ecology and Evolution 10, 3798-3813. https://doi.org/10.1002/ece3.6178

Teichroeb, J.A., Sicotte, P., 2008. Social correlates of fecal testosterone in male ursine colobus monkeys (Colobus vellerosus): the effect of male reproductive competition in aseasonal breeders. Horm Behav 54, 417-423. https://doi.org/10.1016/j.yhbeh.2008.04.006

Terrien, J., Perret, M., Aujard, F., 201l. Behavioral thermoregulation in mammals: A review. Frontiers in bioscience : a journal and virtual library 16, 1428-44. https://doi.org/10.2741/3797

Thompson, C.L., Powell, B.L., Williams, S.H., Hanya, G., Glander, K.E., Vinyard, C.J., 2017. Thyroid hormone fluctuations indicate a thermoregulatory function in both a tropical (Alouatta palliata) and seasonally cold-habitat (Macaca fuscata) primate. American Journal of Primatology 79, e22714. https://doi.org/10.1002/ajp.22714

Thompson, N.A., Higham, J.P., Heistermann, M., Vogel, E., Cords, M., 2020. Energy balance but not competitive environment corresponds with allostatic load during development in an Old World monkey. Hormones and Behavior 119, 104664. https://doi.org/10.1016/j.yhbeh.2019.104664

Touitou S., Heistermann M., Schülke O., Ostner J., 2021. Triiodothyronine and cortisol levels in the face of energetic challenges from reproduction, thermoregulation and food intake in female macaques. Hormones and Behavior 131, 104968. https://doi.org/10.1016/j.yhbeh.2021.104968

Triandafillou, J., Gwilliam, C., Himms-Hagen, J., 1982. Role of thyroid hormone in coldinduced changes in rat brown adipose tissue mitochondria. Canadian Journal of Biochemistry and Physiology 60, 530-537. https://doi.org/10.1139/o82-065

Tsuji, Y., Kazahari, N., Kitahara, M., Takatsuki, S., 2008. A more detailed seasonal division of the energy balance and the protein balance of Japanese macaques (Macaca fuscata) on Kinkazan Island, northern Japan. Primates 49, 157-60. https://doi.org/10.1007/s10329007-0070-1

Valé, P.D., Béné, J.-C.K., N’Guessan, A.K., Crockford, C., Deschner, T., Koné, I., Girard-Buttoz, C., Wittig, R.M., 2020. Energetic management in wild chimpanzees (Pan troglodytes 
verus) in Taï National Park, Côte d'Ivoire. Behavioral Ecology and Sociobiology 75, 1. https://doi.org/10.1007/s00265-020-02935-9

van Schaik, C.P., Noordwijk, M.A. van, 1988. Scramble and contest in feeding competition among female long-tailed macaques (Macaca fascicularis). Behaviour 105, 77-98.

Vynne, C., Booth, R.K., Wasser, S.K., 2014. Physiological implications of landscape use by free-ranging maned wolves (Chrysocyon brachyurus) in Brazil. Journal of Mammalogy 95, 696-706. https://doi.org/10.1644/12-MAMM-A-247

Wade, G.N., Jennings, G., Trayhurn, P., 1986. Energy balance and brown adipose tissue thermogenesis during pregnancy in Syrian hamsters. American Journal of PhysiologyRegulatory, Integrative and Comparative Physiology 250, R845-R850. https://doi.org/10.1152/ajpregu.1986.250.5.R845

Wade, G.N., Schneider, J.E., 1992. Metabolic fuels and reproduction in female mammals. Neuroscience \& Biobehavioral Reviews 16, 235-272. https://doi.org/10.1016/s01497634(05)80183-6

Wallace, R.B., 2006. Seasonal variations in black-faced black spider monkey (Ateles chamek) habitat use and ranging behavior in a southern Amazonian tropical forest. American Journal of Primatology 68, 313-332. https://doi.org/10.1002/ajp.20227

Wasser, S.K., Azkarate, J.C., Booth, R.K., Hayward, L., Hunt, K., Ayres, K., Vynne, C., Gobush, K., Canales-Espinosa, D., Rodríguez-Luna, E., 2010. Non-invasive measurement of thyroid hormone in feces of a diverse array of avian and mammalian species. General and Comparative Endocrinology 168, 1-7. https://doi.org/10.1016/j.ygcen.2010.04.004

Watts, H.E., Holekamp, K.E., 2009. Ecological determinants of survival and reproduction in the spotted hyena. Journal of Mammalogy 90, 461-471. https://doi.org/10.1644/08MAMM-A-136.1

Weingrill, T., Gray, D., Barrett, L., Henzi, P., 2004. Fecal cortisol levels in free-ranging female chacma baboons: Relationship to dominance, reproductive state and environmental factors. Hormones and behavior 45, 259-69. https://doi.org/10.1016/j.yhbeh.2003.12.004

Weng, R.-C., 2019. Dietary supplementation with different types of fiber in gestation and lactation: Effects on sow serum biochemical values and performance. AsianAustralasian Journal of Animal Sciences 33. https://doi.org/10.5713/ajas.19.0545

Wessling, E.G., Deschner, T., Mundry, R., Pruetz, J.D., Wittig, R.M., Kühl, H.S., 2018a. Seasonal Variation in Physiology Challenges the Notion of Chimpanzees (Pan troglodytes verus) as a Forest-Adapted Species. Frontiers in Ecology and Evolution 6. https://doi.org/10.3389/fevo.2018.00060

Wessling, E.G., Kühl, H.S., Mundry, R., Deschner, T., Pruetz, J.D., 2018b. The costs of living at the edge: Seasonal stress in wild savanna-dwelling chimpanzees. Journal of Human Evolution 121, 1-11. https://doi.org/10.1016/j.jhevol.2018.03.001

Wheatley, K.E., Bradshaw, C.J.A., Harcourt, R.G., Hindell, M.A., 2008. Feast or famine: Evidence for mixed capital-income breeding strategies in Weddell seals. Oecologia 155, 11-20. https://doi.org/10.1007/s00442-007-0888-7

White, T.C.R., 2008. The role of food, weather and climate in limiting the abundance of animals. Biological Reviews 83, 227-248. https://doi.org/10.1111/j.1469185X.2008.0004l.x

Widmaier, E.P., 1992. Metabolic feedback in mammalian endocrine systems. Hormone and Metabolic Research 24, 147-153. https://doi.org/10.1055/s-2007-1003282

Wikelski, M., Cooke, S.J., 2006. Conservation physiology. Trends in Ecology and Evolution 21, 38-46. https://doi.org/10.1016/j.tree.2005.10.018 
Williams, T.M., Noren, S.R., Glenn, M., 2011. Extreme physiological adaptations as predictors of climate-change sensitivity in the narwhal, Monodon monoceros. Marine Mammal Science 27, 334-349. https://doi.org/10.11l1/j.1748-7692.2010.00408.x

Wilmore, J.H., Costill, D.L., 2001. Physical energy: Fuel metabolism. Nutrition Reviews 1, S13-S16.

Wingfield, J.C., Hunt, K., Breuner, C., Dunlap, K., Fowler, G.S., Freed, L., Lepson, J., 1997. Environmental stress, field endocrinology, and conservation biology, in: Clemmons, J.R., Buchholz, R. (editors), Behavioral approaches to conservation in the wild. Cambridge University Press, Cambridge, UK, 95-131.

Wolden-Hanson, T., Davis, G.A., Baum, S.T., Kemnitz, J.W., 1993. Insulin levels, physical activity, and urinary catecholamine excretion of obese and non-obese rhesus monkeys. Obesity Research 1, 5-17. https://doi.org/10.1002/j.1550-8528.1993.tb00003.x

Wolever, T.M., Bolognesi, C., 1996. Prediction of glucose and insulin responses of normal subjects after consuming mixed meals varying in energy, protein, fat, carbohydrate and glycemic index. Journal of Nutrition 126, 2807-2812. https://doi.org/10.1093/jn/126.11.2807

Wrick, K.L., Robertson, J.B., Van Soest, P.J., Lewis, B.A., Rivers, J.M., Roe, D.A., Hackler, L.R., 1983. The influence of dietary fiber source on human intestinal transit and stool output. Journal of Nutrition 113, 1464-1479. https://doi.org/10.1093/jn/113.8.1464

Xia, Y., Sun, J., Chen, D.-G., 2018. Statistical Analysis of Microbiome Data with R. Springer.

Xu, T., Li, X., Yang, L., Zhang, Y., Zhang, L., Guo, Z., Cheng, X., Zheng, X., Chen, B., Hou, Z., Yang, D., 2018. Impact of cold exposure on the reproductive function in female rats. BioMed Research International, 1-8. https://doi.org/10.1155/2018/3674906

Young, B.A., Walker, B., Dixon, A.E., Walker, V.A., 1989. Physiological adaptation to the environment. Journal of Animal Science 67, 2426-2432. https://doi.org/10.2527/jas1989.6792426x

Young, C., Majolo, B., Heistermann, M., Schülke, O., Ostner, J., 2014. Responses to social and environmental stress are attenuated by strong male bonds in wild macaques. PNAS 11l, 18195-18200. https://doi.org/10.1073/pnas.1411450111

Young, R.A., 1976. Fat, Energy and mammalian survival. American Zoologist 16, 699-710. https://doi.org/10.1093/icb/16.4.699

Yousef, M.K., Luick, J.R., 1971. Estimation of thyroxine secretion rate in reindeer, Rangifer tarandus: effects of sex, age and season. Comparative Biochemistry and Physiology Part A: Molecular \& Integrative Physiology 40, 789-795. https://doi.org/10.1016/03009629(71)90264-7

Zhang, V.Y., Williams, C.T., Palme, R., Buck, C.L., 2020. Glucocorticoids and activity in freeliving arctic ground squirrels: Interrelationships between weather, body condition, and reproduction. Hormones and Behavior 125, 104818. https://doi.org/10.1016/j.yhbeh.2020.104818

Zhou, P.-Z., Zhu, Y.-M., Zou, G.-H., Sun, Y.-X., Xiu, X.-L., Huang, X., Zhang, Q.-H., 2016. Relationship between glucocorticoids and insulin resistance in healthy individuals. Medical Science Monitor 22, 1887-1894. https://doi.org/10.12659/MSM.895251

Zhuo, Y., Feng, B., Xuan, Y., Che, L., Fang, Z., Lin, Y., Xu, S., Li, J., Feng, B., Wu, D., 2020. Inclusion of purified dietary fiber during gestation improved the reproductive performance of sows. Journal of Animal Science and Biotechnology 11, 47. https://doi.org/10.1186/s40104-020-00450-5

Ziegler, T., Hodges, K., Winkler, P., Heistermann, M., 2000. Hormonal correlates of reproductive seasonality in wild female hanuman langurs (Presbytis entellus). American Journal of Primatology 51, 119-134. https://doi.org/10.1002/(SICI)10982345(200006)51:2<119::AID-AJP2>3.0.CO;2-O 
Ziegler, T.E., Scheffler, G., Snowdon, C.T., 1995. The relationship of cortisol levels to social environment and reproductive functioning in female cotton-top tamarins, Saguinus oedipus. Hormones and Behavior 29, 407-424. https://doi.org/10.1006/hbeh.1995.1028 



\section{ACKNOWLEDGEMENTS}

Female Assamese macaques were not the only ones that had to overcome challenges. Throughout this thesis I also had to face some energetic and psychological challenges. Although my behavior and physiology did their best to keep me going, the most important coping mechanism I have found on the way was social support and I have many people to thank.

My first big thank you goes to Julia Ostner and Oliver Schülke. Thank you for offering me this $\mathrm{PhD}$ position four years ago which granted me access to such a great field site in Thailand. Thank you for your support, your guidance and your patience. Thank you also for your never-ending availability, even in times of global pandemic.

During my PhD journey I had the chance to live for thirteen months at Phu Khieo Wildlife Sanctuary. A lot of people have contributed to making my stay there unforgettable and my research possible. Thank you to all members of Macaque Team for their amazing work and their support! Thank you Piya for helping me in so many ways and for sharing with me your precious and endless knowledge of the monkeys and the forest. Thank you Wat and Juu for your generosity and for making me feel like part of your family. Special thank you, Wat, for your astonishing skills in fixing anything and your ingenuity in building the 'catching-pee' antennas. Thank you Nok for the friendship and your reassuring presence. Thank you Noom for immortalizing the beautiful monkey faces and many great memories with your photographer's eye. Thank you Kob for your catching good mood and for being such a fast and efficient learner when you joined the team. Thank you Daam for the friendship and thank you Khun San for cooking the best Thai meals.

Thank you Miranda for teaching me how to drive a motorcycle. Thank you for always bringing more plant food items from the forest and constantly coming up with their names. Thank you for your laugh that I could hear from the other side of the forest. Thank you Fabi and Alex. You were great friends to share my forest experience with. Thank you for your help and most importantly, thank you for all the great moments we spent together! Thank you Sofia and Simo for being the perfect companions for my last weeks in the camp and for your support when I had to leave this amazing place that was my home for more than a year. 
Back to Germany, my lab work started and it could not have been more enjoyable since I was surrounded by great people. A huge thank you goes to Michael Heistermann for teaching me everything I know, for answering all my questions and for being such a great and inspiring mentor. I wish my lab work lasted longer! Thank you Andrea and Miriam for being so helpful and for being such nice lab colleagues. Thank you Andrea for sharing all your stories about Ceres and for making the lab a very welcoming place. Verena Behringer, thank you for the insightful conversations and thank you also for being part of my examination board.

I want to thank all my friends and colleagues from the Behavioral Ecology department. Thank you Alan, Nadine, Delphine, Simo, Baptiste, James and Niels. Thank you for contributing to making our department such a friendly and nice place to work at. Thank you also for all the great moments we spent together outside the office. Thank you Louise, Oli, Lauren, Tati and Sarah for the friendship throughout this thesis. Baptiste, thank you for all our conversations about hormones and for being such a great support. Louise, thank you for being always there for me and for being a true friend. My small walks with you and Blau were perfect relaxing moments between two chapters of this thesis. Oli, thank you for your generosity and for being such a great host. Thank you for taking care of me and for all your little attentions (even when I am too stubborn to accept them!). Delphine, it is going to be hard not to write ten pages of acknowledgements just for you and the huge role you played and are still playing in my professional and personal life. Thank you for being an amazing colleague, a great scientist to look up to and above all, an incredible friend. My PhD journey would have been very complicated (if even possible at all) if I would not have met you on the way. Thank you for listening to my constant worries and thank you for not making me believe them (or at least trying to).

Thank you Cédric for the friendship, for welcoming me in Leipzig and for your help with R. A huge thank you goes to Roger Mundry for answering all my questions in statistics and for our informal Skype meetings to break the loneliness and boredom of working from a home office. I want to thank Clarissa Licht and Rebecca Jürgens for their help and administrative support since day one.

I want to thank Fredy Quintero for convincing me that I could do a $\mathrm{PhD}$ and be good at it. Thank you for always believing in me and for your unfailing support over the years. I thank Julia who deserves so much her name in this thesis after more than twenty years of friendship. Thank you for being always there and for showing me that our friendship is stronger than thousands of kilometers between us. Carole, you are an incredible friend I can always count on 
and I thank you for your support and valuable advises throughout my PhD. Thank you also to Tessy, Anne-Charlotte and Camille for always supporting me from the distance and for the friendship.

Last but definitely not least, I want to thank my family. Maman, Papa, merci de toujours croire en moi et de me faire confiance. Merci de me soutenir dans tous mes projets qui m'emmènent aux quatre coins du monde. Merci d'être toujours là et d'avoir fait de moi la personne que je suis aujourd'hui. Léah, merci d'avoir été le meilleur des modèles à suivre pour poursuivre ses rêves, ne pas avoir peur et avoir la conviction que tout est possible. Simon, merci d'avoir écouté mes plaintes sur l'académie et de m'avoir soutenue. Nathan, merci d'être le frère jumeau que n'importe qui rêverait d'avoir. Je suis tellement chanceuse d'être cette personne. Merci à toi et à Anaïs pour votre soutien sans faille. Joanna, tu sais déjà tout. Merci d'être toujours là dans les meilleurs comme dans les pires moments. Merci de croire en moi et de me communiquer ton incroyable force. Robin, merci d'être là et de me faire bientôt découvrir les montagnes grenobloises. Ismaël, Victor, votre tante rentre bientôt à la maison et cette fois, promis, elle reste. Cette thèse vous est dédiée. Merci d'apporter encore plus d'amour à ma vie. 



\section{DECLARATION}

I hereby declare that I have written this thesis entitled 'Energetics in wild female Assamese macaques (Macaca assamensis): a behavioral and physiological approach' independently and with no other aids or sources than quoted.

Göttingen, 23 $3^{\text {rd }}$ of March 2021

Sonia Touitou 